\title{
The Z-axis: Elevation Gradient Effects in Urban America
}

\author{
Victor Yifan Ye Charles $\mathrm{M}$. \\ Becker \\ Duke University \\ Duke University
}

June 7, 2016

ERID Working Paper Number 217

This paper can be downloaded without charge from the Social Science Research Network Electronic Paper Collection:

http://ssrn.com/abstract=2791710

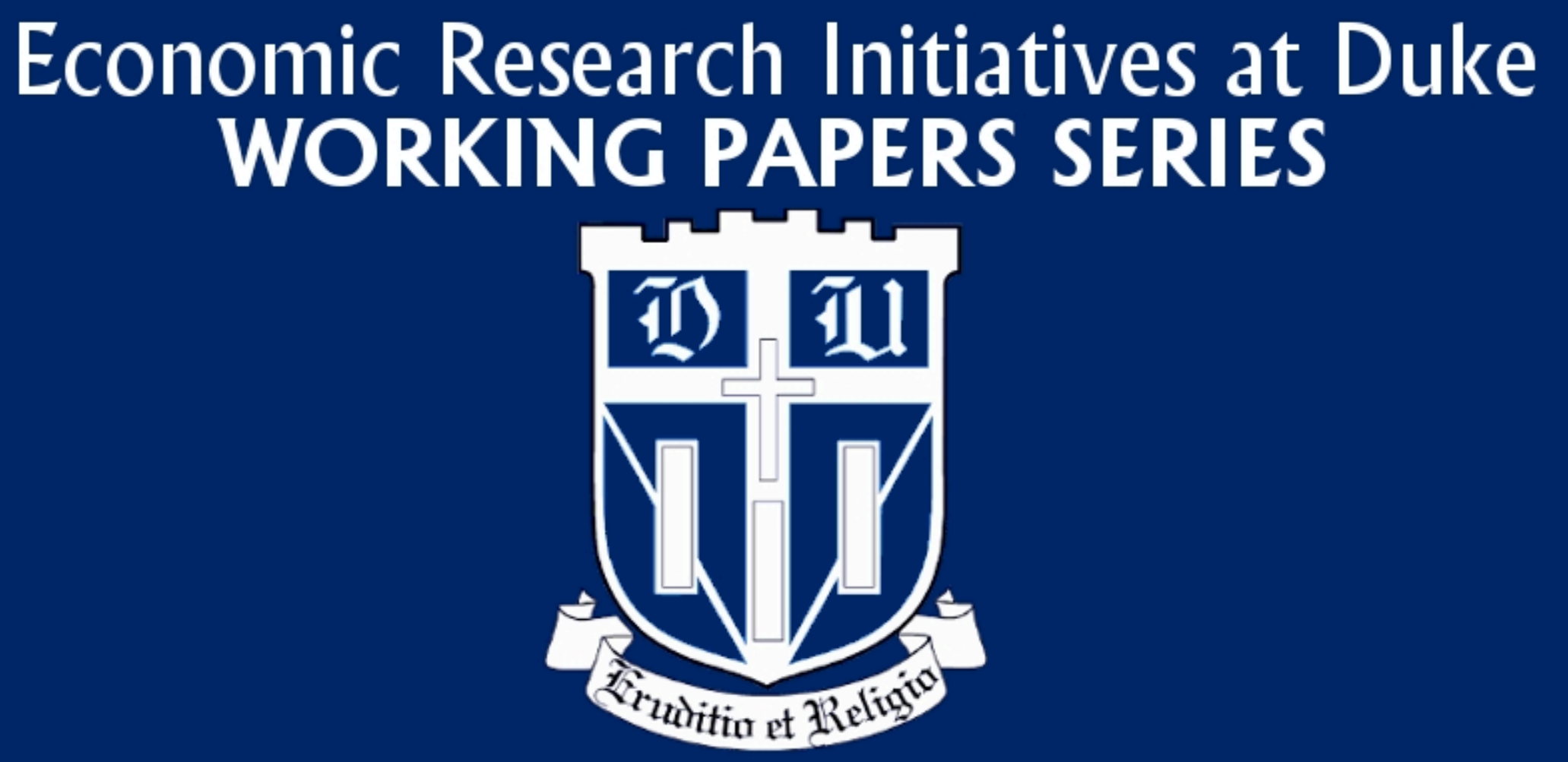




\title{
The Z-axis: \\ Elevation Gradient Effects in Urban America
}

\author{
Victor Yifan $\mathrm{Ye}^{*}$ \\ Charles M. Becker ${ }^{\dagger \ddagger}$
}

June 2016

\begin{abstract}
${ }^{1}$ This paper presents a comprehensive analysis of hilliness effects in American urban communities. Using data from seventeen cities, robust relationships are established between elevation patterns and density and income gradients. We find that high-income households display strong preference for high-altitude, high-unevenness locations, leading to spatial income stratification at both the city and tract-level. We further analyze potential causes of this propensity: micro-climate, crime, congestion, view effects, and use of public transit. We conclude that the role of elevation in urban systems should not be neglected. Multi-dimensional spatial methods are crucial to investigations of cities with substantial unevenness. Redistributive social and economic policies must struggle with a fundamental, topographical dimension to inequality.
\end{abstract}

JEL: J10, R11, R12

Keywords: Elevation, Hilliness, Household Income, Population Density, Segregation, Urban Gradients, Spatial Modelling

\footnotetext{
* Department of Economics and Department of Statistical Science, 213 Social Sciences, Durham, NC, 27708, United States yifan.ye@duke.edu

$\dagger$ Department of Economics, Campus Box 90097, 213 Social Sciences, Durham, NC, 27708, United States cbecker@econ.duke.edu

${ }^{\ddagger}$ Corresponding author

${ }^{1}$ We are thankful to Patrick Bayer for advice and comments.
} 


\section{Introduction}

In the past two decades, spatial methods have experienced a surge in attention among economists. Much empirical research has focused on bi-dimensional, geographical-coordinate-based modelling approaches and operate under locationparity, spatial equilibrium (Glaeser and Gottlieb 2009; Grimaud and Laffont 1989) conditions. Cities are largely assumed to be flat, featureless plains. Governments, workers, households and firms, in the absence of economic incentives, are assumed to be indifferent among locations.

Yet we seem to understand intuitively that locations are not created equally. While walking down or up a slope is undesirable, wealthy individuals seem to strongly prefer living on hillsides; cities with uneven suburbs are centrally denser and often more expensive to live in. Our understanding of these characteristics is so deeply ingrained that one instinctively associates the affixes "hills" or "heights" with high income communities. Conversely, "bottom" or "flats" generally connote low income areas: one can hardly imagine John Steinbeck writing Tortilla Heights rather than Tortilla Flat.

This paper presents a formal study of the economic consequences of elevation as a locational attribute in a US-centric, multi-city framework. By constructing high-resolution Digital Elevation Models (DEMs) for seventeen major metropolitan areas, we demonstrate that altitude and unevenness of terrain strongly influence income and population patterns at the census-tract-level. Specifically, we find that controlling for spatial factors, doubling of a tract's elevation variance, defined as the standard deviation of altitude samples within the tract, is associated with a decrease in population density of $20.8 \%$, an increase in median household income of $4.4 \%$, and an increase in the tract Gini coefficient of $1 \%$. Mean household income of all quintile groups increase by $8-13 \%$, with higher-income quintiles experiencing the larger effects.

These income effects have a wide range of implications: we find that controlling for centricity and spatial autocorrelation, individuals in census tracts with higher relative altitude, defined as the number of standard deviations above or below the city-average altitude, and higher elevation variance are older, more likely to be married, less likely to be African-American, have smaller families, and are significantly better educated.

Beyond the intuitive explanation of "view" effects causing high-income individuals to choose high-altitude, uneven locations, we provide evidence for four additional intermediaries through which elevation patterns influence major urban gradients: micro-climate, crime, congestion, and costs of accessing public transit. Ceteris paribus, our models indicate that households in high-altitude, high-unevenness tracts enjoy milder weather patterns, significantly lower rates for a range of crimes, less local congestion, and they commute less by public transit and walking. 
We conclude that elevation plays an enormous role in shaping structures and patterns of urban systems. Areas with high unevenness and high relative altitude behave differently, compared to respective city averages, in terms of a wide range of major urban gradients. Spatial models of metropolitan areas with sufficiently significant elevation variance, such as San Francisco, Pittsburgh and Washington, DC, are expected to suffer from large, systemic biases if not constructed to account for elevation effects.

The salient prediction of our findings is that independent of centricity, local amenities and historical conditions, spatial socioeconomic stratification contain an elevation gradient component: for a given city, some locations are intrinsically attractive to high-income individuals and unattractive to low-income individuals. It is not difficult to conceptualize how outcomes predicted by sorting and search models of racial aversion (Courant 1978; Bailey 1966; Bayer and McMillian 2005) could be reinforced and perhaps even exacerbated by a purely geographical aspect to segregation. Such persistent and fundamental barriers to integration no doubt pose significant challenges to designers of redistributive microeconomic policies.

Furthermore, establishing elevation as a third, "z" dimension in the spatial paradigm opens up the possibility of cities differing qualitatively because of elevation: that is, hilliness may not simply be a characteristic desired by some groups relative to others, and who therefore would have lived in distinct locations even in a flat city. Rather, our results suggest that cities with higher unevenness will display greater levels of inequality, variations in population patterns, and differences in local crime rates. It is likely that levels of income segregation and central densities in such cities differ, to a certain extent, from those of otherwise-similar flat cities. Such cities also incur inefficiencies in developing public transit and walk-friendly amenities and are expected to face greater constraints in term of optimizing public infrastructure investment.

To isolate and accurately quantify elevation gradient effects, our empirical approach combines an innovative "pseudo-data bootstrapping" procedure, designed to incorporate uncertainty within both the structure of the data and the data collection process, with linear mixed effects (LME) and random intercept models. We show that, while computationally demanding, this statistical approach displays a number of desirable properties, including high performance, stabilization of significant coefficient estimates, and the ability to draw inferences on city-specific elevation effects.

Section 2 reviews prior literature related to elevation effects and spatial modelling. Section 3 provides a brief conceptual overview of the effect of an elevation parameter in a monocentricity framework. Section 4 outlines empirical methodologies and data sources utilized in the geospatial modelling process. Section 5 discusses model robustness and presents evidence for elevation effects in density and income gradients; section 6 presents evidence for intermediary effects. Section 7 concludes. 


\section{Prior Literature}

With rapidly decreasing costs of computation, spatial modelling methods have been applied to address an extremely broad range of economic issues. Recent examples in the literature include testing the Tiebout (1956) mechanism via examining connections between neighborhood income and air quality (Banzhaf and Walsh 2008), investigating gentrification caused by remediation of sites contaminated by hazardous waste (Gamper-Rabindran and Timmins 2011), geographical overlaps of trade and technology shocks in the US (Autor, Dorn, and Hanson 2013), using road network models to understand spatial differentiation in gasoline retail markets (Houde 2012), the role of leisure-oriented amenities in urban growth (Carlino and Saiz 2008), and the impact of government-controlled retailing in liquor sales (Seim and Waldfogel 2013).

However, spatial literature addressing relationships between aspects of natural geography and economic outcomes is sparse. Somewhat similar to our multi-city framework, Bosker and Buringh (2015) utilize broad, geographical perspectives to explain initial, historical locational choice of major European cities. Rappaport (2007) models nice weather as a consumption commodity in explaining migration flows of US residents. The role of water bodies in urban economies have been investigated from perspectives such as the constraining of land supply due to lakes and oceans (Rose 1989) and the economic attractiveness of coastal living (Rappaport and Sachs 2003). Geographical boundaries have also been used instrumentally toward explaining disparities in the stimulative effects of local business policies (Briant, LaFourcade, and Schmutz 2015), to investigate cultural barriers to economic activity (Falck et al. 2012), and to test for housing price response to local school quality (Gibbons, Machinb, and Silva 2013).

Literature specifically concerning elevation effects is even sparser. Existing research primarily focuses on flood risk as an undesirable outcome of low elevation (Scawthorn, Iemura, and Yamada 1982; Shilling, Sirmans, and Benjamin 1989). Recent work on similar topics features significantly more advanced methods such as the combining of spatial methods with hedonic housing data (Bin et al. 2011) or with dynamic models (Husby et al. 2014). While not featuring elevation as a primary investigative target, Kok, Monkkonen, and Quigley (2014) find evidence of elevation effects in San Francisco land value. Although only tangentially related to elevation effects as discussed in this paper, these analyses are nonetheless relevant in suggesting the possibility that elevation may influence urban gradients such as rent and density.

Saiz (2010) presents a study of geographical influences in housing and land markets of 73 major MSAs, finding that undevelopable land on the city periphery is a strong predictor of low housing supply elasticity. While his work directly investigates the relationship between elevation and urban gradients, we identify two shortcomings with the paper's approach. First, by modelling undevelopable 
land using a $15 \%$ slope cutoff, an artificial dichotomy is created between developable versus undevelopable land, while in reality the decision to develop a location depends on a wide range of supply and demand-side factors. Second, his model implicitly assumes that the primary channel through which elevation influences urban gradients is by limiting land supply, whereas phenomena such as high-income household preferences for elevation do not seem to be driven by the supply of land. Here, we demonstrate that by modelling elevation not as a binary term but as continuous factors of unevenness and altitude and by investigating each city not as a single data point but as a spatial agglomeration of neighborhoods, these issues can be successfully addressed.

Extending the scope of search beyond the economics paradigm yields a far greater amount of literature. An enormous amount of research in architecture and urban design involves the relationship between topography and city planning (Golany and Ojima 1996; Jiao et al. 2012; Steiner 2000; Zexin et al. 2013). Notable areas of inquiry include methods of visualizing terrain profiles at the city level to conceptualize goals of urban design (Robinson 2011), links between terrain and ecological elements of cities (Lang 1994; McGrath 2013), and social-cultural aspects of the role of terrain in shaping cities (Golany 1995).

In Spectator and the Topographical City, Aurand (2006) details how Pittsburgh's unique terrain and location contributed to its current environment and architecture, focusing on how the "artificial" city landscape becomes adapted and attuned to the natural landscape. By pointing out this connection, Aurand hints at-yet does not quite fully articulate-the possibility that geography and, in particular, elevation effects may play a role in conditions of urban economic systems. While this body of work is generally nontechnical in nature, the attention that effects of geographical patterns on cities receive from architecture and urban planning perspectives suggests that such effects may be quantifiable and significant from an economist's perspective.

Using data from the Hong Kong government-subsidized housing market, Ye and Becker (2016) find significant elevation gradient effects in apartment sale prices. The paper concludes that walking up or down an incline to public transit hubs is highly undesirable: holding other factors constant, a 1-decimaldegree increase in the slope between an apartment and the closest metro station decreases its selling price by up to $1.9 \%$. Across cities, one would expect this effect to lead to greater density in hilly cities, and this is indeed the case. A simple analysis of 93 major urban areas worldwide finds a positive correlation between unevenness and city-level population density and negative correlation between unevenness and city size by population. While Hong Kong may be an outlier among global cities because of restrictive housing policies and highly uneven terrain, these results are nonetheless significant.In this present paper we not only demonstrate existence of public transit-elevation effects in US cities in general, but also expand the influence of elevation to a much broader framework of urban gradients. 


\section{Conceptual Framework}

Our empirical investigation in Section 5 suggests four major urban gradient effects of local hilliness: higher altitude and unevenness are associated with lower population density, and unevenness is also associated with higher average household income, as well as higher income inequality. By presenting a modified version of the Alonso-Muth-Mills (AMM) model (Alonso 1964; Mills 1972; Muth 1969) that incorporates elevation as an exogenous amenity, we show that these effects are internally consistent and can be understood from a centricity perspective. Our formulation draws from the study of central amenities with multiple bid-rent curves by Bruekner, Thisse and Zenou (1999), but is less concerned with the shape of bid-rent curves over a centralized urban area and more concerned with the localized effect of an exogenous amenity.

We assume a perfectly circular city. Let $\left(b_{1} \ldots b_{n}\right)$ be a total of $n$ discreet plots in a given district with distances $\left(x_{1} \ldots x_{n}\right)$ to the city center. Without loss of generality, we can let $x_{1}<x_{2}<\cdots<x_{n}$ such that $x_{n}-x_{1}=B$, where $B$ is the lateral width of the district as projected from the center. We assume that $B$ is neither so large that it occupies a significant proportion of the city, nor so small that the bid-rent difference between two adjacent plots is negligible. Each plot has an altitude $l_{i}$, initially assumed to be $l_{i}=0$ for $\forall i \in 1: n$. A high-income group and a low-income group occupy the city with incomes $y_{h}$ and $y_{l}$ and per-unit-distance commuting costs of $t_{h}$ and $t_{l}$ for a given mode of transportation. We assume that $y_{h}>y_{l}$ and $t_{h}>t_{l}$; i.e., the high-income group values time at a higher rate. Individuals divide their budgets between housing consumption $q$ at unit cost $p$, which is a function of $x$, and consumption of a basket of non-housing goods $g=y-t x-p q$.

At a distance to the city center of $x_{i}$, the maximum price that the two groups are willing to pay for one unit of housing are:

$$
\begin{aligned}
& p_{h}\left(x_{i}\right)=\left(y_{h}-t_{h} x_{i}-g_{h}\right) / q_{h}\left(x_{i}\right) \\
& p_{l}\left(x_{i}\right)=\left(y_{l}-t_{l} x_{i}-g_{l}\right) / q_{l}\left(x_{i}\right)
\end{aligned}
$$

where bundles $\left(q_{h}, g_{h}\right)$ and $\left(q_{l}, g_{l}\right)$ are given by maximizing utility function $u(q, g)$ over a budget constraint adjusted by transit costs $y-t x_{i}$. Note that the willingness to pay in equation 1 is determined jointly by the marginal utility of an extra unit of housing consumption and marginal per-distance transit cost: endowed with different preferences, the rich and poor are capable of outbidding each other at different levels of $x$.

Initially, we assume that the rich are outbid at all $\left(b_{1} \ldots b_{n}\right)$, i.e. $p_{h}\left(x_{i}\right)<$ $p_{l}\left(x_{i}\right) \forall i \in 1: n$. The district's average income, given perfect homogeneity of low-income residents, is $\bar{y}=y_{l}$. The level of inequality, represented by the variance of plot resident incomes, is $\operatorname{var}(y)=0$. Assuming that housing con- 
sumption is strictly proportional to land use within a given district, housing density is given by $d\left(x_{1: n}\right)=n / n q_{l}\left(x_{i}\right)=1 / q_{l}\left(x_{i}\right)$.

Now suppose that a subset of $m \leq n$ plots contain an exogenous, numeraire elevation good with amount $e$ at a plot altitude of $l=l^{e}$. Let $e$ only be valued by the high-income group. For convenience, $e$ is best considered in terms of how much one would pay for access: wealthy people living in these plots experience an endowment that expands total potential consumption from $y$ to $y+e$. Highincome households choose between the utility function $u(q, g)$ given constraint $y-t x$ or a function $u^{\prime}\left(q^{\prime}, g^{\prime}\right)$ given constraint $y+e-t x_{i}$ exclusively accessible at elevation-endowed location $x_{i}$. For a plot with elevation amenities, the bid price difference between the two groups is:

$$
p_{l}\left(x_{i}\right)-p_{h}^{\prime}\left(x_{i}\right)=\frac{\left(y_{l}-t_{l} x_{i}-g_{l}\right) q_{l}\left(x_{i}\right)-\left(y_{h}+e-t_{h} x_{i}-g_{h}^{\prime}\right) q_{h}^{\prime}\left(x_{i}\right)}{q_{l}\left(x_{i}\right) q_{h}^{\prime}\left(x_{i}\right)}
$$

where $q_{h}^{\prime}$ and $g_{h}^{\prime}$ are determined by maximizing $u^{\prime}\left(q_{h}^{\prime}, g_{h}^{\prime}\right)$ over the new constraint $y_{h}+e-t x_{i}$. Solving equation 2 for $p_{l}\left(x_{i}\right)-p_{h}^{\prime}\left(x_{i}\right)=0$ yields:

$$
\bar{e}_{i}=\frac{\left(y_{l}-t_{l} x_{i}-g_{l}\right) q_{l}\left(x_{i}\right)}{q_{h}^{\prime}\left(x_{i}\right)}-\left(y_{h}-t_{h} x_{i}-g_{h}^{\prime}\right)
$$

$\overline{e_{i}}$ is the amount of elevation amenity for a plot at which the two income groups place equal bids at distance $x_{i}$. The low-income group outbids the high-income group when $e<\overline{e_{i}}$ and the high-income group outbids the low-income group when $e>\bar{e}_{i}$. By selecting some altitude $l^{\prime}$ and the corresponding $e^{\prime}$ such that the low-income group is outbid for $k \leq m$ plots, we have a district mean income of:

$$
\bar{y}_{\text {new }}=\left(k y_{h}+(n-k) y_{l}\right) / n,
$$

and a district income variance of:

$$
\operatorname{var}(y)_{n e w}=\left(k\left(y_{h}-\bar{y}\right)^{2}+(n-k)\left(y_{h}-\bar{y}\right)^{2}\right) / n .
$$

The local average altitude, denoted as the simple average of altitudes of all local plots, increases from 0 to $\bar{l}=m l^{\prime} / n$. The variance of local elevation increases from 0 to:

$$
\operatorname{var}\left(l^{\prime}\right)_{\text {new }}=\left(k\left(l^{\prime}-\bar{l}\right)\right) / n
$$


Note that while the high-income group may have to give up some housing consumption as cost per unit of housing has increased, we nonetheless have $q_{h}^{\prime}\left(x_{i}\right)>q_{l}\left(x_{i}\right)$, i.e. that the median high-income household will still consume more housing than the low-income household under this scenario. ${ }^{2}$ Given that $p_{l}\left(x_{i}\right)$ reflects the budget constraint at $x_{i}$ of the low-income group, the highincome group can place a bid that is only marginally higher than $p_{l}\left(x_{i}\right)$ and optimize at that unit price between the housing and non-housing good. Under a reasonable utility function that assumes some complementarity between $g$ and $q$, the high-income individual will consume more housing, which we assume is proportional to the income gap $y_{h}-y_{l}$, than his or her low-income counterpart. ${ }^{3}$ We can write the new housing density as:

$$
d\left(x_{1: n}\right)_{n e w}=\frac{n}{(n-k) q_{l}\left(x_{i}\right)+k q_{h}^{\prime}\left(x_{i}\right)}
$$

The mean altitude $\bar{l}=m l^{\prime} / n$, proportionality of $k$ and $m$, and (equation 4) gives a positive relationship between altitude and district mean income. $\operatorname{var}(y)$ increases with elevation variance for all $k \leq n$, and $\bar{y}$ increases with elevation variance up to $k=n / 2$, or when there is a majority of elevation-amenity plots occupied by high-income individuals. Density $d\left(x_{1: n}\right)_{\text {new }}$ is inversely proportional to $k$ and converges to $1 / q_{h}^{\prime}\left(x_{i}\right)$ as $k$ approaches $n$. Therefore, compared to the perfectly flat district and given some fixed elevation amenity, the district with higher altitude is expected to have lower density, and the district with unevenness is expected to have lower density, higher mean income and, if the high-income group remains a minority, higher income inequality.

The model as presented is symmetric with regard to income and elevation effect direction: the same conclusions can be reached by initializing with a highincome group scenario and introducing a disutility associated with low altitude that allows low-income individuals to outbid high-income ones at discreet locations. Letting the high-income group be indifferent but the low-income group averse to high altitude, i.e. see consumption shrink to some $y_{l}-e$ at $l^{e}$, will also yield similar results. In the standard AMM model, income segregation exists but is only present at the city-scale: any local interval $x_{[1, n]}$ that does not contain an intersection of bid-rent curves will only be occupied by one of the two income groups. Changes in the local mean or stratification of income levels can only occur by introducing multiple bid-rent curves. In contrast, elevation as an amenity allows income segregation and mean income differences to occur

\footnotetext{
${ }^{2}$ Assuming that the elevation amenity does not change the shape of the high-income group's utility function, if we let marginal demand for housing grow faster than commuting costs with regard to income, i.e. a rich-suburb scenario, the high-income individual gives up some housing by moving toward the center to access the elevation amenity. On the other hand, if we assume that the marginal demand for housing grows more slowly than commuting costs with regard to income and suburbs that are poor, the high-income individual instead suffers greater commuting costs by moving away from the center.

${ }^{3}$ If there are many high-income household bidding for good views, rents will be bid up until the marginal cost of living perfectly reflected the elevation amenity.
} 
at neighborhood $x_{[1, n]}$ of any size within the city bounds.

While we focus only on the amenity effect of high altitude, the model can easily be expanded to include hilliness effects by modifying the elevation amenity to $c \cdot e$ with $c$ being an inflation factor proportional to the district's elevation variance $\operatorname{var}\left(l^{\prime}\right)$. A rationale for this exercise could be that high income households are more likely to use private vehicles rather than public transportation, and thereby pay a lower penalty for walking up or down local hills to bus or subway stops. It is also possible that since public transit infrastructure is more costly in uneven areas, these areas also suffer from a lack of public transit supply. If unevenness leads to greater gains from elevation for the rich or greater loss for the poor, we expect a strengthening of the predicted elevation variance effects, as well as a preference of the rich for plots with both higher altitude and local hilliness. Holding other factors constant, it would take a lower altitude gain to entice high-income households or discourage low-income households if unevenness effects are built into the model.

Also note that none of these results require any assumptions on how elevation affects locational choices in terms of distances from the city center. While it is not unlikely that a model based on elevation as a geographical barrier may arrive at similar conclusions, it is difficult to imagine such effects being a strong determinant of urban gradients for anything but urban fringes or the most uneven cities. Modelling elevation as an amenity allows for the possibility of localized elevation effects in city centers as well as in cities with mild unevenness. Regardless of the actual distribution of altitudes or level of development of a given location, the fixed elevation amenity remains attractive to high-income individuals and will be reflected in local urban gradients. We provide evidence for view effects providing such amenities, as well as several other explanations, in Section 6.

\section{Methodology}

\subsection{Data Collection and Summary}

At the core of our empirical analysis is the merging of two datasets: a panel of information on census-tract-level employment, wealth and demographic statistics, and a dataset of altitude, representations of unevenness and other geospatial factors. For altitude and unevenness, we use the Microsoft Representational State Transfer (REST) Services to construct city-level DEMs. ${ }^{4}$ Altitude figures are sampled from each city on a 0.3 -by-0.3 decimal-degree square region centered on respective downtown areas at a grid resolution of $500 \times 500$, and joined to individual census tracts using boundary data from the US Census Bureau's Topo-

${ }^{4}$ DEM contour plots of select cities are presented in Figure A7 in the appendix. 
logically Integrated Geographic Encoding and Referencing (TIGER) database. ${ }^{5}$ The mean altitude and elevation variance of each census tract is then calculated by taking the simple average and standard deviation of all interior elevation sample points. We henceforth abbreviate these metrics as, respectively, mal (mean altitude) and elv (standard deviation of elevation).

Since tract boundaries do not usually coincide with edges of the sampling area, tracts on the border of the sampling square that, excluding water area, are not at least $80 \%$ covered by elevation sample points are excluded from the dataset. ${ }^{6}$ To prevent elv estimates from being calculated from samples that are too small, we also exclude tracts that contain less than 20 elevation sample points. To address downward bias in elevation variance caused by local water areas, we examine spatial models of each city and remove elevation samples at the local water level. Sea-level elevation samples are removed from coastline cities, as are samples from major local rivers, reservoirs and lake surfaces of landlocked cities.

To illustrate the existence of general elevation gradient effects across cities, we select cities for elevation data collection to maximize diversity both in terms of unevenness and geographical orientation. Seventeen major cities and their surrounding suburban areas are selected: Atlanta, Boston, Charlotte, Cincinnati, Dallas, Denver, Kansas City, Los Angeles, Miami, Nashville, New York City, Pittsburgh, Portland (Oregon), San Diego, San Francisco, Seattle, and Washington, DC. All of the ten Standard Federal Regions are represented by at least one city, and cities are divided roughly equally among Census Bureau statistical regions. Figure 1 contrasts the distribution of census tract elv of dataset cities.

Performing elevation sampling over the aforementioned cities yields usable elevation data for a total of 6,645 census tracts, with an average sampling density of 463.1 points per tract for a total of approximately 3.08 million samples in total, or about 181,000 per MSA. To account for outliers in elevation level (Denver), we transform altitude measurements from meters to a "relative altitude" metric ral of standard deviations above or below the city average. This approach guarantees equal altitude representation of coastal cities versus landlocked cities. To control for fixed effects of tract proximity to the ocean, we construct a separate spatial model using National Oceanic and Atmospheric Administration (NOAA) coastline profiles and calculate tract distances to the coastline. $^{7}$

Instead of conventional, linear methods of controlling for centricity, we utilize

\footnotetext{
${ }^{5}$ Decimal degrees translate to marginally different distances in regular length terms at different latitudes. For the range of latitudes in the dataset, the side length of the sampling square may vary from $22.5 \mathrm{~km}$ (Seattle, $47.5^{\circ} \mathrm{N}$ ) to $30 \mathrm{~km}\left(\right.$ Miami, $\left.25.8^{\circ} \mathrm{N}\right)$.

${ }^{6}$ We estimate coverage by comparing the per-unit area point count of partially covered tracts with that of fully covered tracts in the same city.

7 "Coastline" is defined by NOAA guidelines. http://shoreline.noaa.gov/glossary.html
} 
Figure 1: Standard boxplot of tract elevation variance $(\log )$ by city

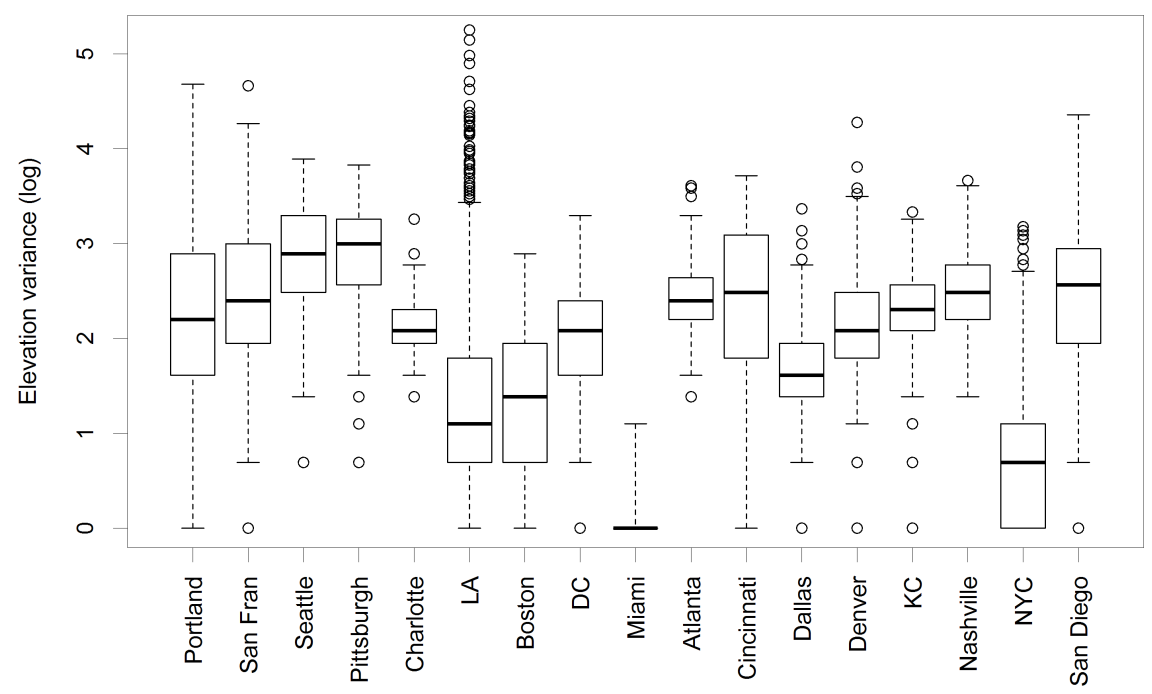

the REST routes Application Program Interface (API) to generate driving distance and time estimates from each census tract to respective downtown areas. ${ }^{8}$ Three sets of driving time estimates are collected: a hypothetical "no-traffic" estimate, an estimate assuming traffic conditions at a local time of 7:00am, and a third one assuming conditions at 7:00pm. By introducing a road-network based centricity metric and separately controlling for driving times at different intervals of the day, this approach accounts for the presence of natural barriers to commuting (New York City, San Francisco) as well as possible temporal differences in marginal commuting time costs; i.e., heavy downtown traffic that only occurs during the morning or evening commute.

The routes API is also used to construct an innovative measurement of local traffic congestion. From the center of each census tract, we calculate "no-traffic" and 7 am driving time estimates to eight different destinations at an equal linear distance of 8 kilometers, at bearings from $0^{\circ}$ to $315^{\circ}$ in 45 -degree increments. If a destination point is on water or otherwise inaccessible as estimated by the API, the furthest accessible point within the 8km-range with the same bearing is used. The proportional time penalties of the 7am drive in all directions are averaged and standardized on a 0-100 scale to create a tract "congestion score", with 0 representing maximum and 100 representing minimum congestion among dataset tracts.

${ }^{8}$ The API is set to optimize for driving time and, if time estimates are equal for two or more routes, to choose the shortest route. 
Elevation and spatial data are combined with demographic, income and education information on census tracts from the 2009-2013 five-year American Community Survey (ACS). Removing observations with missing data yields a remaining total of 6,383 observations usable for the regression model. ${ }^{9}$ Population density figures are generated by dividing ACS population figures over standardized TIGER tract area size estimates. To adjust for potential spatial autocorrelation (Dubin 1991; Hubert, Golledge, and Costanza 1981) on variables of interest, we calculate city-specific spatial autocorrelation values for all response variables using between-tract point distances and a squared Euclidean distance (L2) penalty scheme.

\subsection{Modelling methods}

In determining the existence and size of elevation effects, we face two evident challenges. First, given the nature of our data as an unbalanced city-level panel, a random-intercept (RI) or linear mixed effect (LME) model (Goldstein 1987) is clearly desirable. However, the evaluating of fixed effect statistical significance in LME models is a topic of contention in modern statistics (Bolker et al. 2008; Pinheiro and Bates 2000), and equivalents of p-value-based measures in generalized linear models, such as the Wald Z-test, are generally considered insufficiently conservative and hence unreliable. Variations of Chi-square tests perform better, but usually are limited to balanced panels. Second, the reliability of ACS census tract data, as suggested by reported standard errors of estimates, varies greatly between tracts and categories. Our procedure must therefore account for disparities in data accuracy across these dimensions and confirm or reject significance given this extra aspect of uncertainty.

Our solution is also twofold. First, we utilize error estimates provided by ACS by drawing large numbers of "pseudo-datasets" from Gaussian distributions centered on the actual tract-figure estimates with variance determined by the reported error. Percentage estimates are drawn from normal distributions truncated on $[0,100]$ and count estimates drawn from distributions truncated to non-negative values. This approach introduces diffused uncertainty across both tracts and regression parameters: by iterating over all pseudo-datasets, the influence of high-error tracts and variables is reduced. Second, we perform bootstrapping over observations in each pseudo-dataset to characterize "normal" uncertainty of regression models independent of errors associated with ACS. For each bootstrapped pseudo-dataset, we perform an LME regression with random intercepts by city and by bearing indicators (being Northwest, Southwest, Northeast and Southeast of downtown), as well as random slopes by city on elv, ral and the interaction effect $\mathrm{elv} \cdot \mathrm{ral}$.

More formally, we describe our model using the following notation. We begin

${ }^{9} \mathrm{~A}$ discussion on the rationale for not utilizing imputation methods is provided in the supplementary appendix 
with a dataset of $n$ observations $\left(y_{i}, \mathbf{x}_{i}\right)$. The bootstrapping process involves drawing, with replacement, an identically-sized set of $n$ pseudo-observations $\left(y_{j}^{*}, \mathbf{x}_{j}^{*}\right)$ from an "original" pseudo-dataset $\left(y_{i}^{*}, \mathbf{x}_{i}^{*}\right)$ with $i \in[1: n] .{ }^{10}$ For census tract $i$, variable of interest $y_{i}$, a set of $d$ covariates $\mathbf{x}_{i}=\left(x_{i 1} \ldots x_{i d}\right)^{\prime}$ and corresponding reported standard errors $\sigma_{y_{i}}$ and $\sigma_{x_{i}}=\left(\sigma_{x_{i 1}} \ldots \sigma_{x_{i d}}\right)^{\prime}$, pseudodata are drawn according to $y_{i}^{*} \sim N\left(y_{i}^{*} ; y_{i}, \sigma_{y_{i}}^{2}\right)$ and:

$$
\begin{aligned}
\mathbf{x}_{i}^{*} & =\left(x_{i 1}{ }^{*}, x_{i 2}{ }^{*} \ldots x_{i d}{ }^{*}\right)^{\prime} \\
& \sim\left(N\left(x_{i 1}{ }^{*} ; x_{i 1}, \sigma_{x_{i 1}}^{2}\right), N\left(x_{i 2}{ }^{*} ; x_{i 2}, \sigma_{x_{i 2}}^{2}\right) \ldots N\left(x_{i n}{ }^{*} ; x_{i n}, \sigma_{x_{i n}}^{2}\right)\right)^{\prime}
\end{aligned}
$$

where respective normal distributions are truncated for $y_{i}$ and $\mathbf{x}_{i}$ that are percentage or count variables. Variables in the "original" data that lack available error estimates enter directly into the bootstrapping process. For re-sampled observation $\left(y_{j}^{*}, \mathbf{x}_{j}^{*}\right)$ of city $k$ and bearing $m$, we fit:

$$
\hat{y_{j}^{*}}=\mathbf{B}_{\mathbf{E}_{\mathbf{k}}} \mathbf{E}_{j}+\mathbf{B}_{\mathbf{x}} \mathbf{x}_{j}^{*}+a_{k}+a_{m}+s_{y_{j}}+\varepsilon
$$

where $\mathbf{B}_{\mathbf{E}_{\mathbf{k}}}$ is a vector of slopes on elv, ral and elv $\cdot$ ral specific to city $k, \mathbf{E}_{j}=$ $\left(e l v_{j}, r a l_{j}, e l v_{j} \cdot r a l_{j}\right)^{\prime}, \mathbf{B}_{\mathbf{x}}$ is a vector of coefficients $\left(B_{1}, B_{2}, \ldots B_{d}\right)$ corresponding to the $d$ covariates, $a_{k}$ is a fixed effect of being in city $k, a_{m}$ a fixed effect of having bearing $m$, and $s_{y_{j}}$ the spatial autocorrelation factor for observation $j$ and variable of interest $y_{j}$ under L2 penalization. Variables are transformed for better fit and standardized prior to the regression process.

Compared to a standard, single-model LME regression, our approach is significantly more conservative: it allows for uncertainty within the data itself and is not necessarily confined to equal-tail-ness or normality of standard errors. The effects of observations and covariates of observations that are highly uncertain given the data collection process naturally will be pulled toward zero by the high draw-to-draw variance. Conversely, higher weight is given to observations that are well-collected as they are drawn from tighter distributions. We demonstrate in section 5.1 that this method not only outperforms simpler models with the same re-sample bootstrapping procedure, but also presents better estimations of significance than Wald Z-tests via a single LME regression performed on actual ACS estimates.

There is yet another key advantage of pseudo-data-bootstrapping: the ability to test for random effects on individual cities. While beyond the scope of this paper, obtaining a set of random effect coefficient draws allows one to perform alternative hypothesis tests on elevation gradient effects of a particular city, test for differences between city-specific effects and the fixed effect, or test for

\footnotetext{
${ }^{10}$ The identical set sizes preserve the original sizes of standard errors. If for some reason it is desirable to artificially inflate standard errors, one can simply draw fewer observations than the size of the original dataset.
} 
effect differences among multiple cities. We present suggestive evidence of cities responding differently to elevation gradients in section 4 , but do not present an in-depth discussion of these issues on a city-by-city basis.

Elevation as a spatial attribute is perhaps unique in its lack of reciprocity: it shapes how cities are built, yet only in rare cases do human activity actively and significantly change the profile of land. This is both a blessing and a curse in economic analysis: we do not need tools such as instrumental variables or temporal modelling to establish basic causality, but are limited in ability to isolated direct causal effects from indirect effects that initially originate from elevation, yet should be attributed to other, "intermediary" urban gradients. This is reflected in the highly significant correlation coefficients between elevation effects and a range of ACS statistics, summarized in Table 1.

Table 1: Correlation and Pearson product-moment significance tests between elevation effects and select census tract statistics

\begin{tabular}{cccccc}
\hline & $\begin{array}{c}\text { Population } \\
\text { density } \\
(\log )\end{array}$ & $\begin{array}{c}\text { Median } \\
\text { household } \\
\text { income } \\
(\log )\end{array}$ & $\begin{array}{c}\text { Tract } \\
\text { Gini } \\
(\log )\end{array}$ & $\begin{array}{c}\text { \% of public } \\
\text { transit } \\
\text { commuters } \\
(\log )\end{array}$ & $\begin{array}{c}\text { Poverty } \\
\text { rate (log) }\end{array}$ \\
\hline elv & -0.55 & 0.187 & -0.076 & -0.344 & -0.188 \\
PPMCC & $<0.001$ & $<0.001$ & $<0.001$ & $<0.001$ & $<0.001$ \\
ral & -0.03 & 0.131 & -0.062 & -0.044 & -0.142 \\
PPMCC & 0.01 & $<0.001$ & $<0.001$ & $<0.001$ & $<0.001$ \\
\hline
\end{tabular}

We address this concern by restricting the size of models to estimate the effect of elevation on major urban gradients: for population density, only spatial factors (coastline distance, driving distance and time estimates, tract size, and presence of water) are controlled for and enter $\mathbf{x}_{j}$; for household income only spatial factors and density, and for census tract Gini coefficients we include only spatial factors, density and median income. This allows for the establishment of basic, "location-neutral" causality between elevation and these major gradients. Extra control variables, such as those for employment, occupancy status, income level and ethnic composition are included in models for intermediary effects in Section 6, as these analyses are intended to demonstrate strong evidence for direct causality. We provide a summary of parameters for each model in Tables A1 and A2 in the appendix.

While this structure may seem somewhat semi-recursive in nature, it avoids the difficulty of interpretation that including extra control variables in the main gradient models or fewer control variables for the intermediate effect regressions may cause. Conceptually, it makes little sense to attempt to establish the exis- 
tence of a general relationship yet control specifically for what may very likely be part of that relationship. However, disentangling elevation gradient effects from other spatial factors, most importantly centricity and proximity to water, is still a necessity because downtown areas and areas close to a lake or ocean are mostly likely the flattest parts of a given city. In a similar vein we control for spatial autocorrelation, given that many, if not all urban gradients we investigate (density, income, crime, congestion) are expected to display high levels of spatial dependency.

\section{Elevation Effects in Major Urban Gradients}

\subsection{Model Performance Checks}

We perform 500 LME regressions with bootstrapped pseudo-datasets for each of the following three response variables log-transformed: population density, median tract household income and the tract Gini. In all cases elv and is also log-transformed. We first examine the performance of significance tests via bootstrapping compared to fixed-effect standard-error tests with the same LME models, but a single iteration on actual ACS estimates. Figure 2 contrasts densities of bootstrapped coefficient distributions for $\log ($ elv $)$ and ral against estimated Gaussian densities of the same coefficients using the single LME model, obtain using a Wald Z-test.

The comparison is strongly in favor of the pseudo-data-bootstrapping method. Coefficients that have high levels of certainty under the single LME (variance and altitude on density) are pulled into significantly denser distributions under bootstrapping, suggesting an advantage in estimating the "true" effect size given strong evidence for the existence of an effect. Other coefficients lose significance under bootstrapping and are pulled towards zero at the density mean (altitude on median household income and Gini), suggesting that estimations of effects with less certainty of existence are penalized by the two-stage randomization process and correspondingly reduced in size. Effects with high confidence of rejecting the null hypothesis and those with low confidence hence are clearly distinguished.

We further contrast model performance of the full, LME method with randomintercept-only and OLS models, utilizing the same coefficients, pseudo-data and bootstrapping approach. Holding elevation, control variables and the bootstrap procedure constant, we obtain Akaike information criterion (AIC) estimates for 500 iterations of the full LME regression, a reduced random effects regression with intercepts by city and bearing, and a standard OLS regression with no panel information. AIC densities are compared for the population density model in Figure 3; similar comparisons for tract median household income and Gini models are available in Figures A1 and A2 in the appendix. 
Figure 2: Coefficient densities from bootstrapping versus single LME model
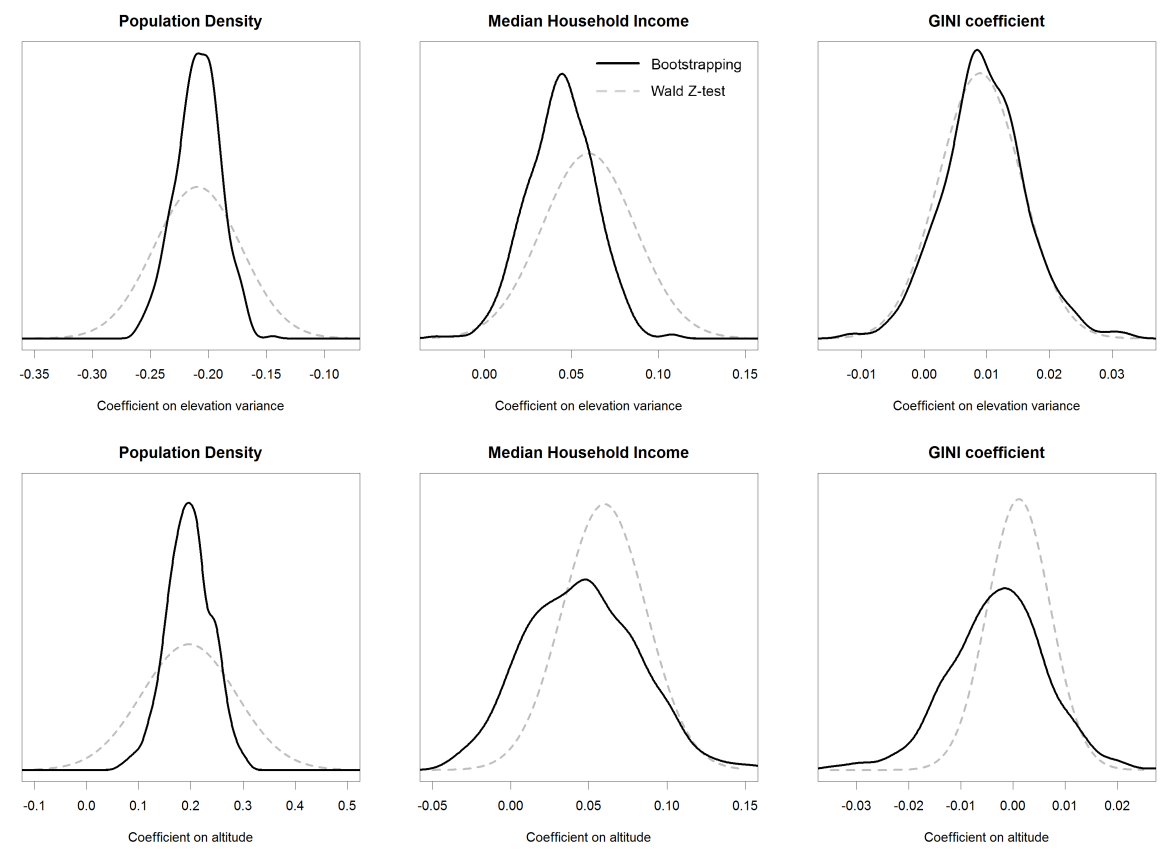

In all three cases (density, income, Gini), both the LME regression and the random intercept regression clearly outperform OLS according to AIC. ${ }^{11}$ This is expected, given that it is highly unlikely that no group fixed effects exist at all across cities. Evidence of superiority of LME over random intercepts is strong for models for population density and tract median household income $(\mathrm{p}<0.001$ via unpaired t-tests), and somewhat significant for the tract Gini model $(\mathrm{p}=0.0525)$.

Note that this suggests a salient feature of elevation gradients in general: beyond fixed effects of $\mathrm{ral}$ and $\mathrm{elv}$, density and income gradients of different cities respond differently to elevation. Evidence for this assertion can also be found in the distribution of random effect estimates on elevation parameters by city: as Figure 4 indicates, while there exists a shared component in the relationship between elv and population density, the mean of coefficient distributions and the possibility of rejecting the null hypothesis differ significantly by city. ${ }^{12}$

The key finding from Figure 4 is that hilliness is associated with reduced

${ }^{11} \mathrm{P}<0.001$ for all comparisons via unpaired t-tests.

${ }^{12}$ Random effects for elevation variance on population density for Seattle, Charlotte, Boston, Miami, Atlanta and NYC cannot be established at 95\% certainty. $\mathrm{p}<0.001$ for unpaired t-tests between the distribution of coefficients on Nashville and that of all other cities. 
Figure 3: AIC densities of full LME regression versus reduced models, Population density model

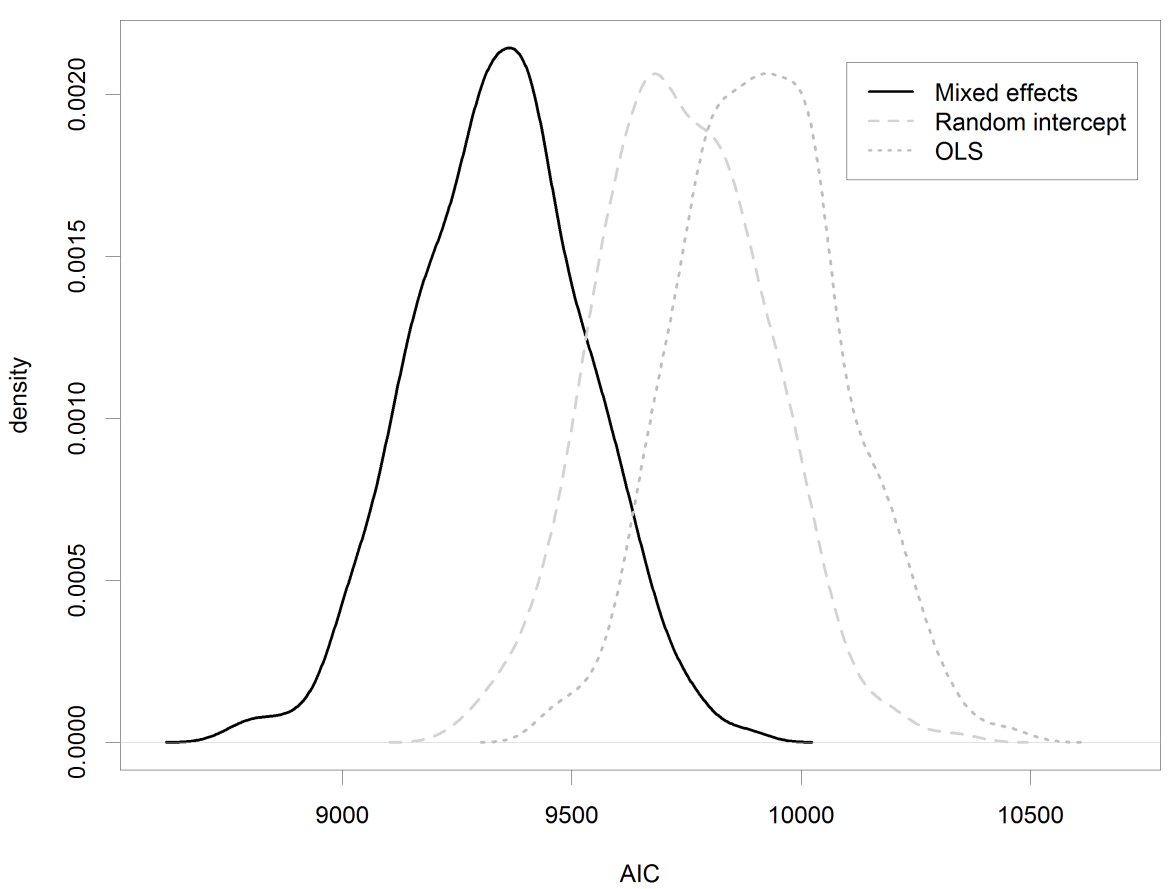

population density in most metropolitan areas, yet that the effect varies considerably across them. A metro area such as Nashville has, in effect, two parts, largely but not perfectly divided by the Cumberland River. The northeast is characterized by low-lying, low altitude variance, high density areas. Heading south toward Williamson County, hilliness increases markedly, as does socioeconomic status of the inhabitants, which in turn is associated with decreased density. In contrast, New York City and Boston are far less hilly, especially near the center, so that socio-economic differentiation is less associated with topographic variation. While a formal investigation of city-specific elevation effects is beyond the scope of this paper, we present select by-city elevation effect estimates in Figures A3, A4, and A5.

\subsection{Results}

Using the statistical approach outlined in Section 4.2 and evaluated in Section 5.1, we find strong evidence for a negative relationship between tract elv and population density $(\mathrm{p}<0.01)$, and a positive relationship between elevation 
Figure 4: Distributions of random effect coefficient estimates of $\log (e l v)$ by city, population density model

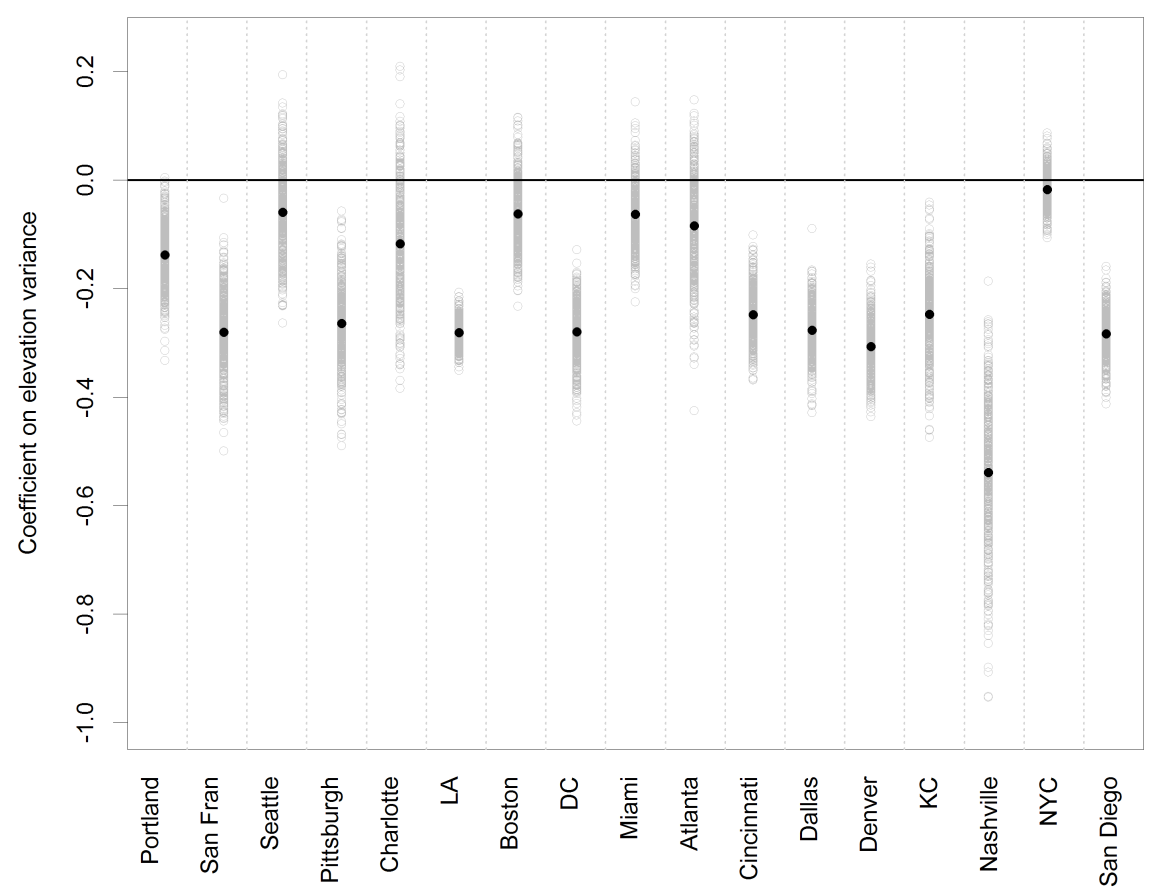

variance and median household income $(\mathrm{p}=0.014) .{ }^{13}$ The relationship between the tract Gini coefficient and elv is marginally significant $(\mathrm{p}=0.07)$. Holding spatial factors constant, we estimate that doubling of elv, assuming city-average $r a l=0$, is associated with a decrease in density of $20.8 \%$, an increase in tract median income of $4.4 \%$, and an approximately $1 \%$ increase in the tract Gini. ${ }^{14}$ The relationship between $\mathrm{ral}$ and population density is also highly significant but positive $(\mathrm{p}<0.01)$, assuming zero elevation variance.

A positive altitude-density relationship may seem counterintuitive. However, in reality increase in altitude is almost always strongly associated with an increase in unevenness: the coefficient on the elv-ral interaction effect is negative and also highly significant $(b=-0.06, p<0.01)$. Consequently, incorporating

${ }^{13}$ For ease of interpretation, we translate coefficient distributions into null hypothesis confirmation rates under a one-tail assumption. Note that because of the limited number of coefficient draws, it is not feasible to inference beyond the $99 \%$ confidence level. For coefficients with less than 5 draws that reject the alt hypothesis, the notation "p $<0.01$ " is used.

${ }^{14}$ To clarify, the effect size is $1 \%$ on the coefficient and not one percentage point. In other words, doubling elv is associated with the change from a given GINI of 0.4 to 0.404 and not 0.41 . 
interaction effects, the negative elevation variance-density connection strengthens as altitude grows, and the positive altitude-density relationship flattens and eventually slopes downward as elv increases. At 3x dataset-average elevation variance (24.3), a increase in $\mathrm{ral}$ of $1 \mathrm{SD}$ translates to a decrease in population density of $4.3 \%$. Fitted curves for both effects, assuming dataset-average density at average altitude and elevation variance, are presented in Figure A6.

To better understand the relationship between elevation and income, we perform pseudo-data bootstrapped random effects regressions on tract mean annual household income data by quintile, controlling for spatial factors, density and autocorrelation of income levels. ${ }^{15}$ The coefficient on elv is strongly significant and positive for all quintiles: mean quintile income increases by $\$ 1,132, \$ 3,074$, $\$ 5,087, \$ 8,777$ and $\$ 24,895$, respectively, per doubling of elevation variance, and mean income of the top $5 \%$ of households by annual income increases by $\$ 42,628$.

Two observations can be made with regard to quintile income effects: first, income is higher for all quintiles in tracts with high elevation variance. Ceteris paribus, even low-income communities in high-variance tracts are richer than their counterparts in low-variance tracts. Second, the proportional changes in quintile income levels are quite similar: assuming dataset-average annual income levels, percentage increases in income associated with doubling elv are between $8-13 \%$ for all quintiles. Interaction effects are also significantly positive and similar across quintiles: doubling elv translates to percentage increases in quintile income of $12-17 \%$ at 1-SD above city-average altitude. Changes in absolute and proportional income are contrasted in Figure 5.

These results are consistent with our findings on tract Gini and median household income. Significant and positive income effects that are somewhat consistent across income groups translate to a modest increase in the tract Gini. Given the evidence in Figure 5, the higher within-tract income inequality of high elv tracts is not caused by the presence of impoverished low-income communities, but rather by the existence of wealthier high-income communities. As within-tract income distributions tend to be strongly long-tailed, median income changes are naturally less drastic than changes to the mean.

The income effect of elevation is reflected in a broad range of demographic patterns. After controlling for spatial factors, density and autocorrelation, we find that individuals in high elv, high ral tracts are older, more likely married, have smaller households, and are more highly educated. Holding other factors constant, a doubling of elv is associated with a $4.4 \%$ increase in the proportion of tract residents above the age of 64 , a $1.3 \%$ increase in the tract median age, a decrease in the average household size of 0.026 members, a decrease in the average married household size of 0.045 members, a $1.2 \%$ increase in

\footnotetext{
${ }^{15}$ Random slopes on elevation parameters are removed to reduce computational load. Z-tests are performed on single LME models with mean quintile income data as the response to confirm output significance. Using both methods, all elevation variance coefficients are significant at the $99 \%$ level.
} 
Figure 5: Absolute/proportional change in quintile income level, doubling elevation variance at $r a l=0$
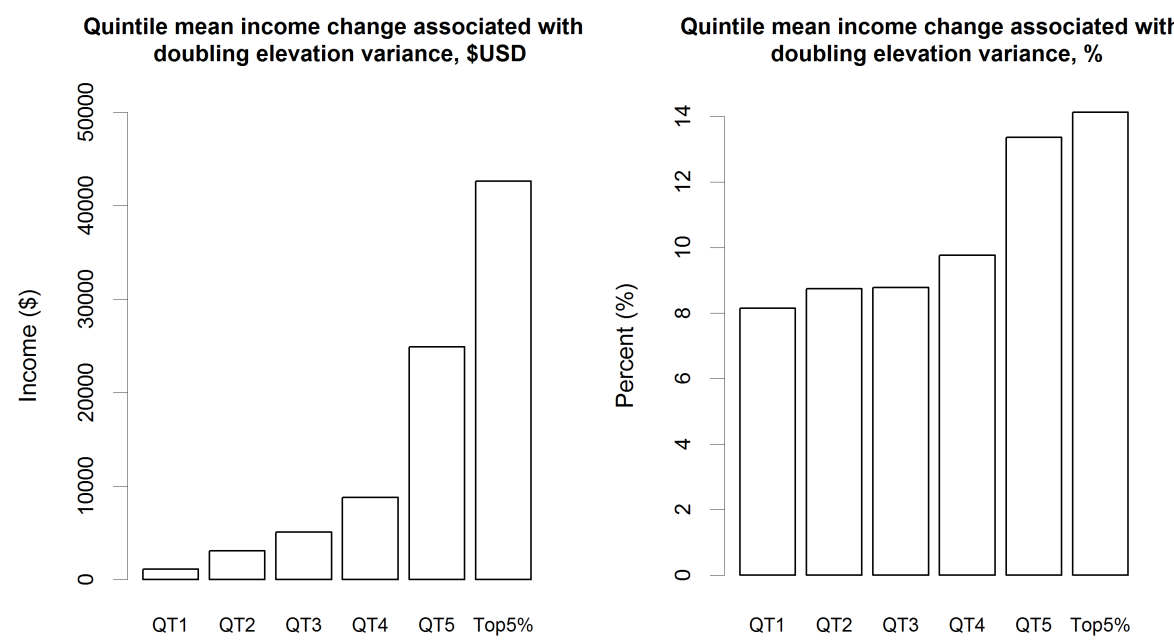

the proportion of married individuals, a $5.2 \%$ increase in the proportion of bachelor's degree holders, and a $8.7 \%$ increase in the proportion of graduate and professional degree holders at city-average altitude. ${ }^{16}$ At $r a l=1$, these effects are respectively strengthened to $6 \%, 2.4 \%, 0.036$ and 0.084 members, $2.7 \%, 8.4 \%$ and $13.9 \%{ }^{17}$

The effects of elevation on ethnicity is less clear-cut. Using a full model which controls for spatial factors, density and autocorrelation, the effects of elv and ral on the percentage of African-American residents are positive. ${ }^{18}$. However, if spatial autocorrelation and density are not controlled for, elv and the interaction becomes negatively associated with the proportion of AfricanAmericans $(\mathrm{p}=0.066 ; \mathrm{p}<0.01)$. The term on ral is significant $(\mathrm{p}=0.048)$ and positive, but does not overwhelm the interaction term at dataset-average elv. ${ }^{19}$ A further-reduced model without any spatial covariates behaves similarly, with smaller African-American proportions associated with higher elv and ral.

${ }^{16} \mathrm{p}<0.01$ for coefficient on elv for regressions on married household size, proportion of bachelor's degree holders and proportion of graduated degree holders. $\mathrm{p}=0.01$ for regression on median age, $\mathrm{p}=0.014$ for regression on proprotion of elderly individuals, $\mathrm{p}=0.024$ for regression on household size, and $\mathrm{p}=0.154$ for regression on proportion of married individuals.

${ }^{17}$ All interaction effects significant at $\mathrm{p}<0.01$ except regressions on elderly individual proportion and household size ( $\mathrm{p}=0.014$ and $\mathrm{p}=0.032$, respectively).

${ }^{18} \mathrm{p}=0.246$ for $\mathrm{ral} . \mathrm{p}=0.044$ for elv. elv $\cdot$ ral is negative but not significant $(\mathrm{p}=0.372)$

${ }^{19}$ At dataset-average variance (8.1), the net effect of the interaction term and the term on ral suggests a decrease of African-American resident proportion of $11.2 \%$ per additional standard deviation above city-average altitude. 
The distinction between the full and reduced model could be explained by strong tendencies toward spatial segregation along racial lines (Courant 1978) leading to far larger spatial autocorrelation effects on ethnic composition than on other demographic parameters. There is evidence for this argument: the spatial autocorrelation covariate in this model is extremely robust, with a doubling of L2-penalization autocorrelation being associated with an increase in African-American proportion of $115.3 \%$. Given the size of this effect, it is very likely that the dataset simply does not have enough gradient between spatially distinct, predominantly white and predominantly black districts to isolate an elevation variance or altitude effect. In other words, inferencing on a tract at the "average" spatial autocorrelation is not productive since almost all of the information on the spatial distribution of ethnicities is explainable by autocorrelation alone.

Note that this does not mean that there is no elevation-ethnicity relationship: the reduced regression suggests that, consistent with income effects, high elv, high ral tracts do indeed have significantly fewer African-Americans. However, it is not possible to separate the elevation gradient effect from general spatial dependency effects unless a set of tracts with a finer gradient of ethnic compositions becomes available across the range of altitudes and elevation variances in the dataset.

The purpose of these models is not simply to reiterate well-established behavioral and demographic patterns of high-income households, but to show that these patterns contain, to some extent, an elevation-oriented component. Much economics literature has focused on the modelling, and much policy on the mitigating of education gaps, inequality and segregation in American cities. Yet while historical and cultural aspects of these issues are at least in principle resolvable, there are few ways to redistribute utility gained from hilliness and altitude to those who live on flat, low-lying land. If, as we demonstrate in Section 6, preference for elv and ral are based on amenities intrinsic to such locations, then these issues will also contain a similarly intrinsic, perhaps unresolvable aspect.

It is important to note that our findings are causal only in the sense of spatial distributions of income stratification and not of the degree of stratification. Although it is likely that uneven cities are indeed more stratified income-wise, it is also possible that elevation gradients are merely deterministic of where stratification occurs. We do not address this question here because, given the focus on census-tract-level effects in this paper, our current dataset is not particularly suitable for drawing inferences at the multi-city-level.

One way to investigate the relationship between elevation gradients and the level of income stratification across cities is the merging of lower-resolution elevation data with a large panel of Metropolitan Statistical Areas. Our work in progress combines this approach with a city-scale counterfactual simulation model (Bayer, McMillian, and Rueben 2004) of the housing market in an effort 
to conclusively determine whether cities would become less stratified if elevation features were removed.

\section{$6 \quad$ Intermediary Effects}

Our findings in Section 5 indicate that holding spatial and autocorrelation effects constant, high-income household strongly prefer locations that are both hilly and at higher altitudes. Conceptually, the most straightforward explanation of this preference is the existence of view effects: a combination of high altitude and high elevation variance leads to access to beautiful scenery, a strictly luxury good among housing amenities. Low-income households will have more price-elastic demand for scenery, and hence be priced out of high-ral, high-elv neighborhoods.

Figure 6: Percentage of high-income households by annual income bracket/elevation block ${ }^{20}$
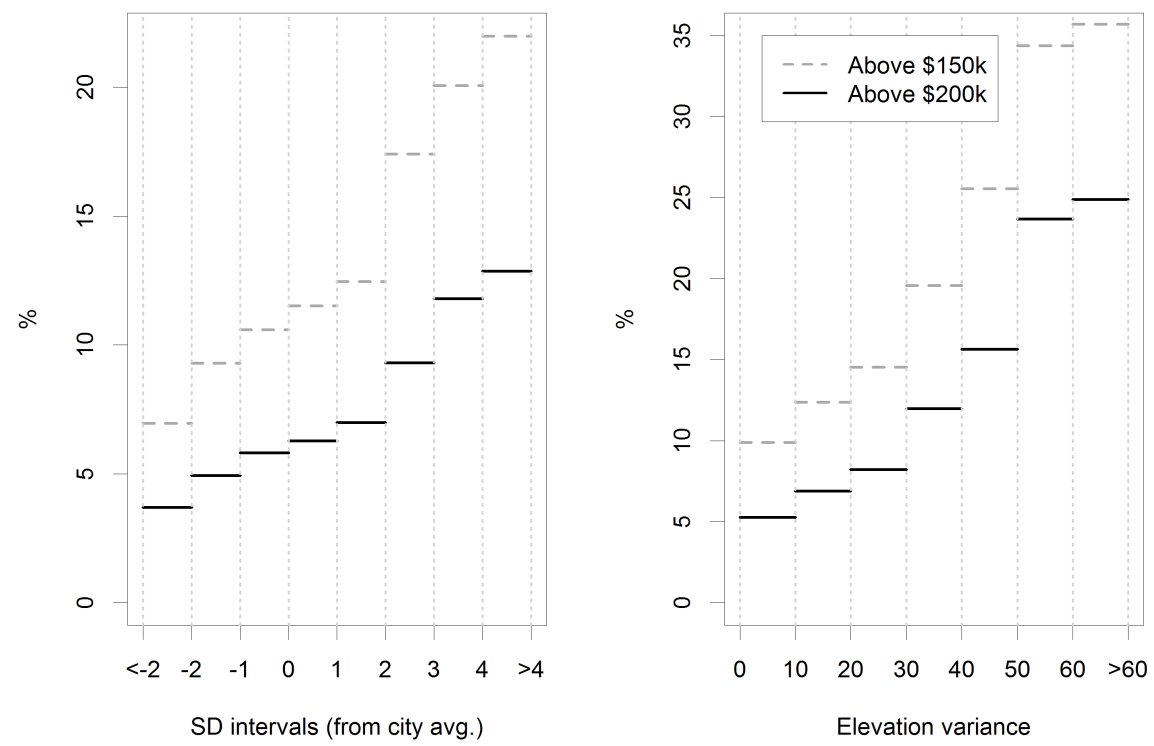

Although view effects are difficult to test directly, there is suggestive evidence. First, as shown in Figure 6, the proportion of high-income households is progressively higher in high-elv, high-ral tracts. In tracts with elevation variance greater or equal to $60,35 \%$ of households have an annual income of

${ }^{20}$ Each percentage estimate denotes average level of tracts with elv/ral between the two bounds. 
above $\$ 150,000$, more than three times the dataset average of $11.1 \%{ }^{21}$ Second, elv and elv $\cdot$ ral effects remain positive and significant $(\mathrm{p}<0.01)$ for the regression on the proportion of households with annual income above $\$ 200,000$ after controlling for spatial factors, autocorrelation, income level, income inequality, demographics, proxies for local economic conditions, public transit use, local congestion and local weather conditions. ${ }^{22}$ We consider this result suggestive of a "pure" elevation amenity that exists independent of local economic conditions and intermediary effects, most conceivably through the form of scenery effects.

However, there are two reasons to suspect that view effects do not tell the whole story. First, the proportion of high-income households, which is generally low at below city-average $\mathrm{ral}$ and low elv levels of 0-20, increases on the margin at these levels of altitude and variance. Yet it is conceptually unlikely for there to be any amenities related to scenery at such variances and altitudes. Second, all income quintiles are of significantly higher income in tracts with greater elv. Yet it seems somewhat improbable that any but the one to two highest-income quintiles are wealthy enough to be strongly influenced by view effects when choosing locations of residency. Based on these observations, we propose four additional explanations of why high elevation-variance, high-altitude locations may be preferable to households with higher income: better micro-climate, difficulty of accessing public transit and lack of walkability, lack of local congestion, and lower crime rates.

\subsection{Micro-climate effects}

While it is well-established that individuals prefer nice weather as a good with high price elasticity of demand (Rappaport 2007) and, in geography literature, that there is a strong relationship between topography and climate (Geiger, Aron, and Todhunter 2009; Linacre 1982), it is not immediately clear whether micro-climate effects are observable at the census-tract level for dataset cities and, if so, whether they are correlated with our estimators of altitude and unevenness. To demonstrate that climate effects exist, we merge our spatial dataset with NOAA historic weather data on monthly temperature levels by zip code. Random-intercept regressions are performed on aggregate metrics of weather against elv, ral, elv $\cdot \mathrm{ral}$ and spatial control variables. Population density is also included as a proxy for temperature effects caused by human activity.

Other factors constant, we find that census tracts with higher elv and ral enjoy better weather. Doubling of elv is associated with a decrease in the standard deviation of monthly average temperatures by $2.1 \%(\mathrm{p}<0.01)$ at city-

\footnotetext{
${ }^{21} 31$ out of the 6,383 observations in the data, approximately $0.5 \%$, report elv $\geq 60$.

${ }^{22}$ The elv term is positive but not significant for the regression with proportion of households with annual income above $\$ 150,000(\mathrm{p}=0.13)$, and $\mathrm{elv} \cdot \mathrm{ral}$ is positive and marginally significant $(\mathrm{p}=0.05)$. A list of variables used and details are presented in Table A1.
} 
average altitude, and a decrease of $2.5 \%$ at 1-SD above city average altitude. Doubling variance is also associated with a decrease in the average monthly maximum-minimum temperature spread of $2.6 \%$ and a decrease in the annual number of Cooling Degree Days (CDDs) of $2.8 \%{ }^{23} \mathrm{elv} \cdot \mathrm{ral}$ is also associated with marginally more rainfall: at 1 -SD above city-average $r a l$, doubling variance is associated with $0.8 \%$ more annual rainfall $(\mathrm{p}<0.01)$.

These estimates suggest that there are statistically significant micro-climate effects at the zip-code level. Areas with higher elv and $\mathrm{ral}$ are cooler, receive slightly more rainfall, and enjoy lower volatility in temperature both between months of the year and within each month. These effects are not trivial: an increase in elv of one or two orders of magnitude translates into significantly smoothed temperature cycles independent of general climatic effects associated with centricity, local water bodies or human activity.

\subsection{Public transit and congestion}

We investigate public transit effects by analyzing of commuting methods of individuals in high-variance, high-altitude tracts: using ACS estimates, we perform pseudo-data bootstrapped random-intercept regressions on the percentage of tract workers commuting by public transit and by walking. In addition to spatial factors and autocorrelation of use of alternative methods of transit, we introduce control variables for tract income level, income inequality, and demographics, as well as proxies for local economic conditions. ${ }^{24}$

Holding all other factors constant, we find that workers commute significantly less via public transit and walking in tracts with high elevation variance. At city-average altitude, doubling elv translates to a $3.7 \%$ reduction in the percentage of workers who commute by public transit $(p \approx 0.03)$. Doubling elv at 1-SD above city-average altitude increases this effect to a reduction of $7.1 \%$. The interaction effect $e l v \cdot r a l$ is not significant for effects on percentage of workers who commute by walking. However, the elv effect for walking is significant, with the percentage of commute-by-walking workers decreasing by $5.6 \%$ per doubling of elevation variance.

The difference in altitude effects perhaps can be explained by the extra supply-constraint of public transit use versus walking: individuals also use public transit less when there are fewer options available. Mass transit systems, by the nature of cost-optimization, will almost always be restricted by elevation disparities along routes. Here, we attribute the elv effect to undesirability of walking down or up steep slopes, which applies equally to commuting by walking and to walk-oriented public transit hubs, and the ral effect for public

${ }^{23}$ All $\mathrm{p}<0.01$. Annual CDDs are calculated by subtracting $65^{\circ} \mathrm{F}$ from the daily average temperature when the daily average is greater than $65^{\circ} \mathrm{F}$, and then summing over all days of the year.

${ }^{24}$ Detailed specifications are provided in Appendix Table A1 
transit to a lack of transit options in tracts with higher altitude, relative to the city-average.

The effects of extra costs of public transit are threefold. First, when considering the existence of a city-level equilibrium of public transit costs, low-income households may outbid high-income households in locations where public transit is relatively accessible (Glaeser, Kahn, and Rappaport 2008), resulting in central concentration of poverty. Our findings imply that households that utilize public transit would prefer flatter instead of uneven areas. This provides poor, public-transit dependent populations with strong incentives to reside in generally flatter downtown areas, even if suburbs are well-endowed with public transit options. Second, high-income households that do not use public transit will pay a "flatness premium" when not selecting areas with relatively high elv and ral, and display opposite preferences. Third, public transit hubs may also be associated with higher levels of local traffic and commercial activity (Kahn 2007). If major hubs are mostly located in flat regions of a city, local highincome communities also, in an attempt to avoid close proximity to hubs, may choose areas with high elv and ral.

Performing the same regression procedure on congestion scores, we find the coefficient on ral to be negative and highly significant $(\mathrm{p}<0.01)$. elv $\cdot r a l$ is positive and somewhat suggestive $(\mathrm{p}=0.134)$. Holding other factors constant and elv at zero, a 1-SD increase in ral decreases the congestion score by 0.82 points. This effect is reduced at higher elevation variance levels: at datasetaverage $e l v$, the same increase in ral only decreases the congestion score by 0.59 points.

The direction of the relationship between elv and congestion is consistent with intuition: uneven and windy roads are harder to navigate and contribute to local buildups of traffic. The stronger altitude effect is most convincingly explained by proximity to major roads: freeways and other large road network components are usually not located in areas with significantly higher altitude than the city-average. Being on a different plane of altitude as the freeway may also have additional benefits with regard to noise and air quality. Therefore, high-income households may also view high-altitude location as preferable because they avoid negative externalities associated with major roads.

\subsection{Crime}

To investigate the relationship between elevation patterns and local crime, we merge our dataset with tract-level crime rate data from the 2000 National Neighborhood Crime Study (NNCS). The study, conducted by Peterson and Krivo (2000), provides detailed crime rate statistics by type of offense for seven offense types and 9,593 census tracts in 91 US cities. Of the NNCS study tracts, 2,195 coincide with tracts in our spatial dataset and are used in the following 
regression analysis.

Controlling for spatial factors, autocorrelation, tract income level, demographics and proxies for local economic conditions, we find that tracts with higher ral and elv enjoy significantly lower crime rates. However, this effect does not apply uniformly for all crime types: hilliness effects are highly significant for robbery, aggravated assault, burglary, larceny and motor vehicle theft (MVT; all p <0.01), but less so for rates of murder and rape. ${ }^{25}$ The size of the effects also differs tremendously: doubling elv translates to a decrease in rates of theft categories and aggravated assault by $12.6 \%-21.6 \%$, but to a decrease in murder rate of only $1 \%$ and a decrease in the rape incident rate of $2.2 \%$. Interaction effects are inconsistent in significance, but uniformly negative for theft categories and aggravated assault. ${ }^{26}$ Figure 7 presents a contrast of crime rate changes associated with doubling of elv.

Figure 7: Crime rate reduction by category corresponding to doubling of elv

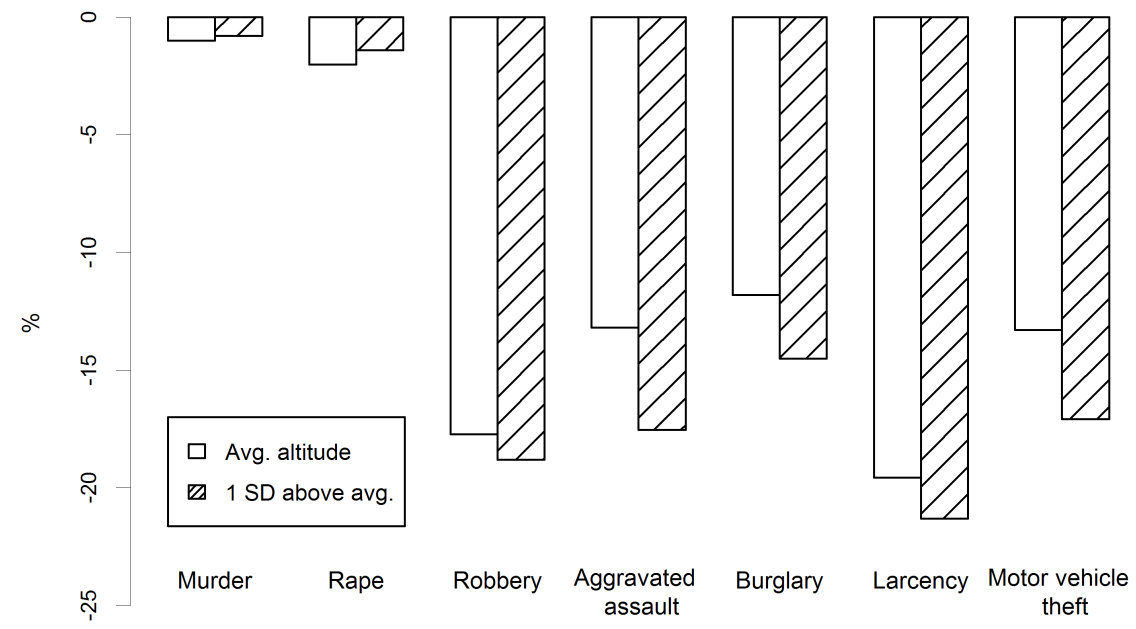

The difference between reductions of crime rates is convincingly explained via the nature of these crimes. Categories such as larceny and MVT are generally "foot" crimes: for example, it is unlikely that a person would drive one vehicle to steal another. For such crime types, unevenness of terrain introduces significant cost: if criminals are indifferent to location and stand to profit equally from all areas, they would choose to commit these crimes in flatter areas to avoid walking up or down slopes. It is also possible that uneven terrain introduces addition risk by hindering one's view in certain directions and hence complicating one's plan

${ }^{25} \mathrm{p}=0.036$ for murder rate. $\mathrm{p}=0.02$ for rape incident rate.

${ }^{26} \mathrm{p}=0.16$ for robbery rate, $\mathrm{p}<0.01$ for aggravated assault rate, $\mathrm{p}=0.016$ for burglary rate, $\mathrm{p}=0.118$ for larceny rate and $\mathrm{p}<0.01$ for rate of MVT. 
of escape. Being on foot, it is also conceivably more difficult to evade capture from law enforcement, which would have ready access to vehicles regardless of local elv or ral.

In contrast, murder and rape are much more commonly committed as domestic crimes and between acquaintances. Their occurrences are hence not as significantly affected by elevation effects as the other crime categories. Given the significance of these effects after controlling for economic conditions and income, we conclude that areas with high elv are likely inherently "safer" than flatter areas of a city, especially for non-violent property crimes. If safety is priced into the cost of housing and other local amenities, these locations are expected to have higher concentrations of high-income households.

While these four effects clearly are not the only intermediaries between elevation and income, establishing their existence is nonetheless illuminating. Contrasted with view effects, these factors are capable of influencing the decisionmaking of middle and upper-middle class households in general: relatively few households are affluent enough to afford a truly beautiful view, yet many can afford to enjoy relatively mild weather, commute regularly by car, live far away from noisy, dirty freeways, and pay for low crime. These effects are consistent with income gradient effects that predict consistently higher income in high-elv, high-ral tracts. Density, in addition to being adversely influenced by higher costs of construction in hilly areas, also decreases because high-income house-

holds demand greater quantities of housing, and because fewer public transit hubs and major roads discourage the buildup of commercial activity.

\section{Conclusion}

America's major cities vary substantially in terms of density, income gradients and degrees of socio-economic integration. They vary in age, climate, industries, geographical constraints and historical legacy, and surely these forces indirectly influence today's social-economic structures. Yet, as we document, there also are marked differences in hilliness and altitude, not only across metropolitan areas and surrounding suburbs but also within and between census tracts of the same city.

We endeavor in this paper to demonstrate that topographical structurespecifically, the standard deviation of elevation and relative altitude of a given location-matters for density and economic and social outcomes. In so doing, we present a simple modification of the AMM model that explains the consistency of our observations. We also introduce an innovative, statistically conservative bootstrapping regression procedure and control for a very large range of characteristics, including spatial factors, autocorrelation, overall density, incomes, and in some regression specifications, occupancy, demographics and indicators for economic conditions. Compared with alternative approaches, we show that our 
pseudo-data-based method, while computationally intensive, is advantageous in a number of key dimensions.

The unmistakable finding is that topographic structure does matter and that its importance interacts with many different variables and differs from one MSA to another. Elevation variance and altitude predict robust density and income gradient effects at both the city-level and the census-tract-level. Controlling for other spatial factors, tracts with greater unevenness and higher altitude are less dense, consist of households with significantly higher average household income, and have higher Gini coefficients.

We show that these effects are rooted in powerful economic incentives such as public transit, micro-climate, crime and the lack of congestion that draw the rich to hilly, high-altitude locations and push the poor toward flat, lowaltitude ones, the realigning of which perhaps may be figuratively as difficult as moving heaven and earth. The finding is an important and sobering one for those who hope to design policies that would reduce social inequality and racial segregation. 


\section{References}

Alonso, William (1964). Location and Land Use. Cambridge: Havard University Press.

Aurand, Martin (2006). The Spectator and the Topographical City. Pittsburgh: University of Pittsburgh Press.

Autor, David H., David Dorn, and Gordon H. Hanson (2013). "The Geography of Trade and Technology Shocks in the United States". In: American Economic Review: Papers $\mathcal{E}$ Proceedings 103.3, pp. 220-225.

Bailey, M. J. (1966). "Effects of race and other demographic factors on the values on single-family homes". In: Land Econ 42, pp. 215-220.

Banzhaf, H. Spencer and Randall P. Walsh (2008). "Do People Vote with Their Feet? An Empirical Test of Tiebout's Mechanism". In: American Economic Review 98.3, pp. 843-863.

Bayer, Patrick and Robert McMillian (2005). "Racial Sorting and Neighborhood Quality". In: NBER Working paper 11813.

Bayer, Patrick, Robert McMillian, and Kim Rueben (2004). "An Equilibrium Model of Sorting in an Urban Housing Market". In: NBER Working paper 10865.

Bin, Okmyung et al. (2011). "Measuring the Impact of Sea-level Rise on Coastal Real Estate: A Hedonic Property Model Approach". In: Journal of Regional Science 51.4 , pp. $751-767$.

Bolker, Benjamin M. et al. (2008). "Generalized linear mixed models: a practical guide for ecology and evolution". In: Trends in Ecology and Evolution 24.3.

Bosker, Maarten and Eltjo Buringh (2015). "City seeds: Geography and the origins of the European city system". Journal of Urban Economics.

Briant, Anthony, Miren LaFourcade, and Benoît Schmutz (2015). "Can Tax Breaks Beat Geography? Lessons from the French Enterprise Zone Experience". In: American Economic Review: Economic Policy 7.2, pp. 88-124.

Brueckner, Jan K., Jacques-Francois Thisse, and Yves Zenou (1999). "Why is Central Paris Rich and Downtown Detroit Poor? An Amenity-based theory". In: European Economic Review 43, pp. 91-107.

Carlino, Jerry and Albert Saiz (2008). "Beautiful City: Leisure Amenities and Urban Growth". In: Federal Reserve Bank of Philadelphia Working Paper.

Courant, Paul (1978). "Racial Prejudice in a Search Model of the Urban Housing Market". In: Journal of Urban Economics 5, pp. 329-345.

Dubin, Robin A. (1991). "Spatial Autocorrelation and Neighborhood Quality". In: Regional Science and Urban Economics 22, pp. 433-452.

Falck, Oliver et al. (2012). "Dialects, cultural identity, and economic exchange". In: Journal of Urban Economics 72.2, pp. 225-239.

Gamper-Rabindran, Shanti and Christopher Timmins (2011). "Hazardous Waste Cleanup, Neighborhood Gentrification, and Environmental Justice: Evidence from Restricted Access Census Block Data". In: American Economic Review: Papers \& Proceedings 101.3, pp. 620-624. 
Geiger, Rudolf, Robert H. Aron, and Paul Todhunter (2009). The Climate Near the Ground. VII. Washington, DC: Rowman \& Littlefield.

Gibbons, Stephen, Stephen Machinb, and Olmo Silva (2013). "Valuing school quality using boundary discontinuities". In: Journal of Urban Economics 75.1, pp. 15-28.

Glaeser, Edward L. and Joshua D. Gottlieb (2009). "The Wealth of Cities: Agglomeration Economies and Spatial Equilibrium in the United States". In: Journal of Economic Literature 47.4, pp. 983-1028.

Glaeser, Edward L., Matthew E. Kahn, and Jordan Rappaport (2008). "Why do the poor live in cities? The role of public transportation". In: Journal of Urban Economics 63 (1), pp. 1-24.

Golany, Gideon S. (1995). Ethics and Urban Design: Culture, Form, and Environment. John Wiley \& Sons.

Golany, Gideon S. and Toshio Ojima (1996). Geo-space Urban Design. New York: John Wiley \& Sons.

Goldstein, Harvey (1987). Multilevel Models in Education and Social Research. Oxford: Oxford University Press.

Grimaud, A and J.J. Laffont (1989). "Existence of a Spatial Equilibrium". In: Journal of Urban Economics 25.2, pp. 213-218.

Houde, Jean-François (2012). "Spatial Differentiation and Vertical Mergers in Retail Markets for Gasoline". In: American Economic Review 102.5, pp. 21472182.

Hubert, L J, R G Golledge, and C M Costanza (1981). "Generalized Procedures for Evaluating Spatial Autocorrelation". In: Geographical Analysis 13, pp. 224-232.

Husby, Trond G. et al. (2014). "Do Floods Have Permanent Effects? Evidence From the Netherlands". In: Journal of Regional Science 54.3, pp. 355-377.

Jiao, Sheng et al. (2012). "Ecological suitability evaluation for urban growth boundary in red soil hilly areas based on fuzzy theory". In: Journal of Central South University 19.

Kahn, Matthew E. (2007). "Gentrification Trends in New Transit Oriented Communities: Evidence from Fourteen Cities that Expanded and Built Rail Transit Systems". In: Real Estate Economics 35.2, pp. 155-182.

Kok, Nils, Paavo Monkkonen, and John M. Quigley (2014). "Land use regulations and the value of land and housing: An intra-metropolitan analysis". In: Journal of Urban Economics 81.1, pp. 136-148.

Lang, Jon (1994). Urban Design: The American Experience. John Wiley \& Sons.

Linacre, Edward (1982). "The effect of altitude on the daily range of temperature". In: International Journal of Climatology 2 (4), pp. 375-382.

McGrath, Brian (2013). "Slow, Moderate, Fast, Urban Adaptation and Change". In: Resilience in Ecology and Urban Design: Linking Theory and Practice for Sustainable Cities. Ed. by S.T.A Pickett, M L Cadenasso, and Brian McGrath. Springer. Chap. 11.

Mills, Edwin S. (1972). Studies in the Structure of the Urban Economy. Baltimore: John Hopkins Press. 
Muth, Richard F. (1969). Cities and Housing. Chicago: University of Chicago Press.

Nakagawa, Shinichi and Holger Schielzeth (2013). "A general and simple method for obtaining R2 from generalized linear mixed-effects models". In: Methods in Ecology and Evolution 4 (2), pp. 133-142.

Peterson, Ruth D. and Lauren J. Krivo (2000). National Neighborhood Crime Study (NNCS), 2000. Government Document.

Pinheiro, J C and D Bates (2000). Mixed-effects models in $S$ and S-PLUS. New York: Springer.

Rappaport, Jordan (2007). "Moving to Nice Weather". In: Regional Science and Urban Economics 37, pp. 375-398.

Rappaport, Jordan and Jeffery D. Sachs (2003). "The United States as a Coastal Nation". In: Journal of Economic Growth 8, pp. 5-46.

Robinson, Darren (2011). Computer Modelling for Sustainable Urban Design. Taylor \& Francis.

Rose, Louis A. (1989). "Topographical Constraints and Urban Land Supply Indexes". In: Journal of Urban Economics 26, pp. 335-347.

Saiz, Albert (2010). "The Geographic Determinants of Housing Supply". In: Quarterly Journal of Economics 125.3, pp. 1253-1296.

Scawthorn, Charles, Hirokazu Iemura, and Yoshikazu Yamada (1982). "The influence of natural hazards on urban housing location". In: Journal of Urban Economics 11.2, pp. 242-251.

Seim, Katja and Joel Waldfogel (2013). "Public Monopoly and Economic Efficiency: Evidence from the Pennsylvania Liquor Control Board's Entry Decisions". In: American Economic Review 103.2, pp. 831-862.

Shilling, James D., C. F. Sirmans, and John D. Benjamin (1989). "Flood insurance, wealth redistribution, and urban property values". In: Journal of Urban Economics 26.1, pp. 43-53.

Snijders, Tom A.B. and Roel J. Bosker (2011). Multilevel Analysis: An Introduction to Basic and Advanced Multilevel Modeling. 2nd ed. Thousand Oaks: SAGE.

Steiner, Frederick (2000). The Living Landscape: An Ecological Approach to Landscape Planning. McGraw-Hill Professional.

Tiebout, Charles M. (1956). "A Pure Theory of Local Expenditures". In: Journal of Political Economy 64.5, pp. 416-424.

Ye, Yifan and Charles M. Becker (2016). "The (Literally) Steepest Slope: Spatial, Temporal, and Elevation Variance Gradients in Urban Spatial Modelling". In: Economic Research Initiatives at Duke (ERID) Working Paper.

Zexin, Li et al. (2013). "Study on Fractal Characteristics of Hilly City". In: Journal of Applied Sciences. 


\section{Appendix}

Figure A1: AIC densities of full LME regression versus reduced models, median household income model

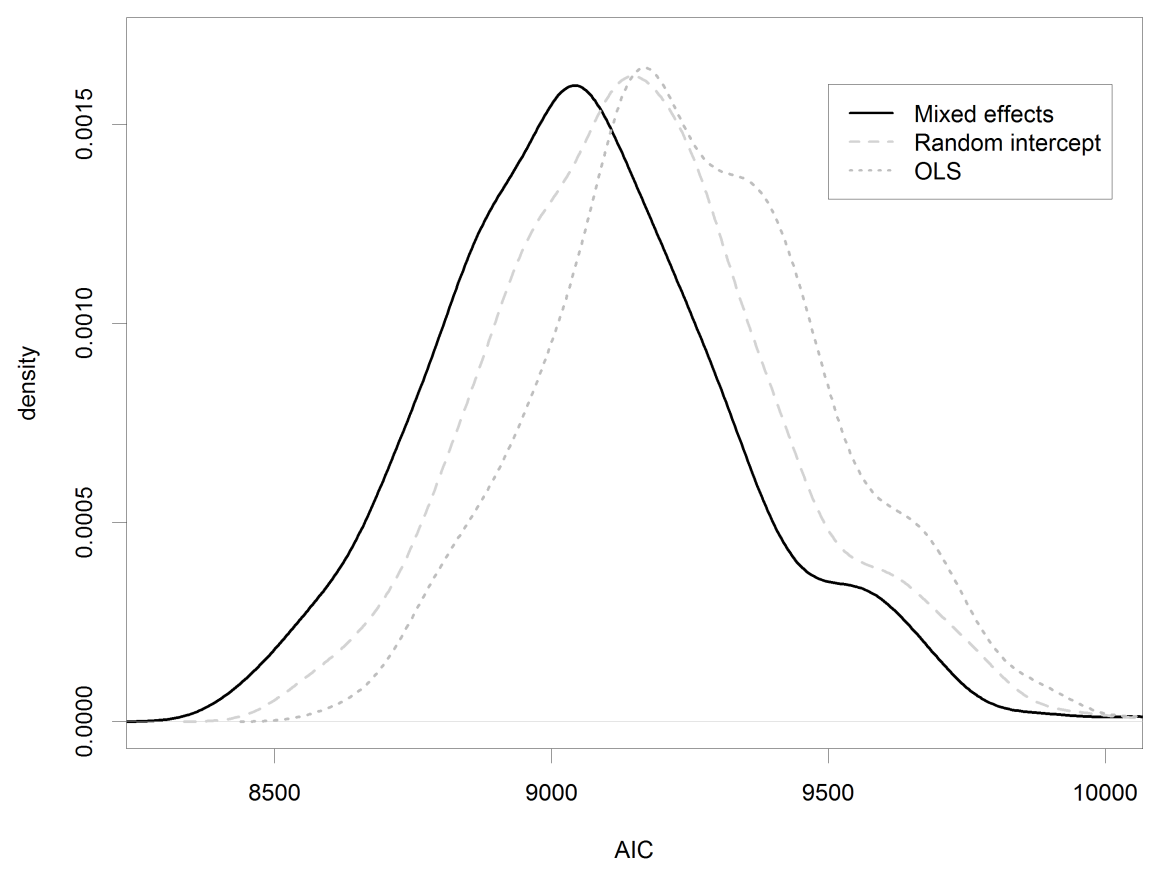



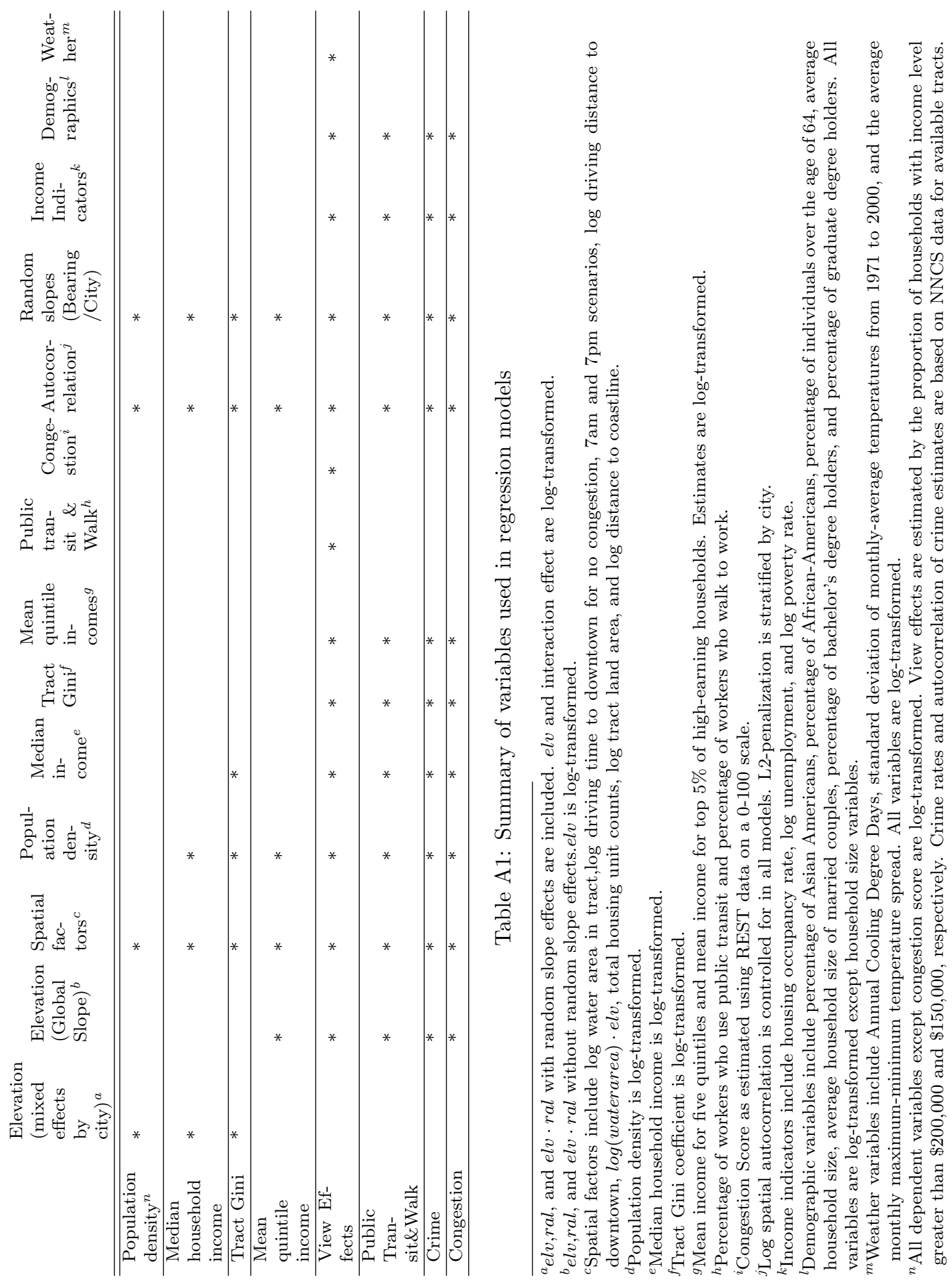


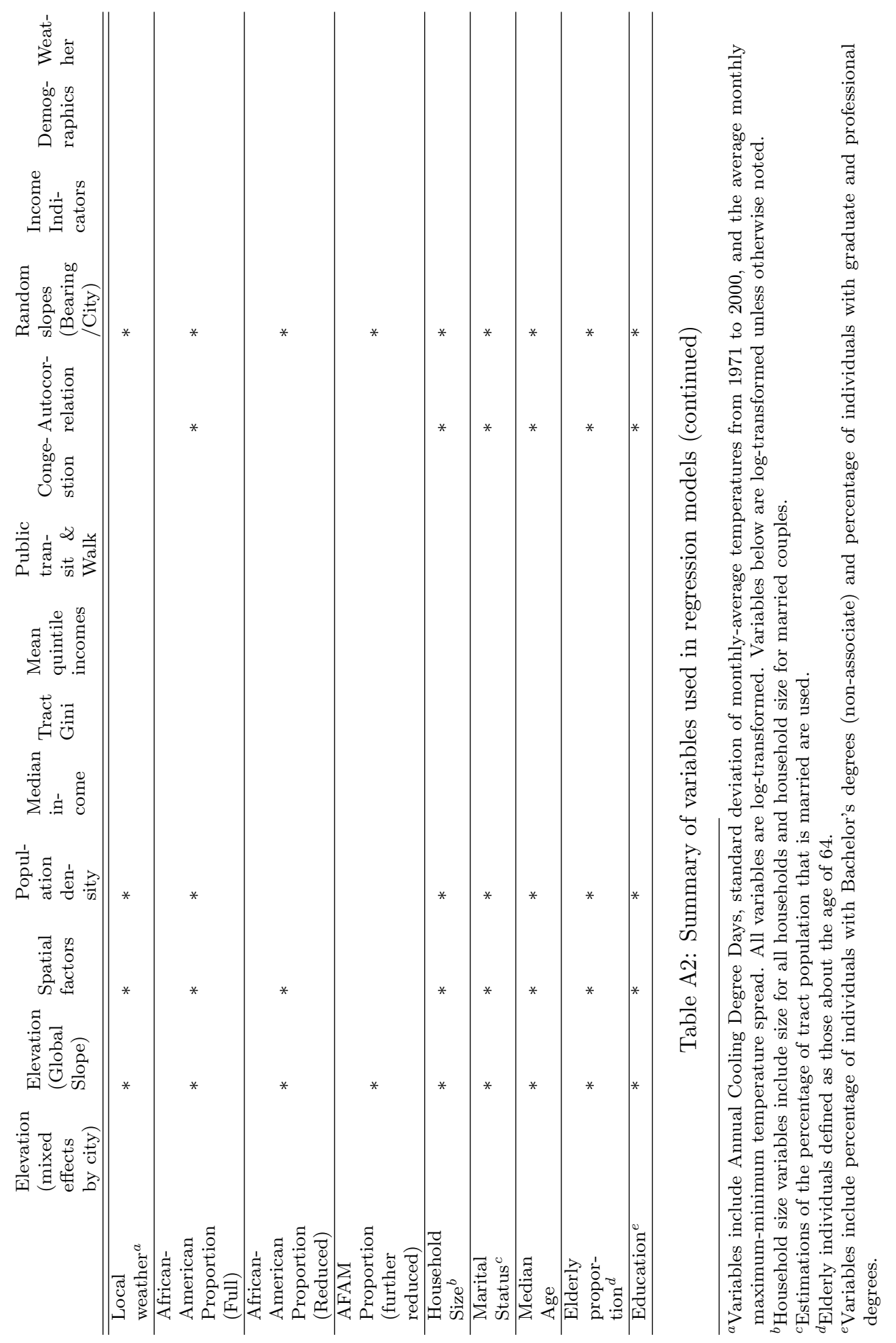


Figure A2: AIC densities of full LME regression versus reduced models, Gini coefficient model

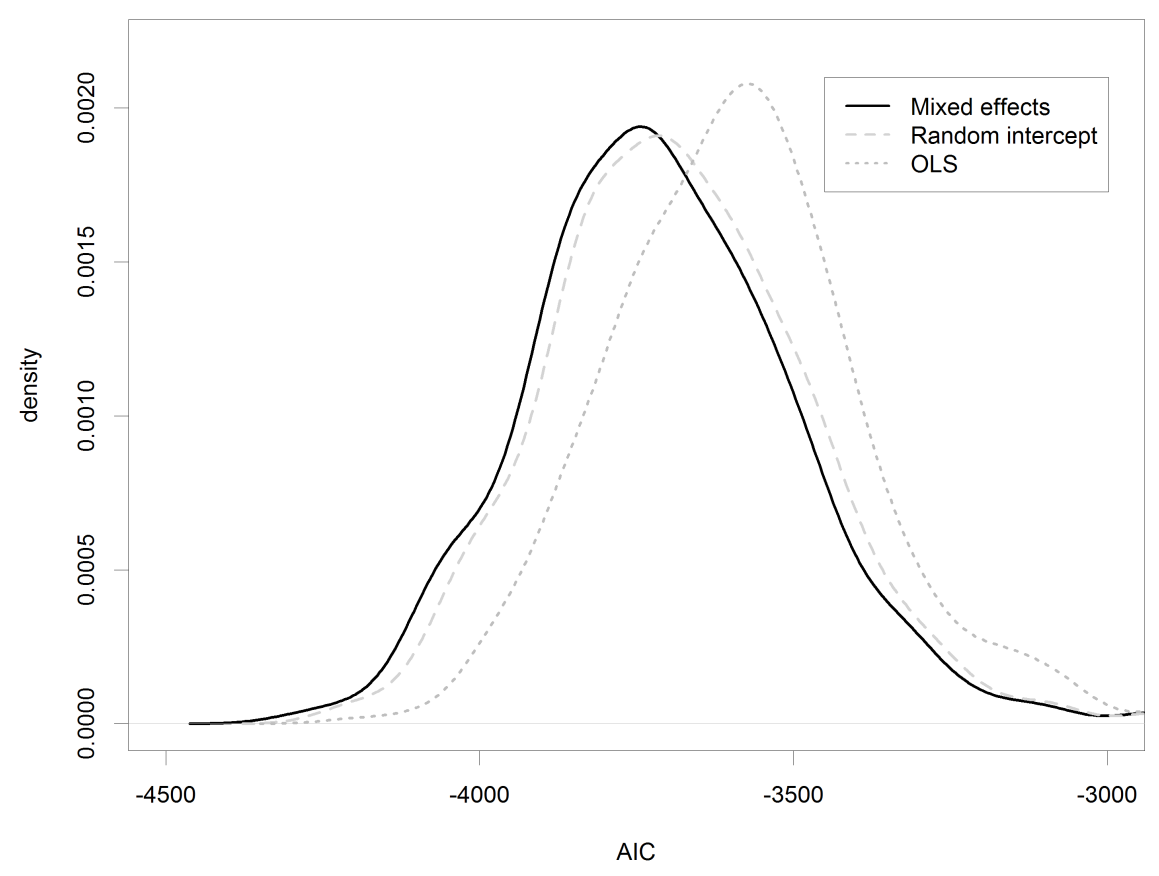


Figure A3: Distributions of random effect coefficient estimates of ral by city, population density model

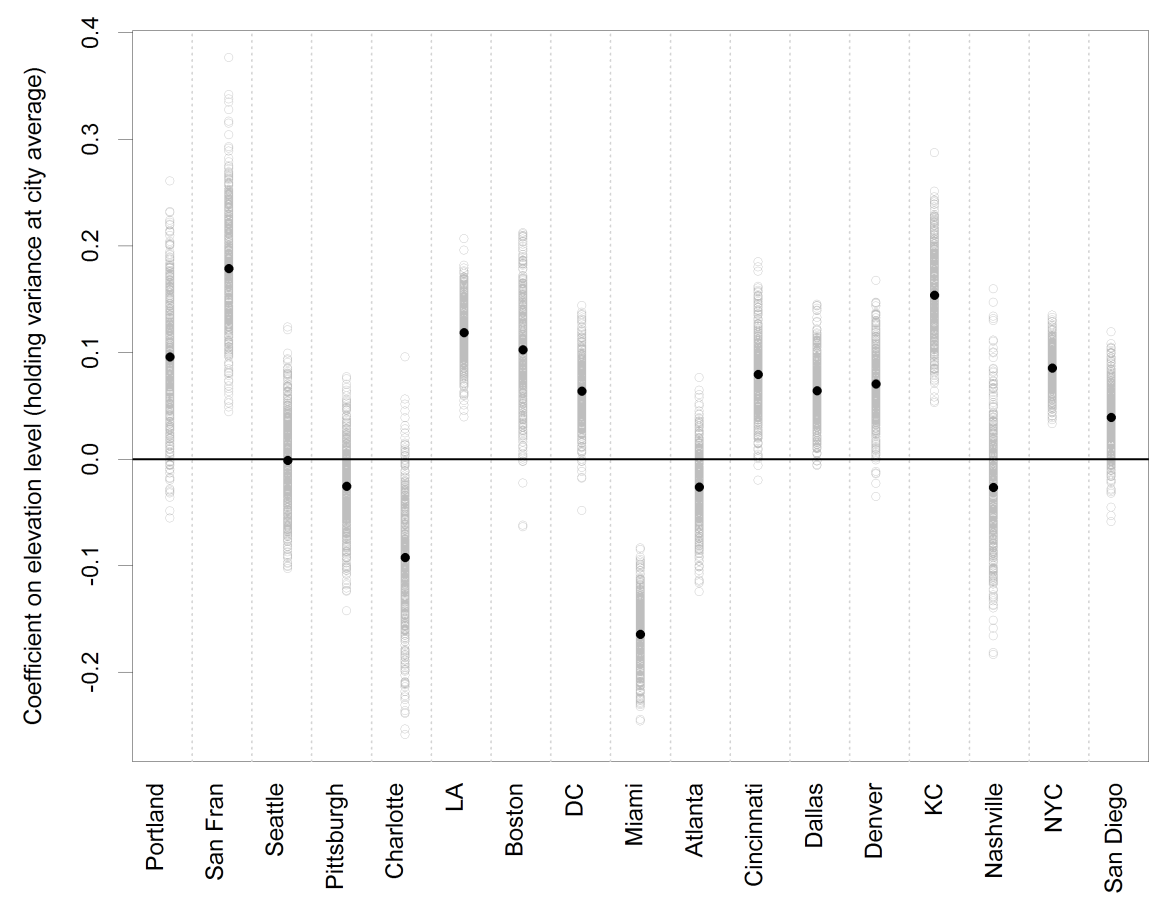


Figure A4: Distributions of random effect coefficient estimates of $\log (e l v)$ by city, median household income model

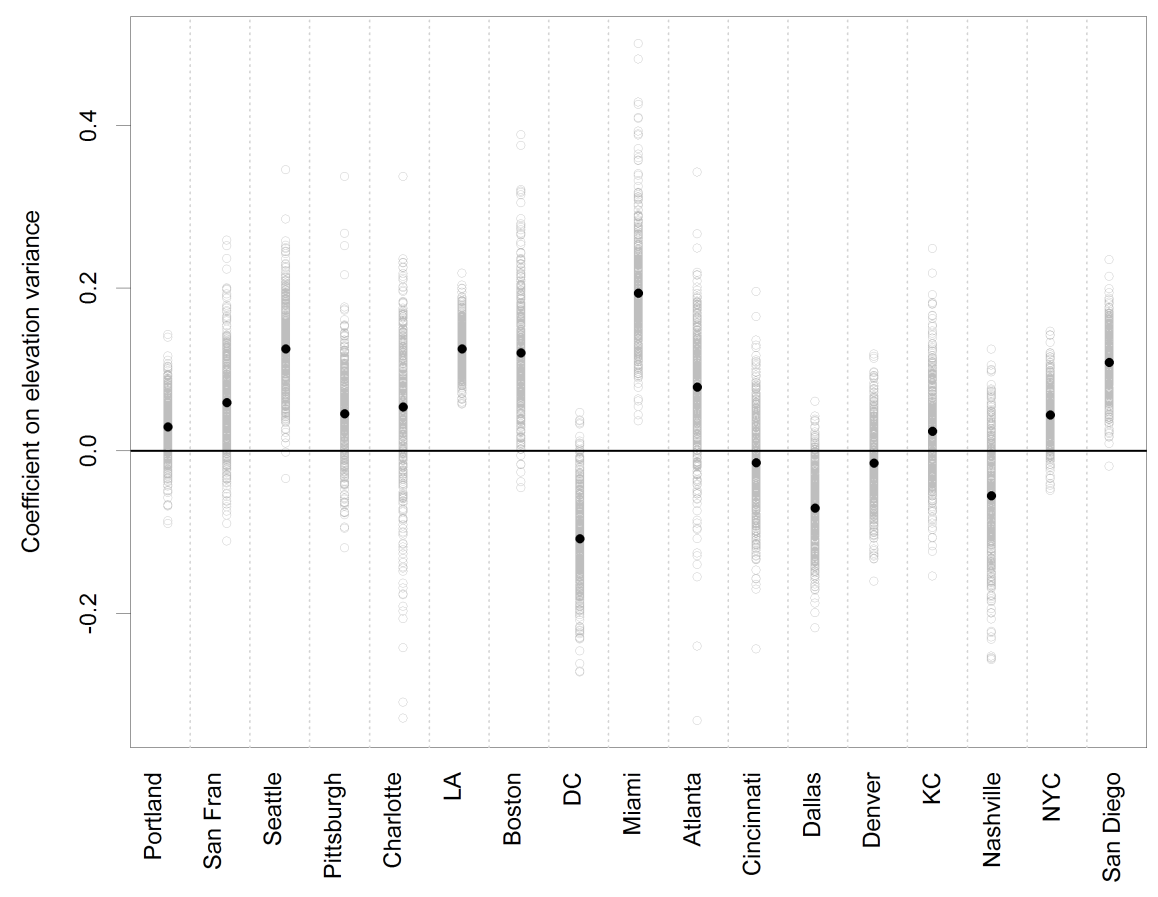


Figure A5: Distributions of random effect coefficient estimates of $\log (e l v)$ by city, gini coefficient model

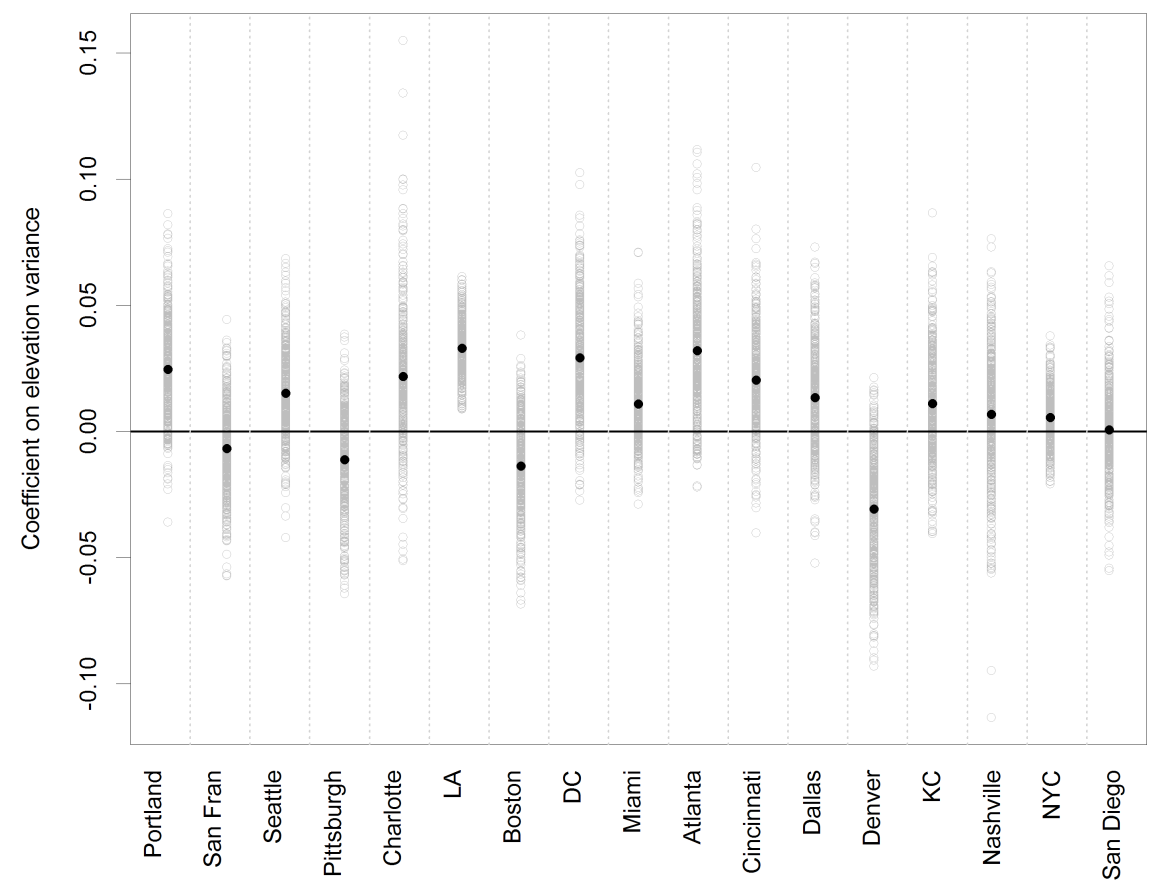


Figure A6: elv-population density and ral-population density curves, holding ral and elv respectively constant
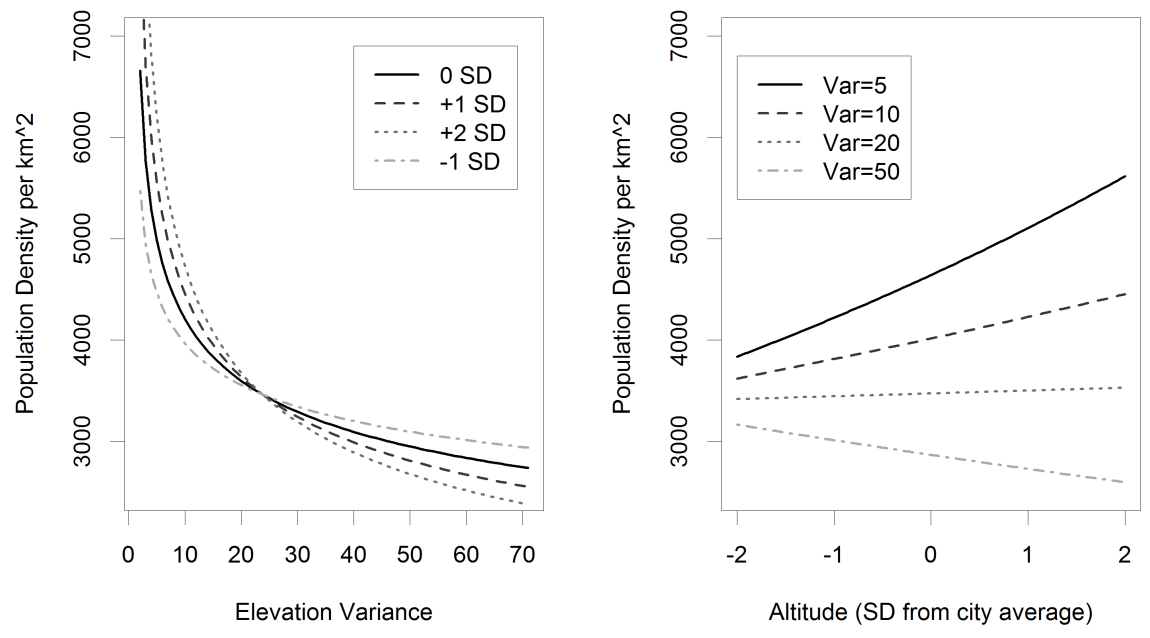
Figure A7: DEM contour density plots of select dataset cities
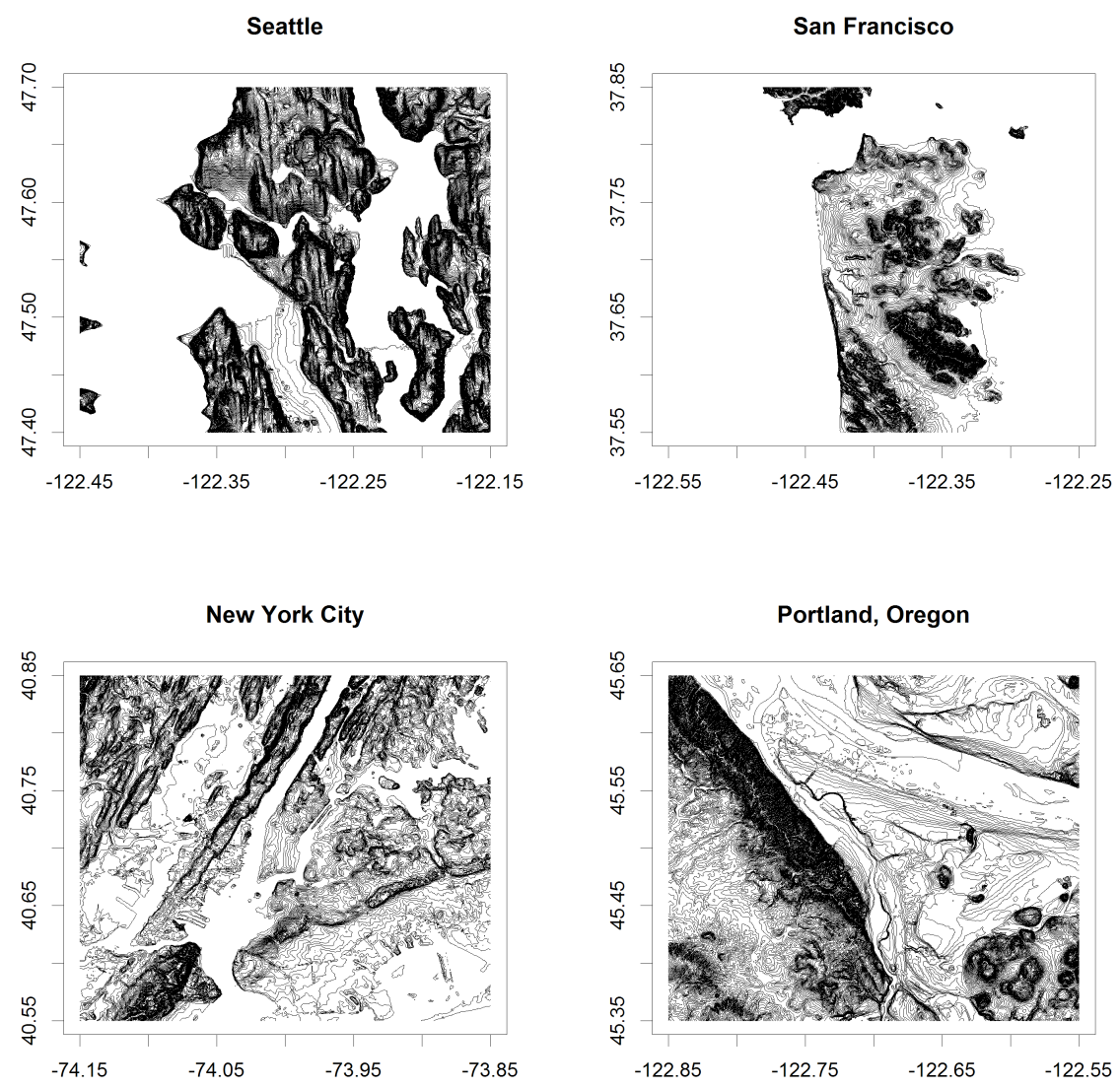


\section{Supplementary Appendix}

\section{Notes for supplementary material}

In this section we provide summarized regression output for all models used in the paper, as well as additional descriptive statistics concerning the dataset. All coefficient sizes are estimated as the simple average of estimated values for all bootstrap iterations. All models are estimated using 500 draws from the full pseudo-dataset. Bootstrap P-values are calculated using a one-sided condition: the number of positive draws as a fraction of 500 for negative coefficient estimates, or the number of negative draws as a fraction of 500 for positive coefficient estimates. If there are less than 5 draws for a given variable that have opposite signs as the estimated coefficient, the notation " $p<0.01$ " is used. We also present density plots of bootstrap coefficient values for elv, ral and the interaction effect. Zero is marked on plots to better visualize the relationship between each elevation effect and the null hypothesis.

With regard to data formatting, we have elected to simply remove noncomplete observations before applying the regression model. Data augmentation is not used for the following two reasons. First, our approach necessarily requires that all ACS variables include reported standard errors for the pseudodata bootstrapping procedure. Even if the values of missing data can be relatively well-estimated via a first-stage imputation process or similar methods, estimating missing standard errors is conceptually much less straightforward. The concern is that data are usually missing for a specific reason: reported standard errors should be much higher for tracts with missing data should the data actually be present. If estimated standard errors are large, these observations will contribute little given the bootstrapping process if they are included. If estimated standard errors are small, the risk that imputed data are overutilized and drive the results becomes a concern.

Second, an observation with one missing covariate typically misses a number of other covariates. Quintile mean income is generally available as a group of six covariates, which are either all present or missing. Out of the 271 observations with at least one missing covariate or standard error value, only 11 miss fewer than 10. This suggests that even if multiple imputation is applied, most observations with missing data will require the estimation of a substantial number of covariates to be usable. This issue significantly lowers the quality of the observations with imputed data. Since at no point in our bootstrapping approach do we explicitly use the "full" dataset as collected (unless the exact same set of observations is drawn at random), benefits of performing imputation are limited to small gains to the representativeness of the data structure and a marginally larger amount of information from which inferences are drawn. We hence conclude that the potential costs of imputation outweigh the benefits.

Note that unless the coefficients on $\mathrm{ral}$ and $\mathrm{elv} \cdot \mathrm{ral}$ point in the same direc- 
tion, a positive or negative sign on ral does not necessarily suggest a correspondingly positive or negative altitude effect for any given response variable. Given a dataset-average $\ln (e l v)$ of $\ln (8.1) \approx 2.09$, the coefficient on $\mathrm{ral}$ must be at least twice as large in absolute value to overwhelm an opposite-direction coefficient on $e l v \cdot r a l$ at dataset-average elevation variance. It is however straightforward to draw inferences on elv at city-average altitude because $r a l=0$ at the city average by design.

The estimation of $R^{2}$ values for linear mixed effects models remains a topic of debate in modern statistics. Here we opt for a two-estimator approach outlined by Nakagawa and Schielzeth (2013), which presents for each model a fixed effects (marginal) $R^{2}$ value and a fixed-and-random effects (conditional) $R^{2}$ value. The former, given our fully Gaussian specification, can simply be regarded as being equivalent to the $R^{2}$ value of the OLS model created by removing all random effects from the LME. The latter includes variance explained by the former as well as variance explained by random intercepts. Variance for random slopes are not included as it is somewhat difficult to integrate such components with regular notions of statistical explanatory power (Snijders and Bosker 2011).

There are two advantages of presenting both marginal and conditional $R^{2}$ values. First, the complementary nature of the values reduces issues that may arise from presenting only one out of the two. Given a large number of groups relative to the dataset size, the conditional $R^{2}$ value will be dominated by between-group variance and fail to adequately reflect explanatory power of fixed effects: in an extreme case, when the group size is very large yet observation count per group is small, the conditional $R^{2}$ will be close to 1 no matter how many fixed effects terms are included. Presenting the marginal $R^{2}$ allows the explanatory power of fixed effects to be examined independent of random effects, yet we would have no knowledge of the role of the random intercept if only the marginal $R^{2}$ were presented. Second, visualizing both $R^{2}$ distributions through bootstrapping allows us to obtain non-quantitative, yet nonetheless useful, information about the importance of between-group variance relative to within-group variance for each model. In the supplementary appendix, we provide side-by-side density plots for the two $R^{2}$ values for each model. Through bootstrap densities, it is possible to not only draw inferences on general explanatory performance of a given model, but also on how consistent performance is with regard to random variations in the data.

Note that in some cases, the reported marginal $R^{2}$ is expected to be extremely low by virtue of the model parameters. This is the case for microclimate effects where differences in annual and monthly temperature variance between cities is naturally far greater than differences among various areas of the same city. Similarly, a fixed-effects-only model of proportions of African American residents that does not control for spatial autocorrelation is expected to have low explanatory power. Since we do not actually draw inferences or present coefficient values based on any fixed-effects-only estimates in the paper, 
this is not an issue of concern.

One anomaly that we note in the data is the unusually low rape incident rate of Los Angeles. (0.004 incidents per thousand persons). This is not because of a lack of crime observations for the Los Angeles area: crime data are available for 424 out of the 796 dataset LA census tracts. Neither is the issue likely caused by missing data: most census tracts with crime data have zero rape incidents during the period covered by the NNCS survey. The distinction appears to be that a far greater percentage of the LA tracts with crime data lack rape incidents. We do not know if this is simply a result of chance given the overlap between our elevation data and NNCS, or if there were potential data collection issues with the original study. However, we have performed the same regression analysis on rape incident rates in section 6.3 with data from LA omitted. Results are similar: the coefficient on elv changes to -0.029 from -0.022 and the corresponding pvalue to 0.015 from 0.02 . Because conclusions remain similar (foot crime effects are still far greater than either the effect on rape or murder), we have reported figures with LA data included in the paper for consistency. 
Table SA1: Names and information of variables in main urban gradient models

\begin{tabular}{|c|c|}
\hline Name & Variable Meaning \\
\hline $\ln (\mathrm{el}$ & $\begin{array}{l}\text { andard deviation of tract elevation samples, log- } \\
\text { ansformed }\end{array}$ \\
\hline elevrelative & $\begin{array}{l}\text { Relative altitude compared to city-average alti- } \\
\text { tude, standard deviations above/below city aver- } \\
\text { age }\end{array}$ \\
\hline elevmeanINTelevvar & $\begin{array}{l}\text { Interaction effect term between } \ln (\text { elevvar }) \text { and } \\
\text { elevrelative }\end{array}$ \\
\hline $\ln$ (DTdrivedist) & $\begin{array}{l}\text { Driving distance to respective downtown areas, } \\
\text { kilometers, log-transformed }\end{array}$ \\
\hline $\ln ($ DTdrivetime7am) & $\begin{array}{l}\text { Driving time to respective downtown areas esti- } \\
\text { mated at 7:00 am, kilometers, log-transformed }\end{array}$ \\
\hline $\ln ($ DTdrivetin & $\begin{array}{l}\text { Driving time to respective downtown areas esti- } \\
\text { mated at 7:00 pm, kilometers, log-transformed }\end{array}$ \\
\hline $\ln$ (DTdriv & $\begin{array}{l}\text { Driving time to respective downtown areas without } \\
\text { traffic, kilometers, log-transformed }\end{array}$ \\
\hline elevre & $\begin{array}{l}\text { Interaction term between elevrelative and } \\
\ln (\text { awater })\end{array}$ \\
\hline $\ln ($ awa & $\begin{array}{l}\text { Water area within census tract, } \mathrm{km}^{2}, \text { log- } \\
\text { transformed }\end{array}$ \\
\hline $\ln (\cos$ & $\begin{array}{l}\text { Linear distance to the coastline, kilometers, log- } \\
\text { transformed }\end{array}$ \\
\hline $\ln ($ hum & $\begin{array}{l}\text { Census tract population density, persons per } \mathrm{km}^{2} \text {, } \\
\text { log-transformed }\end{array}$ \\
\hline $\ln ($ aland $)$ & $\begin{array}{l}\text { Total land area of census tract, } \mathrm{km}^{2} \text {, log- } \\
\text { transformed }\end{array}$ \\
\hline $\ln (\mathrm{r}$ & $\begin{array}{l}\text { Median tract annual household income, } 2013 \text { dol- } \\
\text { lars, log-transformed }\end{array}$ \\
\hline $\ln ($ tot & $\begin{array}{l}\text { Total number of housing units in census tract, log- } \\
\text { transformed }\end{array}$ \\
\hline $\ln ($ tot & $\begin{array}{l}\text { Total number of occupied housing units in census } \\
\text { tract, log-transformed }\end{array}$ \\
\hline $\ln ($ SpaCorL2Densi & $\begin{array}{l}\text { Spatial autocorrelation factor for population den- } \\
\text { sity, log-transformed }\end{array}$ \\
\hline $\ln$ (SpaCorL2HousIncom) & $\begin{array}{l}\text { Spatial autocorrelation factor for median house- } \\
\text { hold income, log-transformed }\end{array}$ \\
\hline $\ln ($ SpaCorL2GINI) & $\begin{array}{l}\text { Spatial autocorrelation factor for census tract } \\
\text { GINI coefficient, log-transformed }\end{array}$ \\
\hline
\end{tabular}




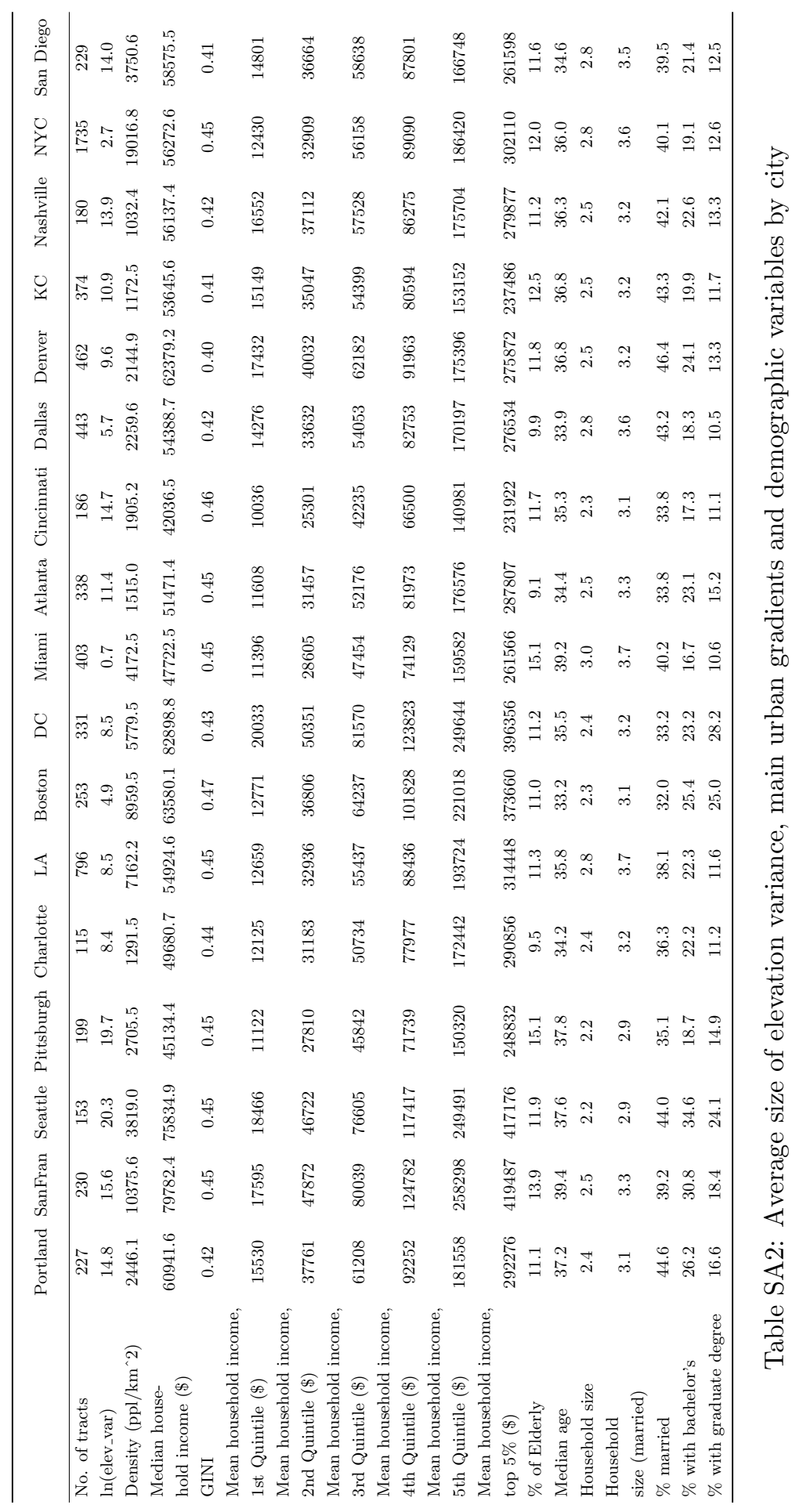




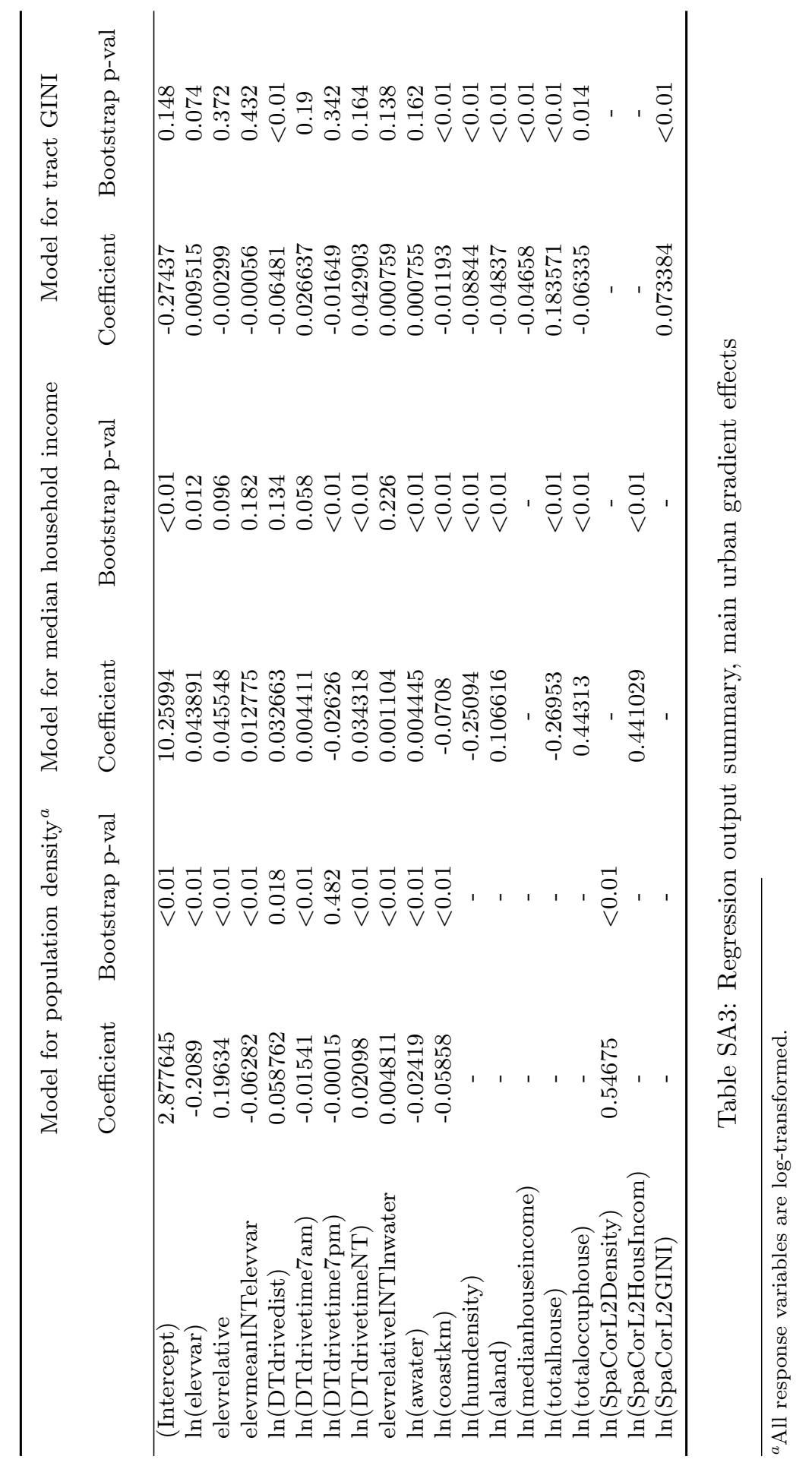


Figure SA1: Bootstrap densities of marginal and conditional R-square values, main urban gradient models
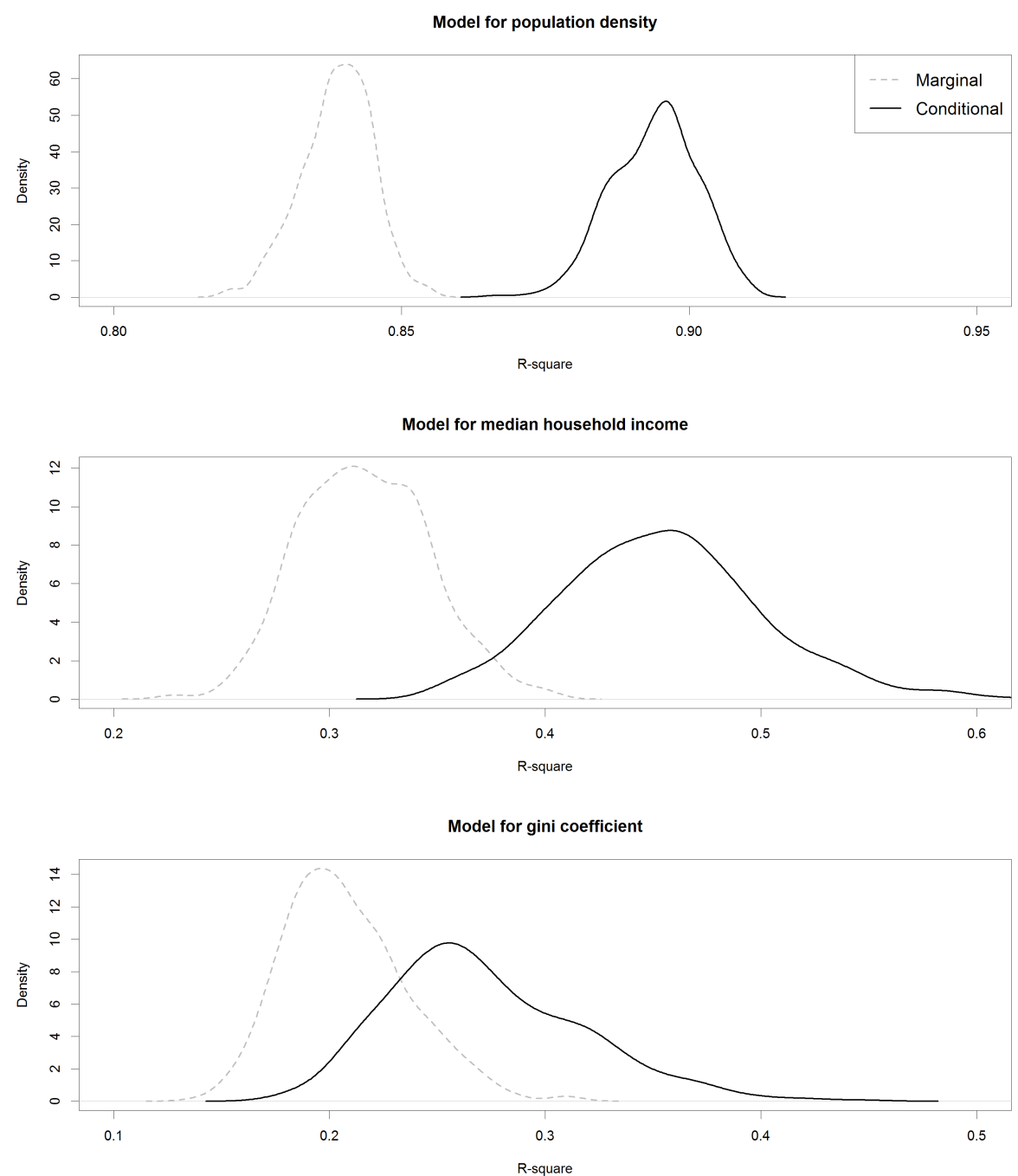


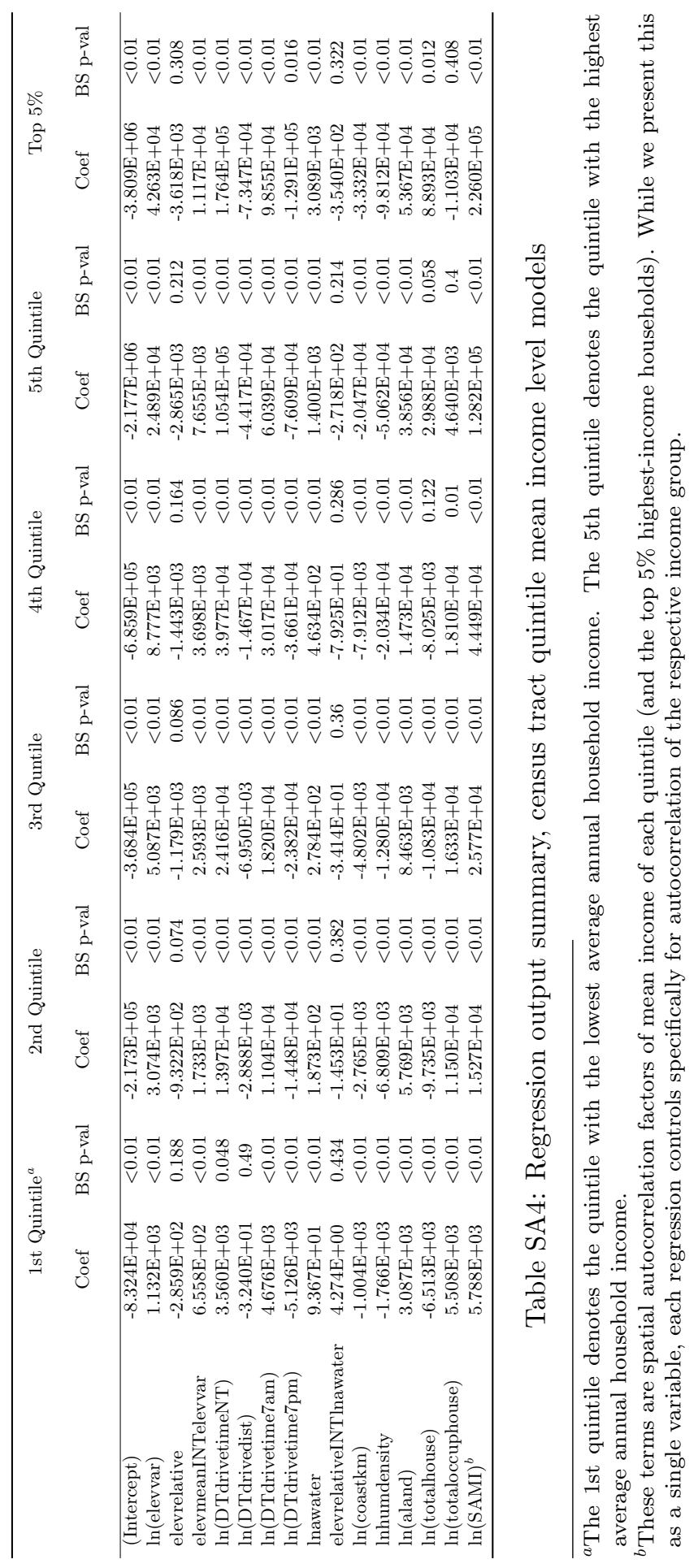


Figure SA2: Bootstrap densities of marginal and conditional R-square values, census tract mean income models
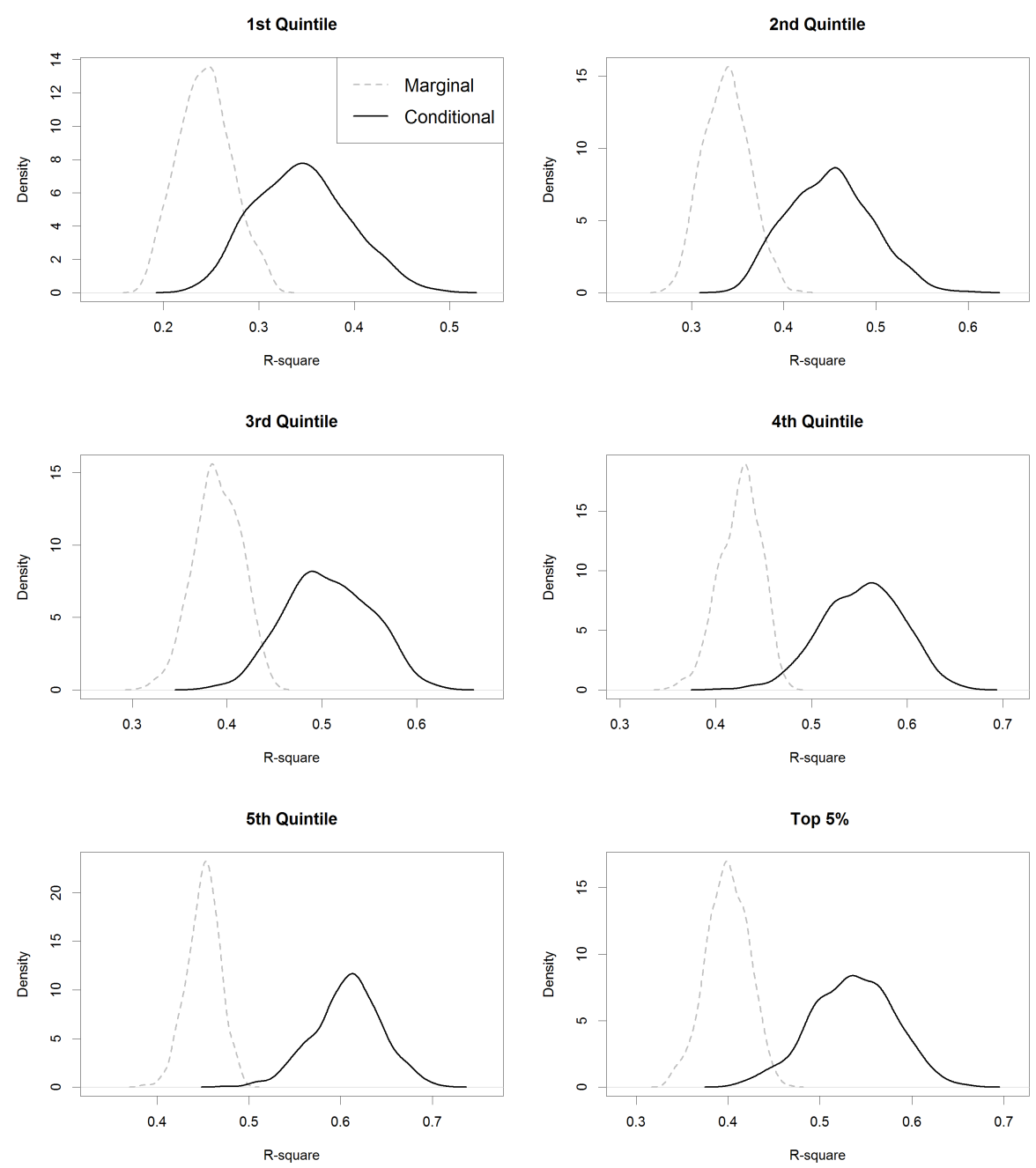
Figure SA3: Bootstrap densities of coefficients on elv, quintile mean income models compared
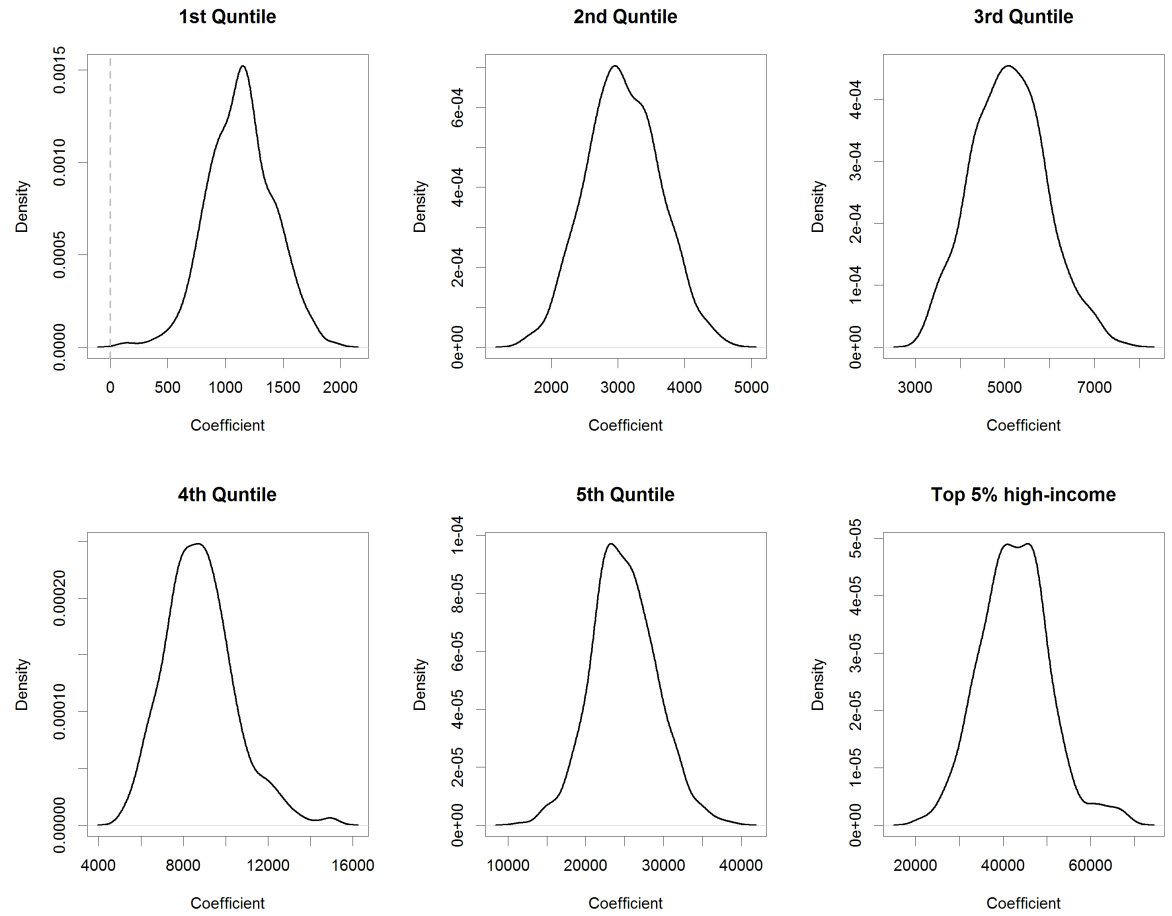
Figure SA4: Bootstrap densities of coefficients on ral, quintile mean income models compared
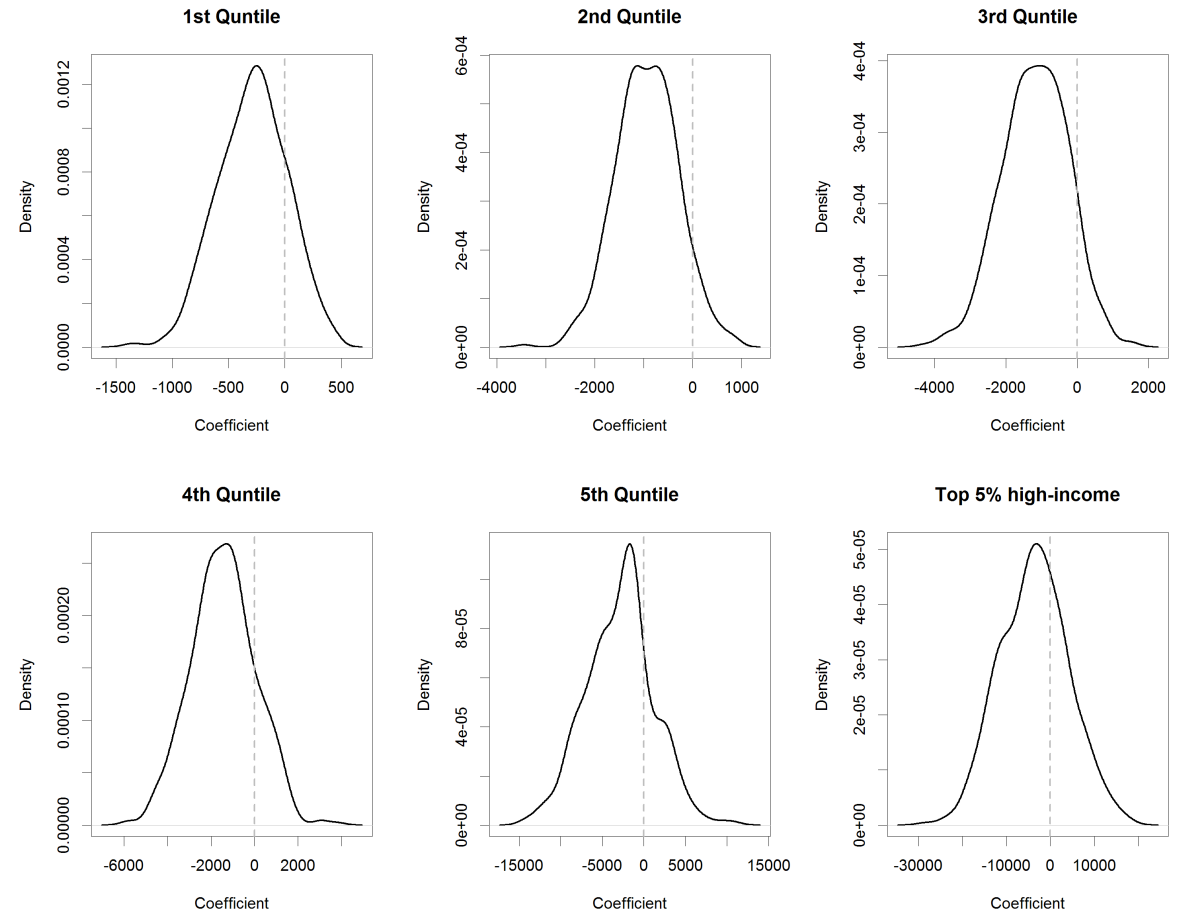
Figure SA5: Bootstrap densities of coefficients on interaction elv $\cdot$ ral, quintile mean income models compared

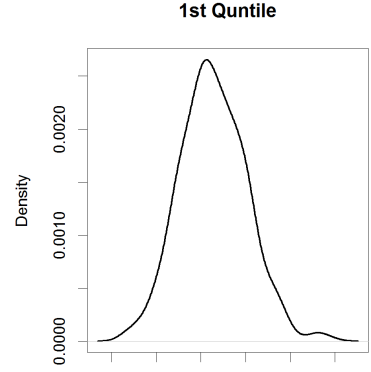

$\begin{array}{lllll}200 & 400 \quad 600 \quad 800 & 1000\end{array}$

Coefficient

4th Quntile

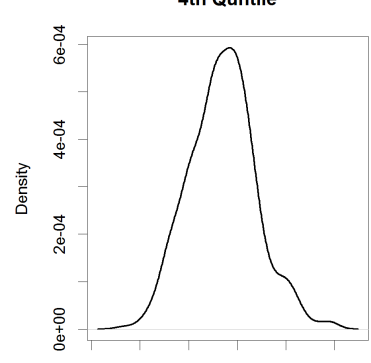

100020003000400050006000

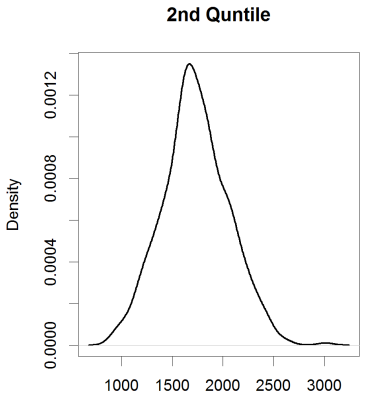

Coefficient

5th Quntile

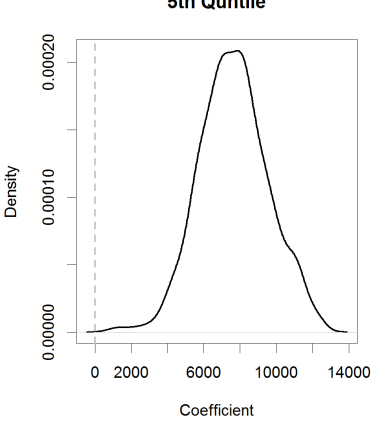

3rd Quntile
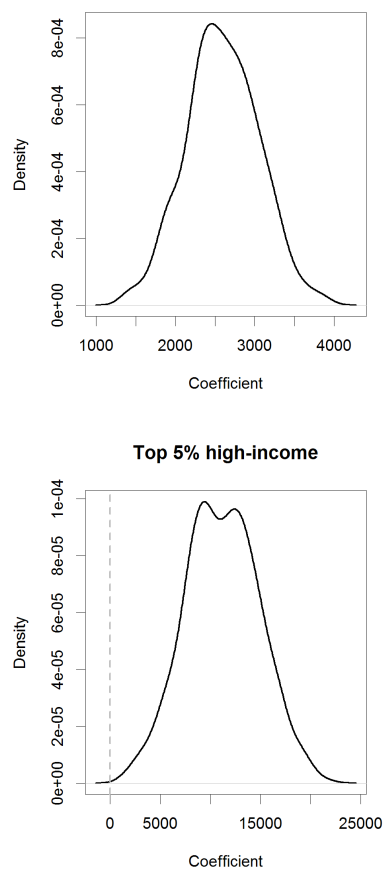


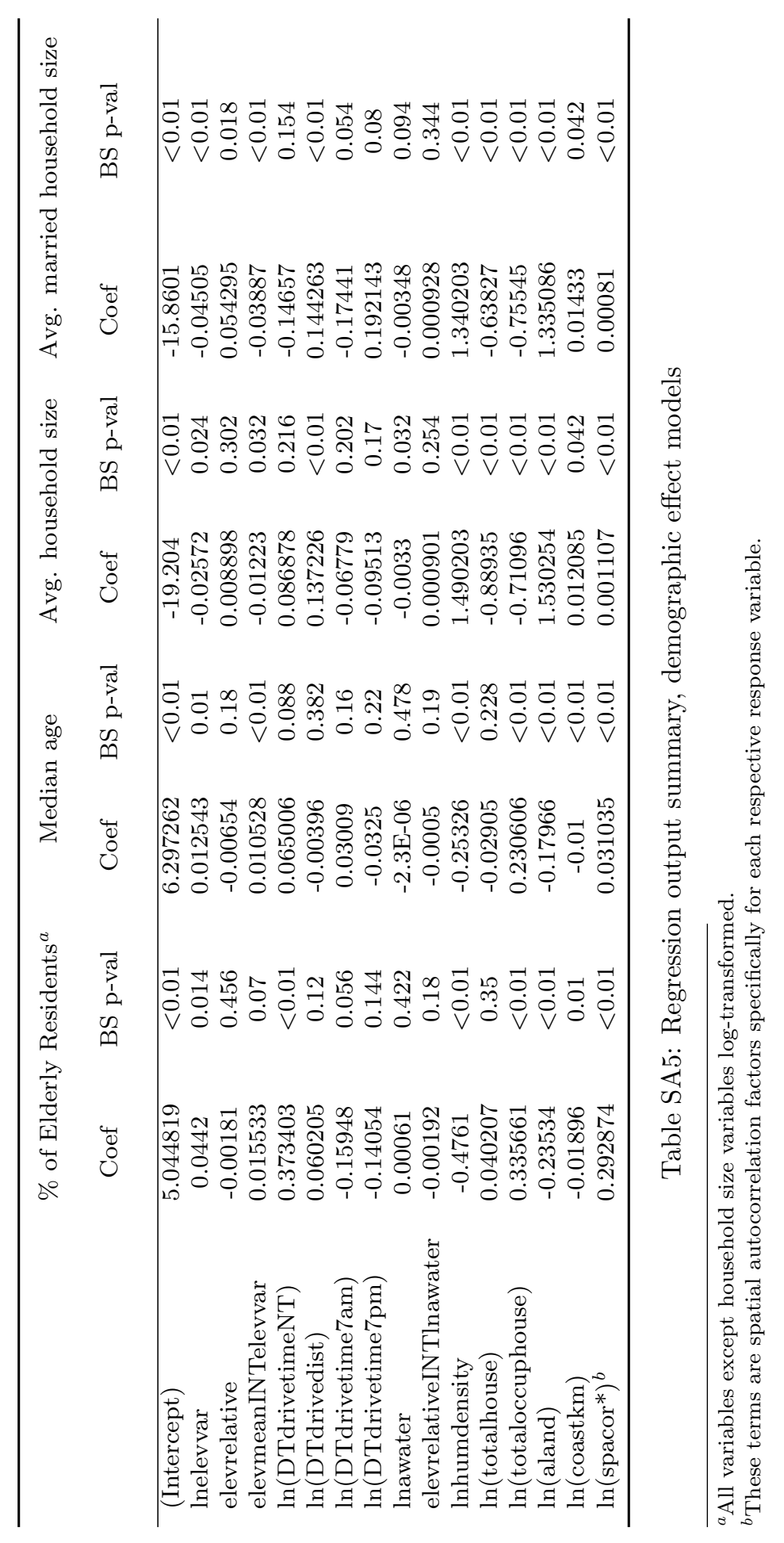




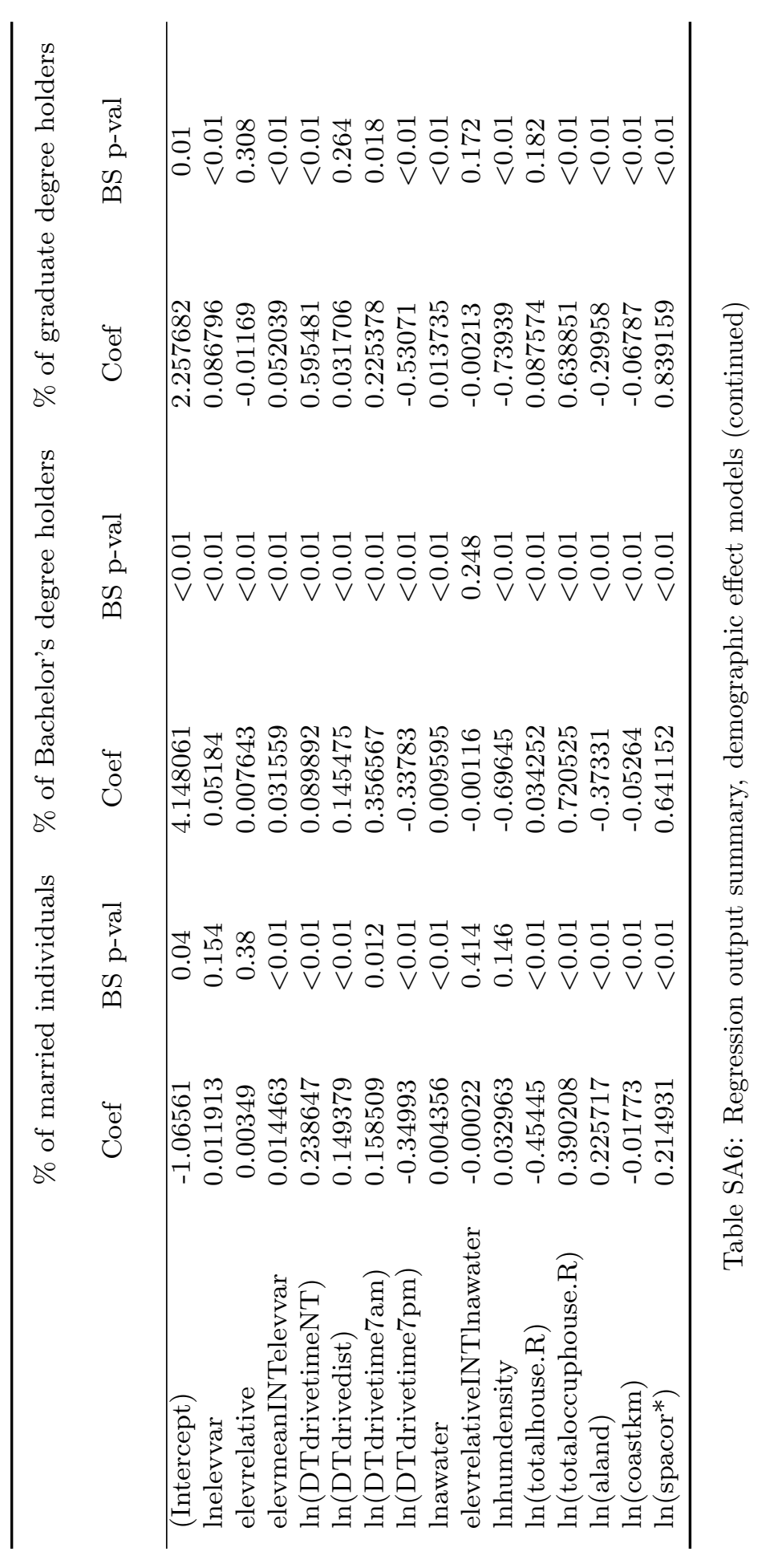


Figure SA6: Bootstrap densities of marginal and conditional R-square values, models of demographic variables
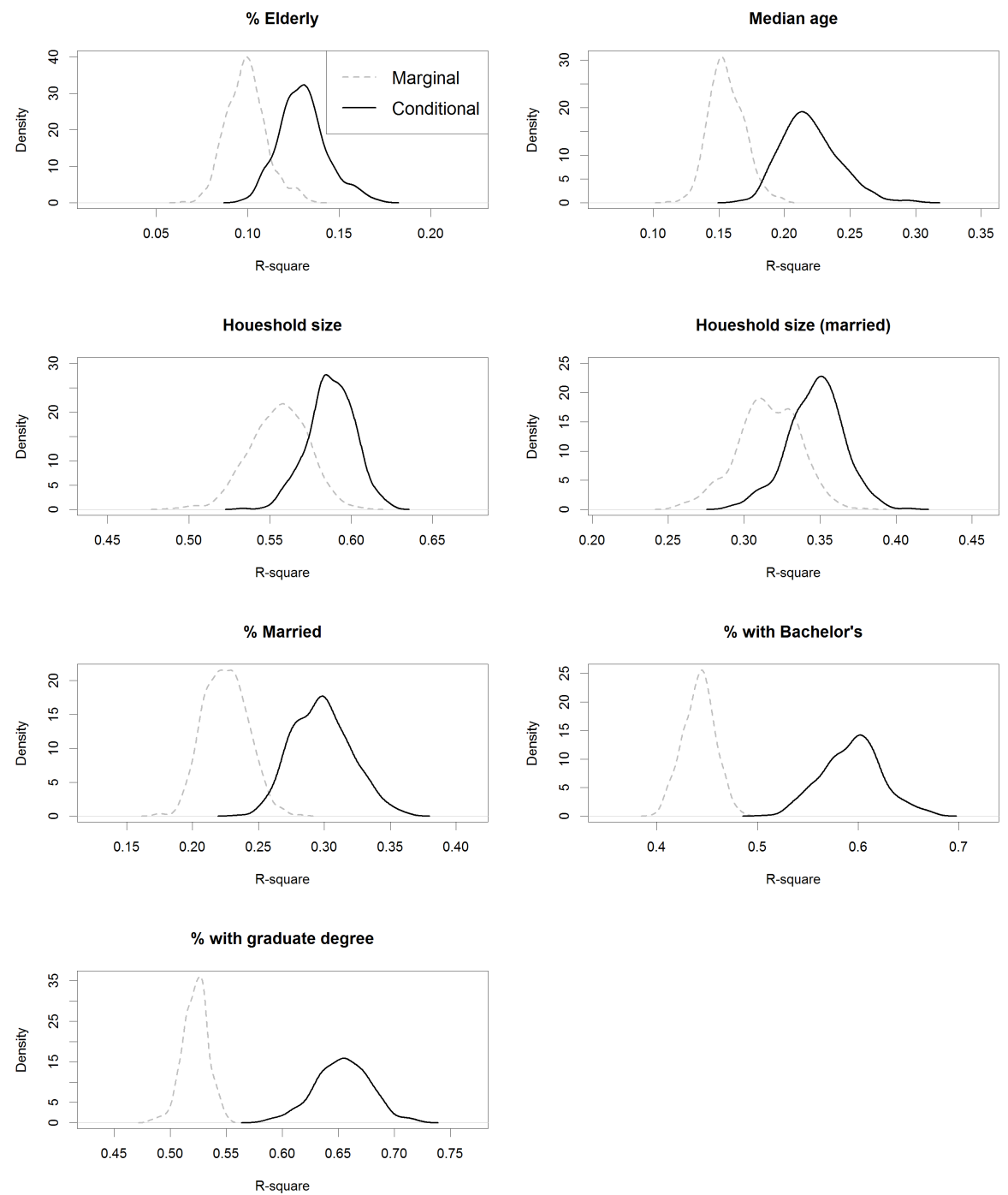
Figure SA7: Bootstrap densities of coefficients on elv, models of demographic variables
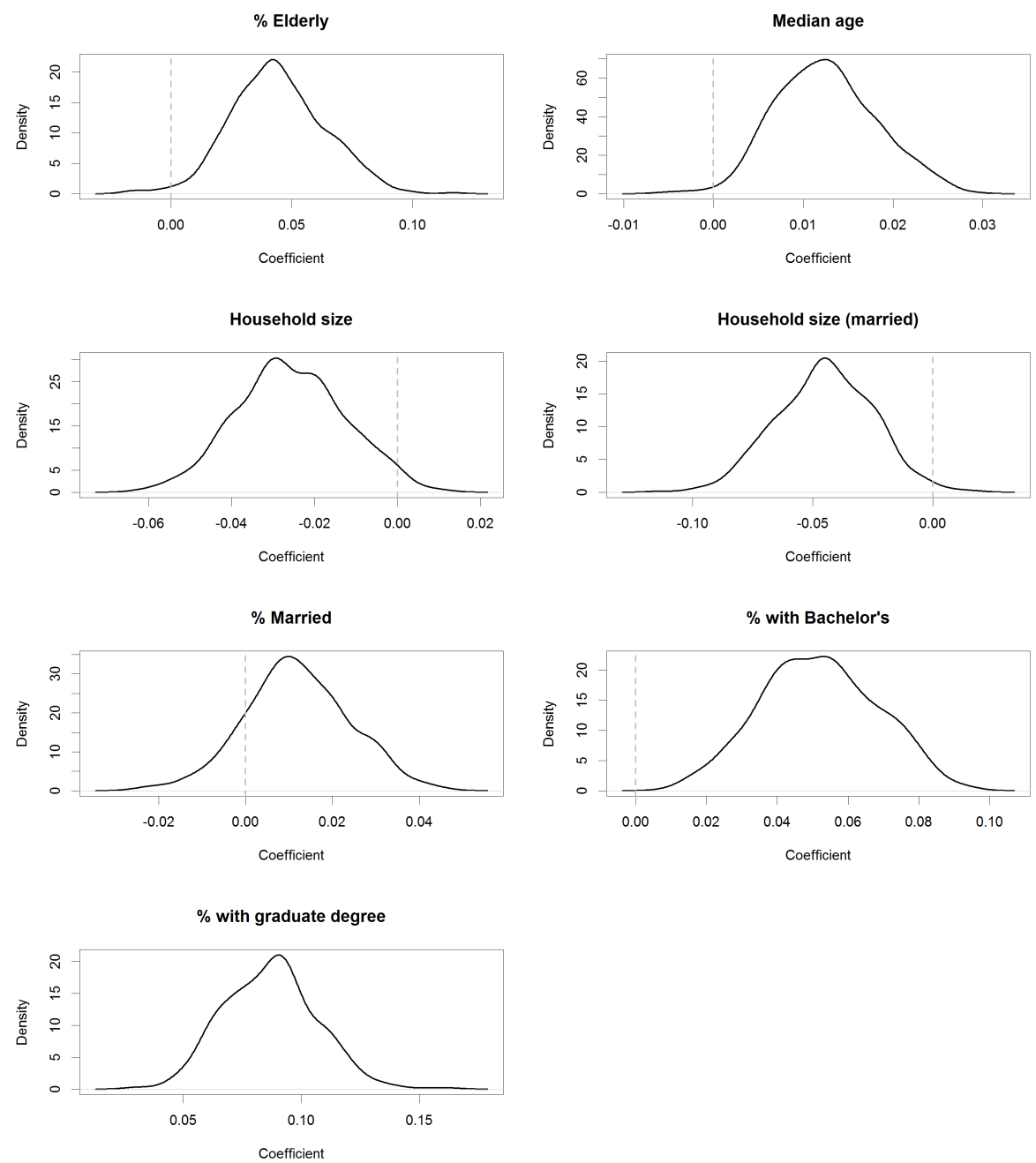
Figure SA8: Bootstrap densities of coefficients on ral, models of demographics variables
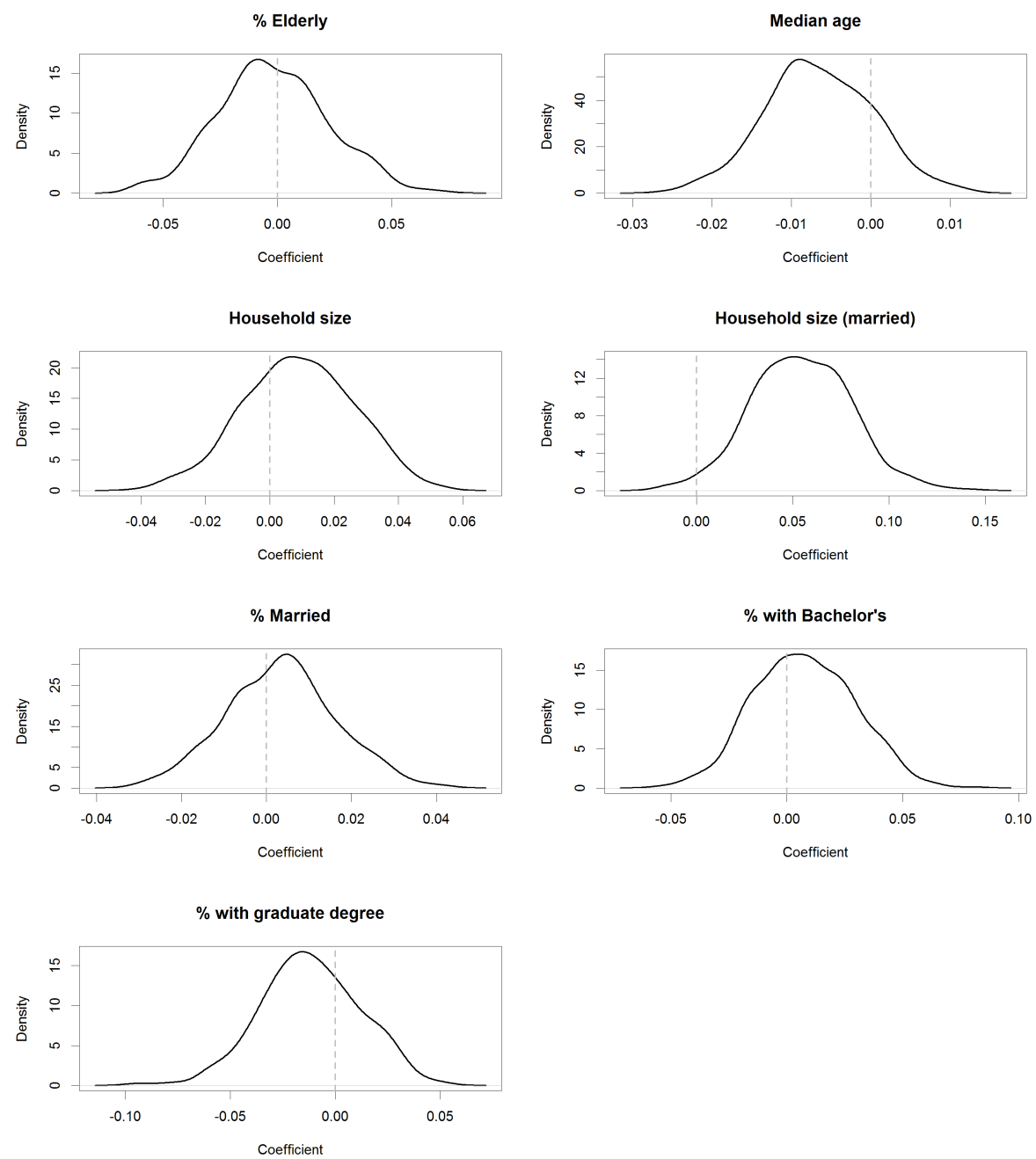
Figure SA9: Bootstrap densities of coefficients on elv $\cdot$ ral, models of demographic variables
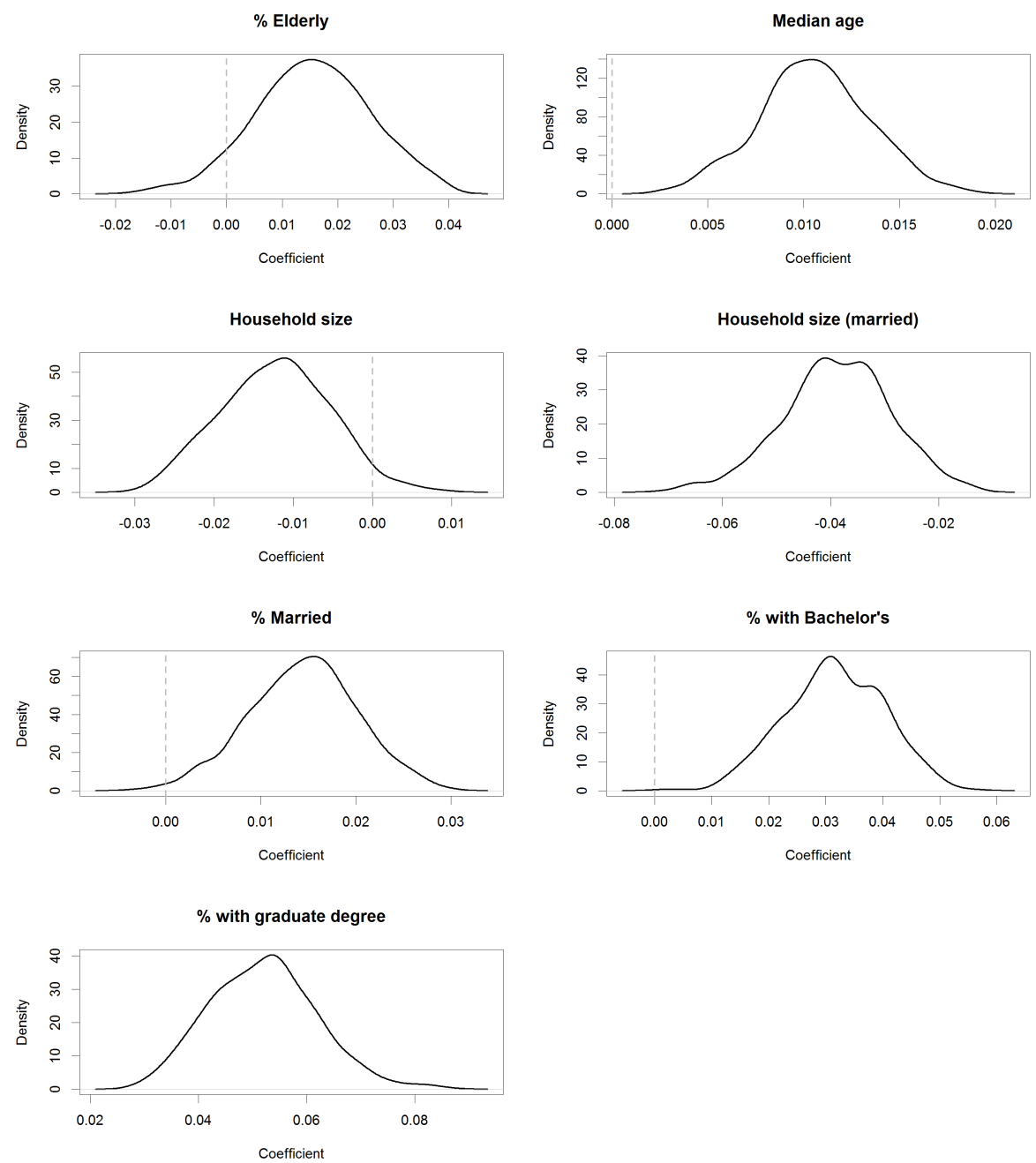


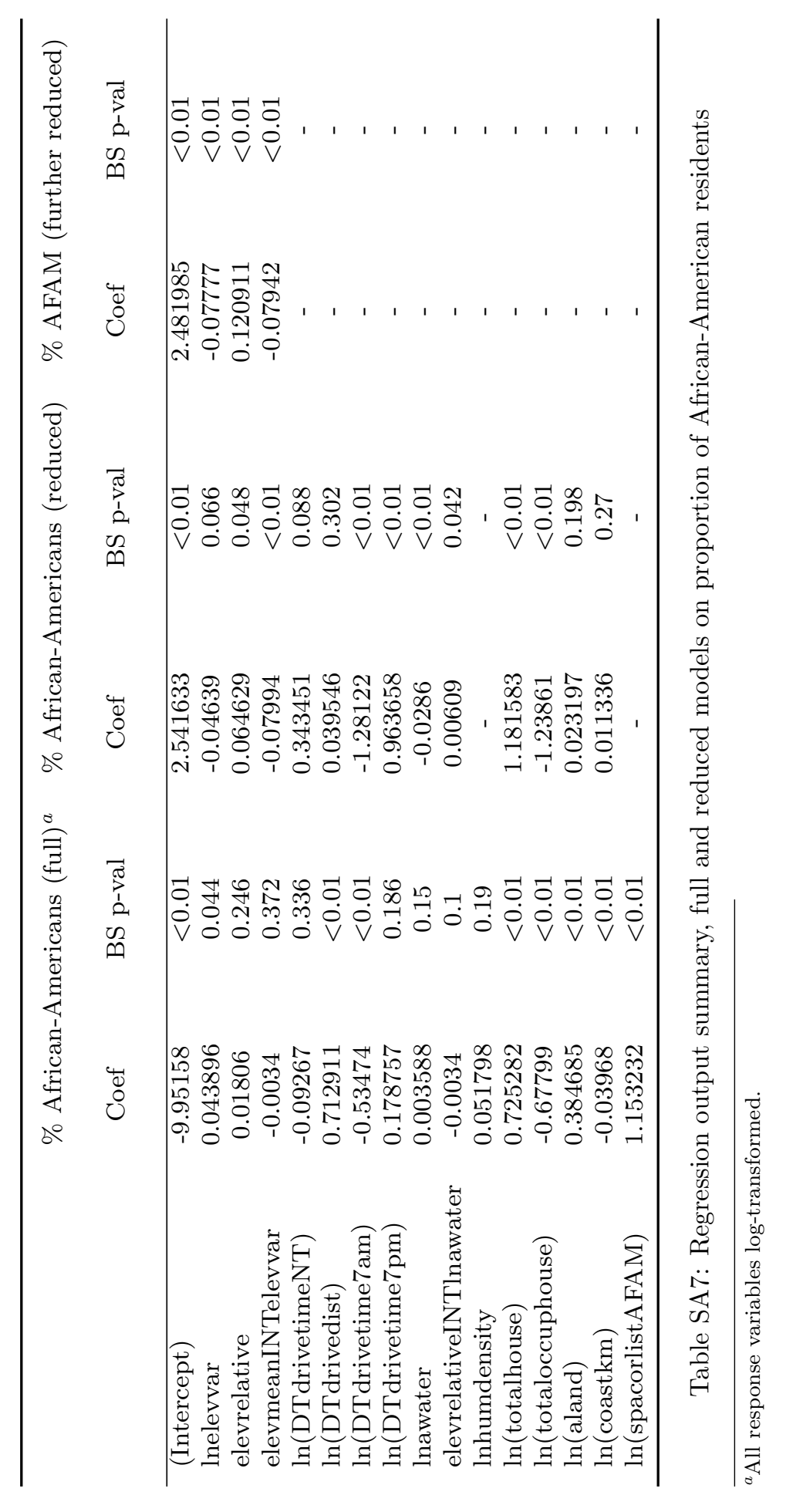


Figure SA10: Bootstrap densities of marginal and conditional R-square values, models of African-American proportion
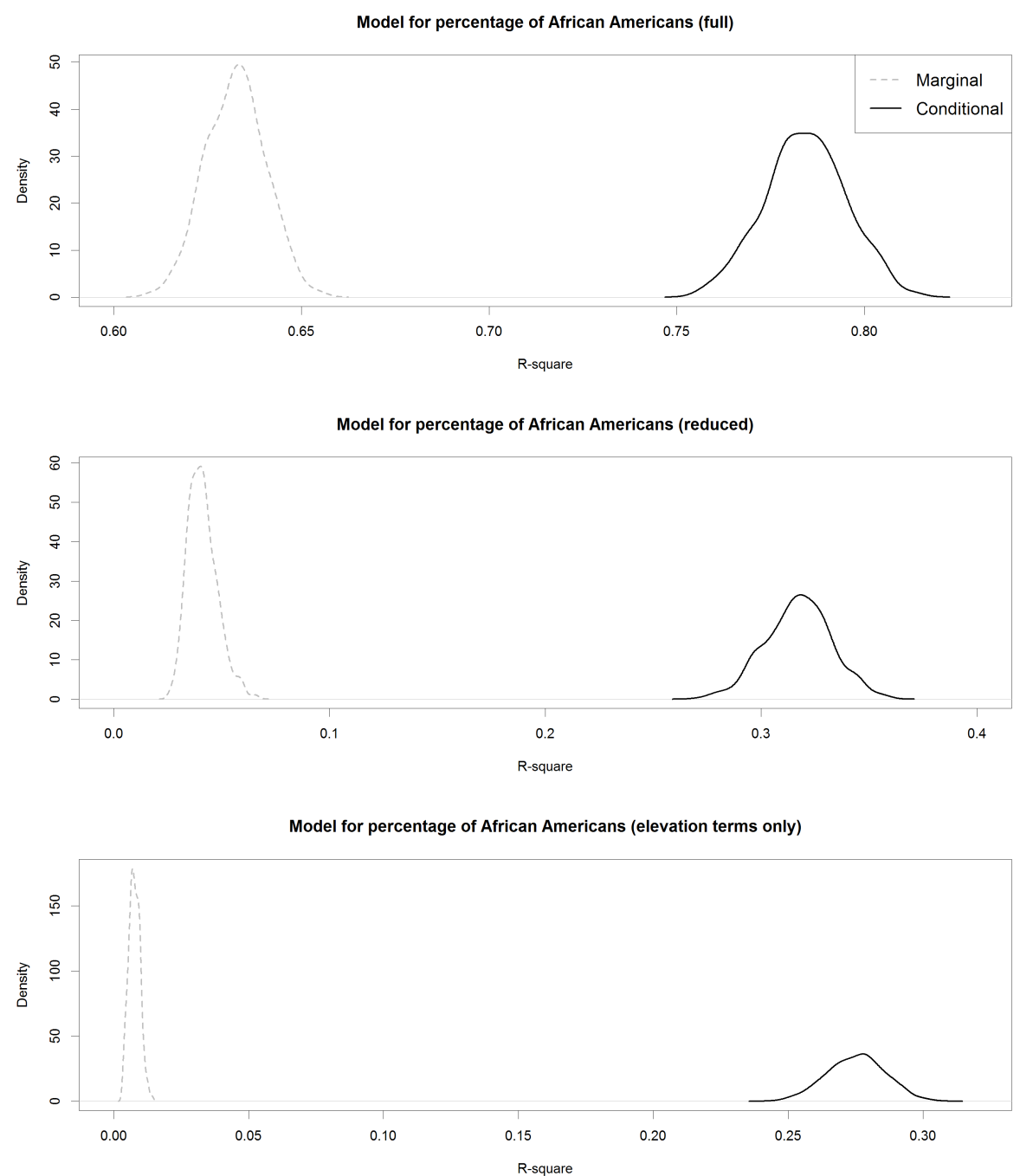
Figure SA11: Bootstrap densities of coefficients on elv, models of African-American proportion
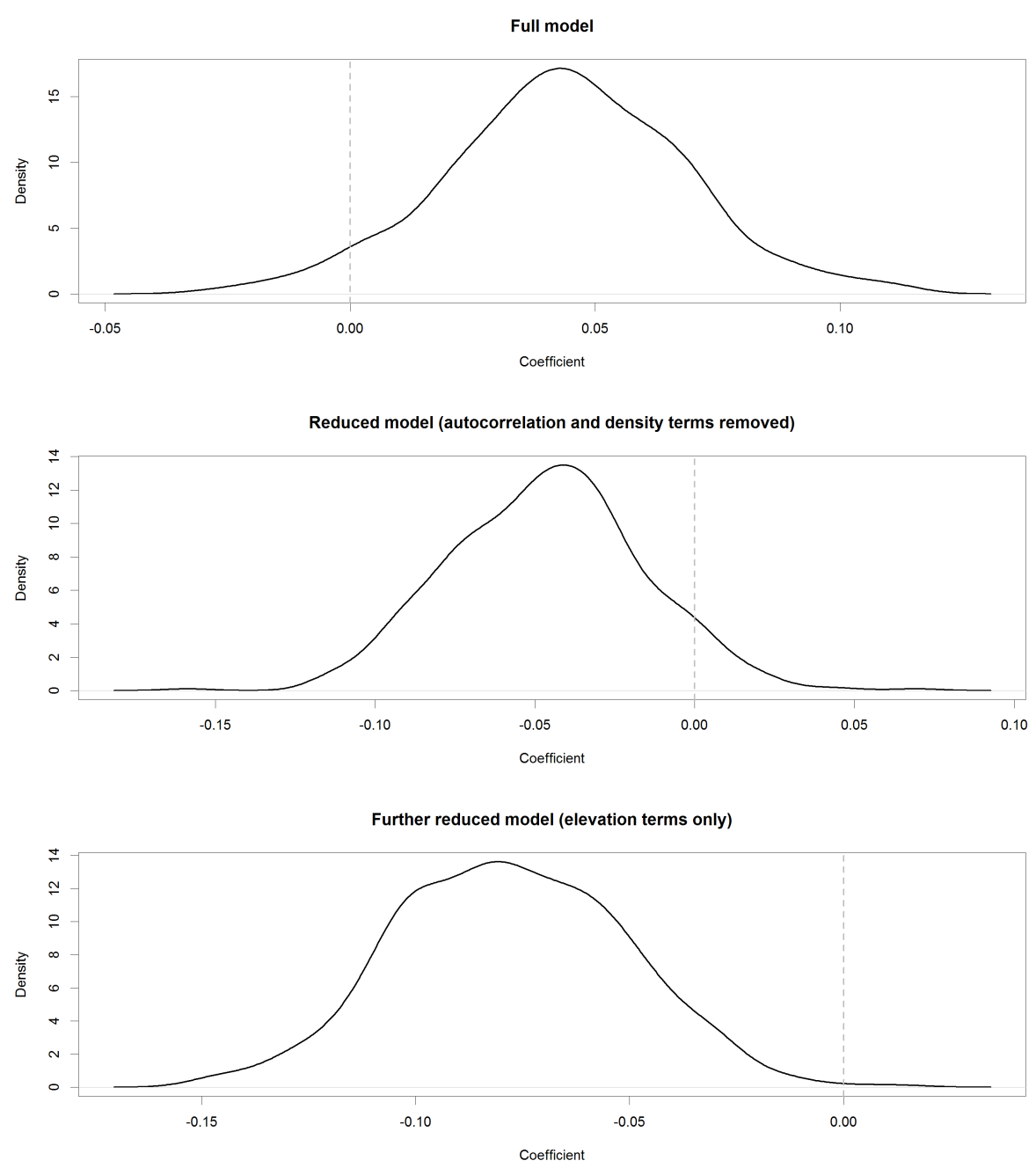
Figure SA12: Bootstrap densities of coefficients on ral, models of African-American proportion
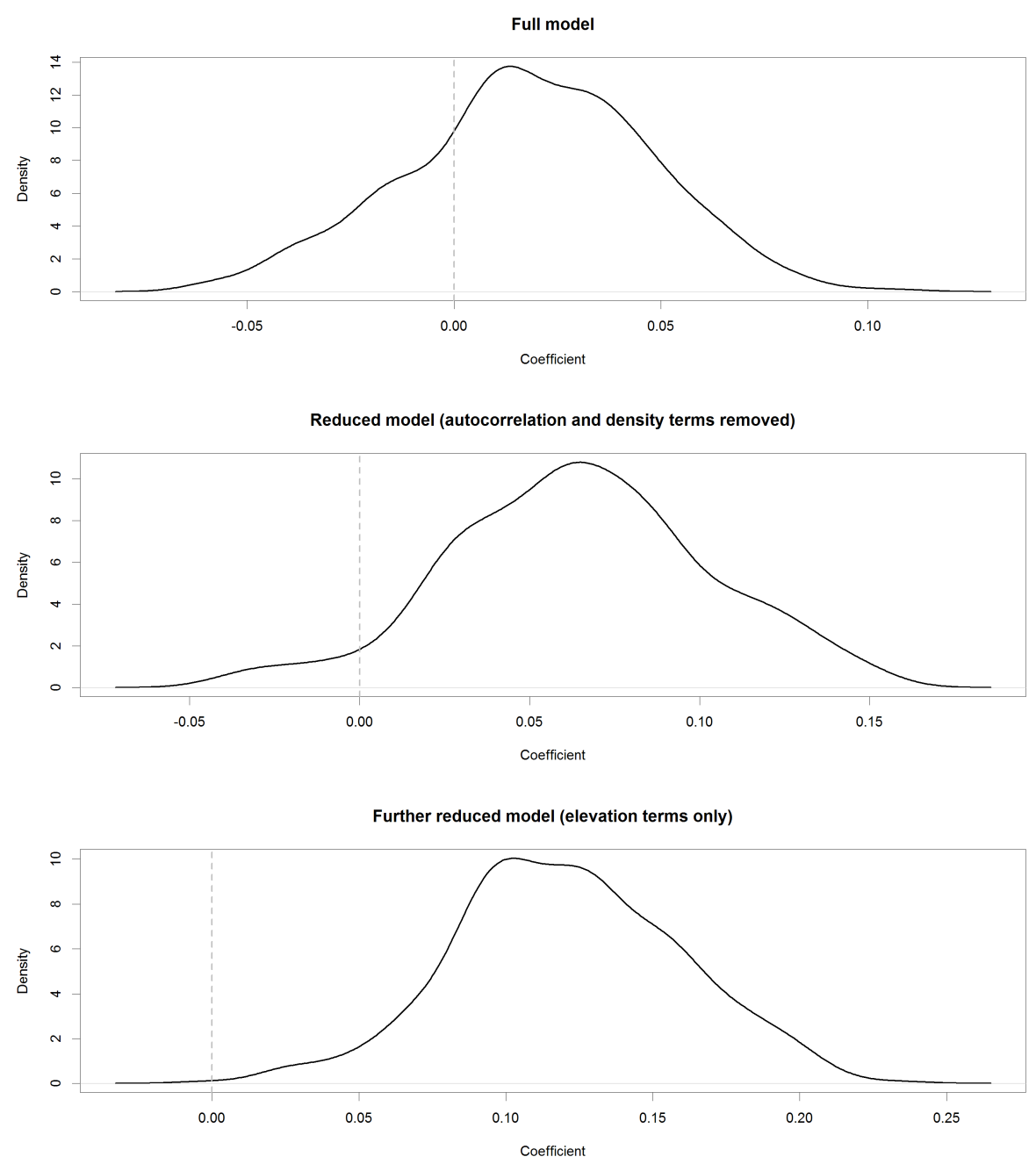
Figure SA13: Bootstrap densities of coefficients on elv $\cdot$ ral, models of African-American proportion
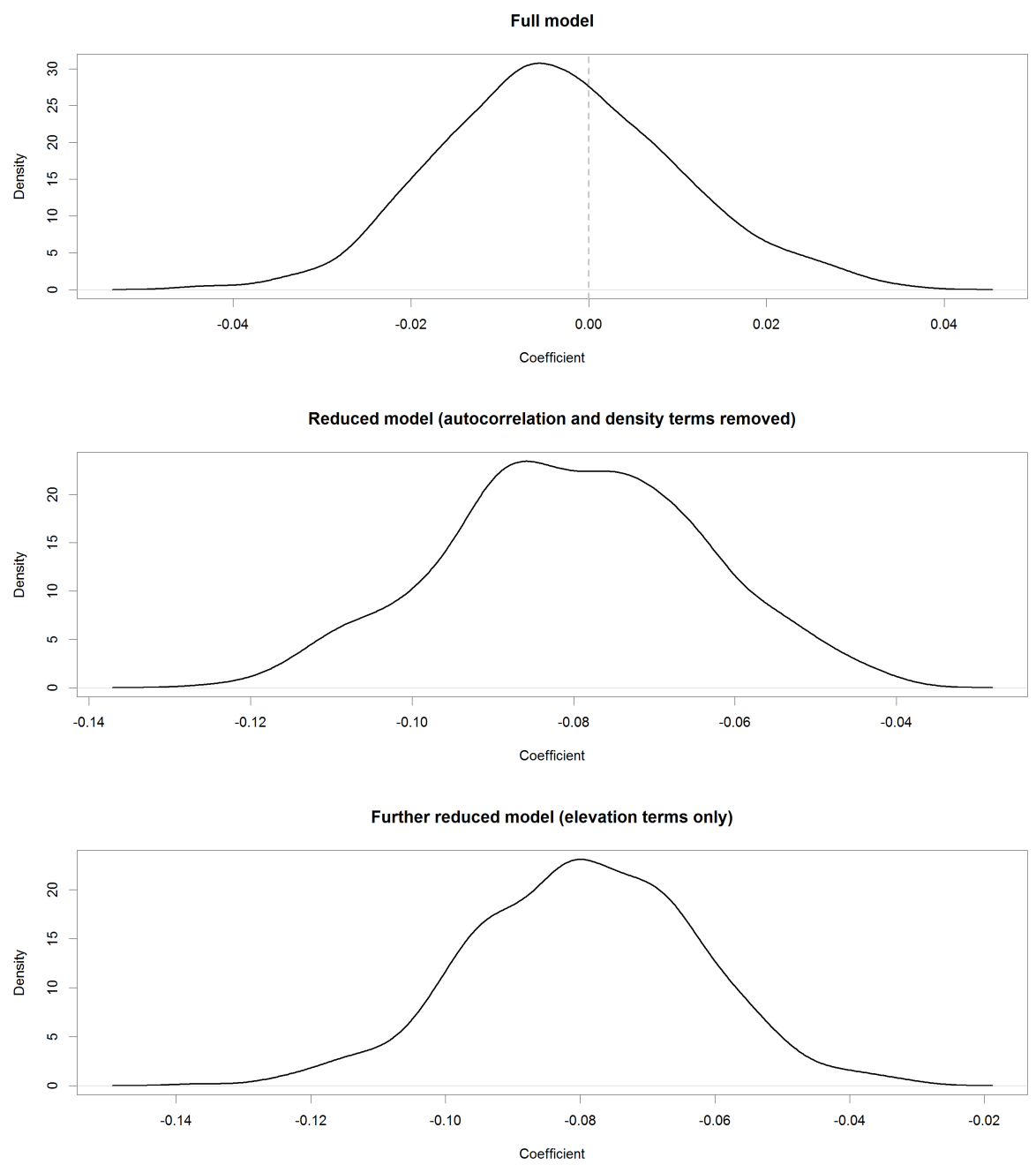
Table SA8: Names and information of variables in intermediary effect models

\begin{tabular}{|c|c|}
\hline Name & Variable Meaning \\
\hline $\ln \left(\right.$ SpaCor*$\left.^{*}\right)$ & $\begin{array}{l}\text { Spatial autocorrelation factor for respective model, } \\
\text { log-transformed }\end{array}$ \\
\hline $\ln$ (housepoverty) & Household poverty rate, log-transformed \\
\hline $\ln$ (unemplo & nemployment rate, log-transformed \\
\hline OOHrate & Owner-occupancy rate of census tract residencies \\
\hline PercentPub & $\begin{array}{l}\text { Percent of census tract workers that commute via } \\
\text { public transit }\end{array}$ \\
\hline PercentWalk & Percent of workers that commute via walking \\
\hline $\ln (\mathrm{GIN}$ & s tract GINI coefficient, log-transformed \\
\hline $\ln ($ meanincomeQT1) & $\begin{array}{l}\text { Mean annual household income of first quintile, } \\
\text { log-transformed }\end{array}$ \\
\hline $\ln ($ meanincomeQT2) & $\begin{array}{l}\text { Mean annual household income of second quintile, } \\
\text { log-transformed }\end{array}$ \\
\hline $\ln ($ meaninco & $\begin{array}{l}\text { Mean annual household income of third quintile, } \\
\text { log-transformed }\end{array}$ \\
\hline $\ln ($ mean & $\begin{array}{l}\text { Mean annual household income of fourth quintile, } \\
\text { log-transformed }\end{array}$ \\
\hline $\ln ($ mes & $\begin{array}{l}\text { Mean annual household income of fifth quintile, } \\
\text { log-transformed }\end{array}$ \\
\hline $\ln ($ mea & $\begin{array}{l}\text { Mean annual household income of top } 5 \% \text { high- } \\
\text { earning households, log-transformed }\end{array}$ \\
\hline $\ln (\mathrm{Bla}$ & $\begin{array}{l}\text { Percent of African-American Residents, log- } \\
\text { transformed }\end{array}$ \\
\hline $\ln (\mathrm{Asi}$ & $\begin{array}{l}\text { Percent of Asian and Asian-American Residents, } \\
\text { log-transformed }\end{array}$ \\
\hline $\ln ($ Eld & $\begin{array}{l}\text { Percent of Elderly Residents above the age of } 64 \text {, } \\
\text { log-transformed }\end{array}$ \\
\hline hhsiz & Average household size \\
\hline hhsizema & Average married household size \\
\hline $\ln ($ marriedpct $)$ & $\begin{array}{l}\text { Percent of residents that are married, log- } \\
\text { transformed }\end{array}$ \\
\hline $\ln$ (bachelorpct) & $\begin{array}{l}\text { Percent of residents with bachelor's degrees ( ex- } \\
\text { cluding associate's degrees), log-transformed }\end{array}$ \\
\hline $\ln ($ gradpct) & $\begin{array}{l}\text { Percent of residents with graduate and professional } \\
\text { degrees, log-transformed }\end{array}$ \\
\hline $\ln (\mathrm{CDD})$ & Average number of Cooling Degree Days per year \\
\hline $\ln ($ AnnualVar) & $\begin{array}{l}\text { Standard deviation of averaged-by-year monthly } \\
\text { temperatures, log-transformed }\end{array}$ \\
\hline $\ln ($ MonthVar) & $\begin{array}{l}\text { Average monthly maximum-minimum tempera- } \\
\text { ture spread, log-transformed }\end{array}$ \\
\hline
\end{tabular}


Table SA10: Regression output summary, scenery effect/ \% of census tract high-income household models

\begin{tabular}{|c|c|c|c|c|}
\hline & \multicolumn{2}{|c|}{ Above $\$ 150,000^{1}$} & \multicolumn{2}{|c|}{ Above $\$ 200,000$} \\
\hline & Coef & Bootstrap p-val & Coef & Bootstrap p-val \\
\hline (Intercept) & -8.10612 & $<0.01$ & -9.58873 & $<0.01$ \\
\hline lnelevvar & 0.022957 & 0.132 & 0.046947 & $<0.01$ \\
\hline elevrelative & -0.022 & 0.208 & -0.03036 & 0.094 \\
\hline elevmeanINTelevvar & 0.019355 & 0.048 & 0.023234 & 0.01 \\
\hline $\ln (\mathrm{DTdrivetimeNT})$ & 0.230969 & 0.054 & 0.157513 & 0.16 \\
\hline $\ln (\mathrm{DTd}$ drivedist $)$ & -0.09249 & 0.03 & -0.11031 & 0.014 \\
\hline $\ln ($ DTdrivetime7am) & -0.07114 & 0.252 & -0.08623 & 0.21 \\
\hline $\ln (\mathrm{DT}$ drivetime7pm) & -0.11622 & 0.21 & -0.01994 & 0.436 \\
\hline lnawater & 0.002819 & 0.134 & 0.004258 & 0.062 \\
\hline elev_relative:Inawater & 0.0005 & 0.416 & -0.00022 & 0.472 \\
\hline $\ln ($ SpaCorL2above150k) & 0.12378 & $<0.01$ & - & - \\
\hline $\ln ($ SpaCorL2above200k) & - & - & 0.155951 & $<0.01$ \\
\hline lnhumdensity & -0.06409 & 0.18 & -0.06955 & 0.134 \\
\hline $\ln ($ totalhouse $)$ & 0.096737 & 0.182 & 0.119475 & 0.096 \\
\hline $\ln ($ aland $)$ & 0.022907 & 0.376 & 0.021701 & 0.376 \\
\hline $\ln ($ coastkm $)$ & -0.0137 & 0.07 & -0.0145 & 0.13 \\
\hline $\ln$ (totaloccuphouse) & -0.25889 & 0.02 & -0.2669 & $<0.01$ \\
\hline $\ln$ (housepoverty) & -0.03199 & 0.018 & -0.02917 & 0.032 \\
\hline $\ln ($ unemployment $)$ & -0.01426 & 0.158 & -0.01105 & 0.208 \\
\hline OOHrate & 0.001594 & 0.018 & 0.000596 & 0.228 \\
\hline PercentPub & 0.000824 & 0.216 & 0.001367 & 0.092 \\
\hline PercentWalk & 0.001683 & 0.136 & 0.002862 & 0.028 \\
\hline $\ln (\mathrm{GINI})$ & 0.327367 & $<0.01$ & 0.468006 & $<0.01$ \\
\hline $\ln ($ medianhouseincome $)$ & 0.075878 & 0.048 & 0.067883 & 0.04 \\
\hline $\ln ($ meanincomeQT1) & 0.000449 & 0.484 & 0.005589 & 0.374 \\
\hline $\ln ($ meanincomeQT2) & 0.067067 & 0.034 & 0.062736 & 0.05 \\
\hline $\ln ($ meanincomeQT3) & 0.127653 & $<0.01$ & 0.11331 & $<0.01$ \\
\hline $\ln ($ meanincomeQT4) & 0.313808 & $<0.01$ & 0.28364 & $<0.01$ \\
\hline $\ln ($ meanincomeQT5) & 0.301434 & $<0.01$ & 0.369645 & $<0.01$ \\
\hline $\ln ($ meanincome5percent) & 0.121352 & $<0.01$ & 0.185866 & $<0.01$ \\
\hline $\ln$ (Blackpercent) & -0.00952 & 0.216 & -0.01541 & 0.06 \\
\hline $\ln ($ Asianpercent $)$ & 0.000815 & 0.464 & -0.01653 & 0.078 \\
\hline $\ln$ (Elderly) & -0.00732 & 0.338 & 0.001702 & 0.46 \\
\hline hhsize & 0.011985 & 0.332 & 0.017496 & 0.28 \\
\hline hhsizemarried & -0.01351 & 0.3 & -0.00379 & 0.432 \\
\hline $\ln ($ marriedpct $)$ & -0.01519 & 0.334 & -0.00805 & 0.382 \\
\hline $\ln$ (bachelorpct) & 0.00437 & 0.434 & -0.03831 & 0.014 \\
\hline $\ln (\operatorname{gradpct})$ & 0.051606 & $<0.01$ & 0.033149 & 0.02 \\
\hline $\ln (\mathrm{CDD})$ & 0.015082 & 0.256 & 0.028622 & 0.164 \\
\hline $\ln$ (AnnualVar) & -0.11122 & $<0.01$ & -0.11776 & 0.038 \\
\hline $\ln$ (MonthVar) & 0.056225 & 0.234 & 0.017285 & 0.404 \\
\hline
\end{tabular}




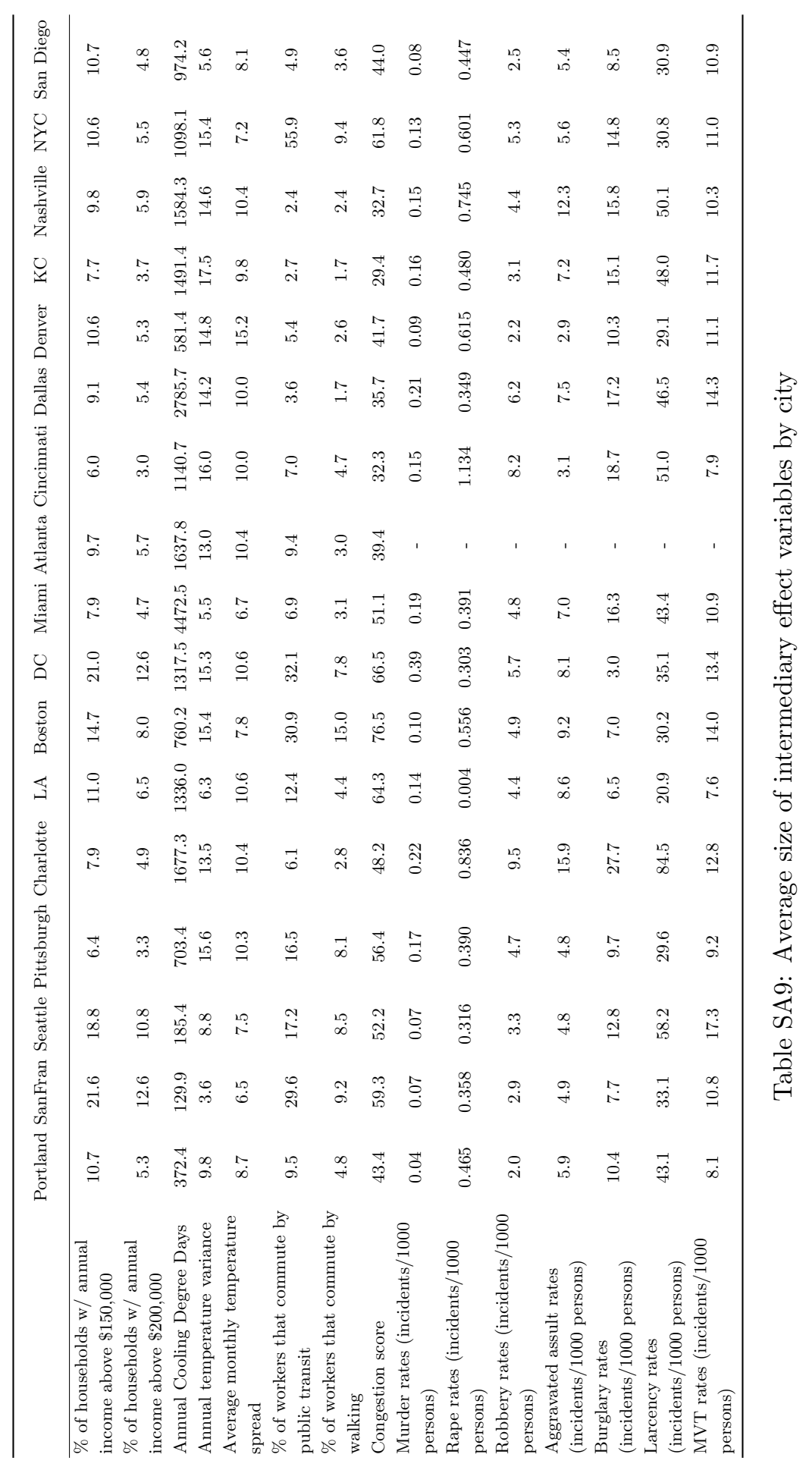


Figure SA14: Bootstrap densities of marginal and conditional R-square values, scenery effect models
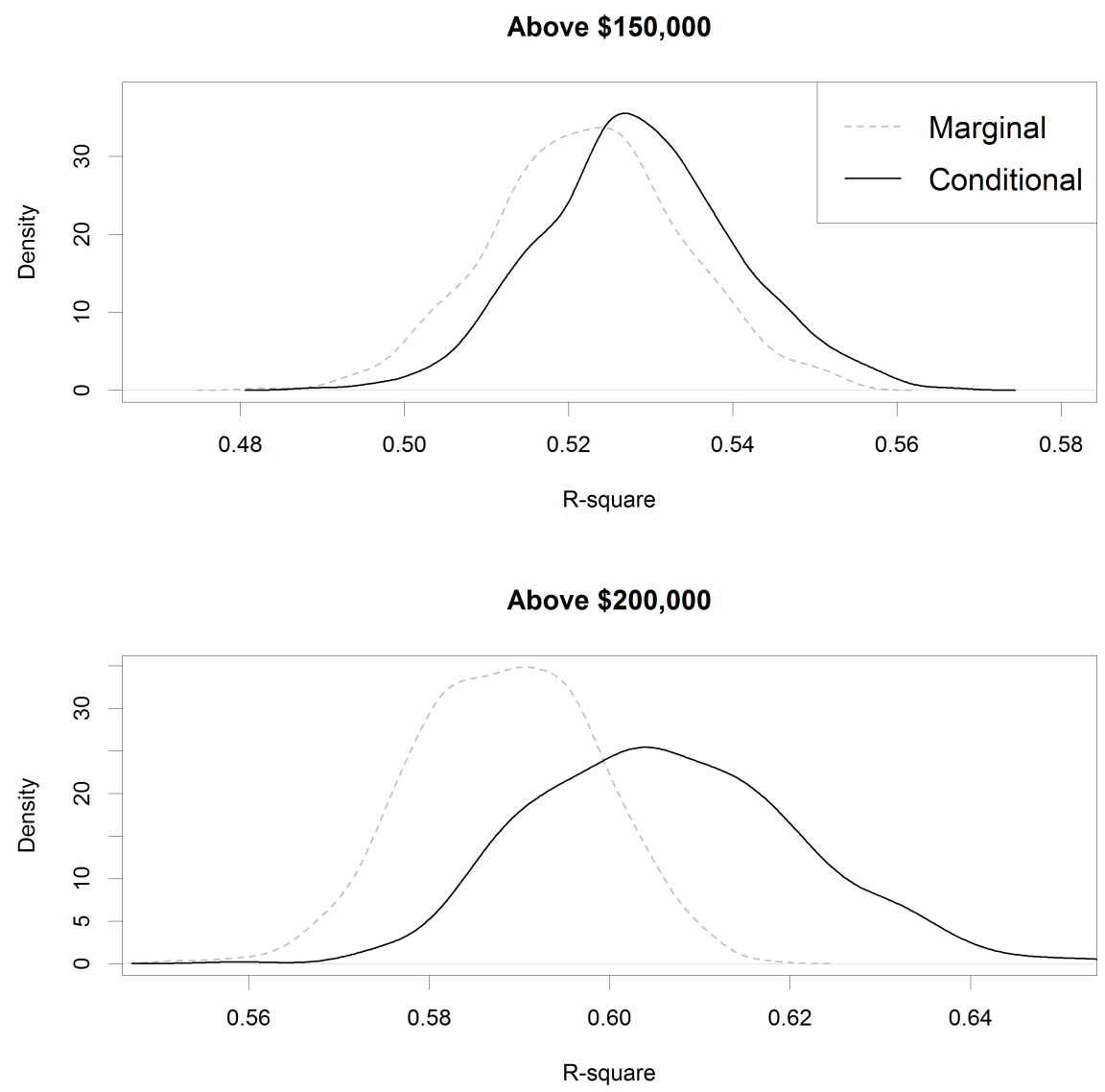

$\overline{{ }^{1} \text { Both high annual income household }}$ percentage variables are log-transformed. 
Figure SA15: Bootstrap densities of elevation coefficients, scenery effect models
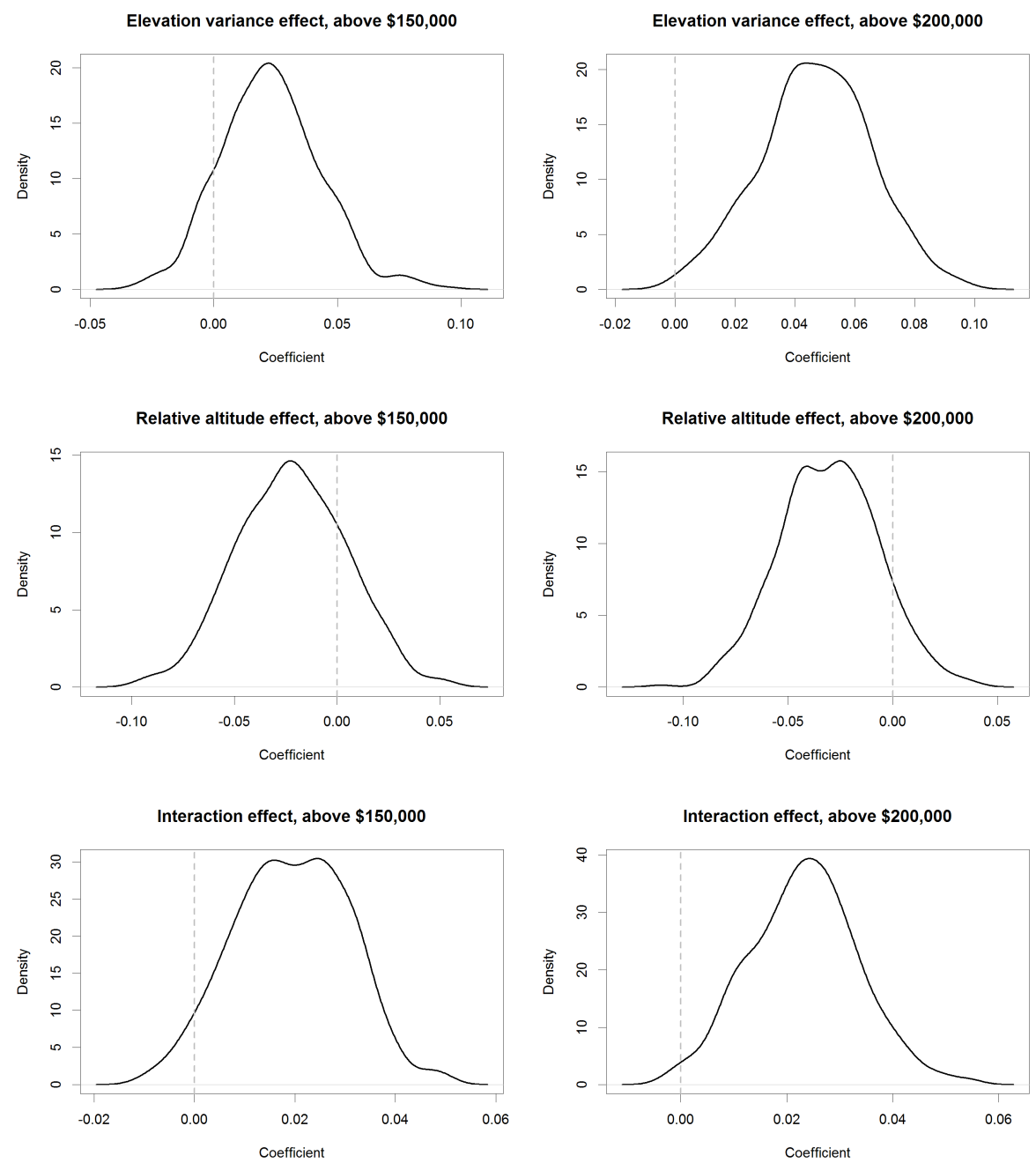


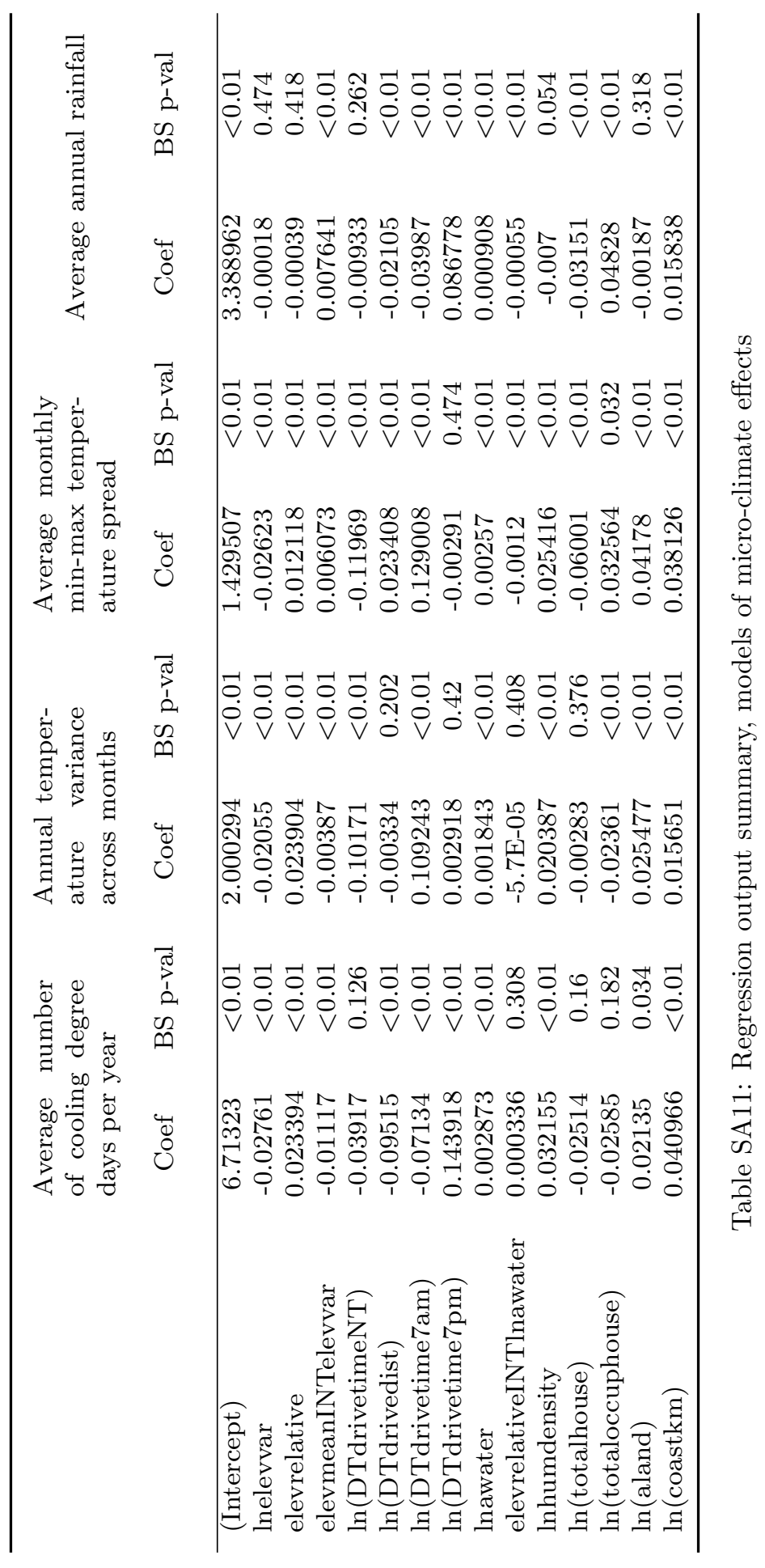


Figure SA16: Bootstrap densities of marginal R-square values, micro-climate effect models ${ }^{2}$
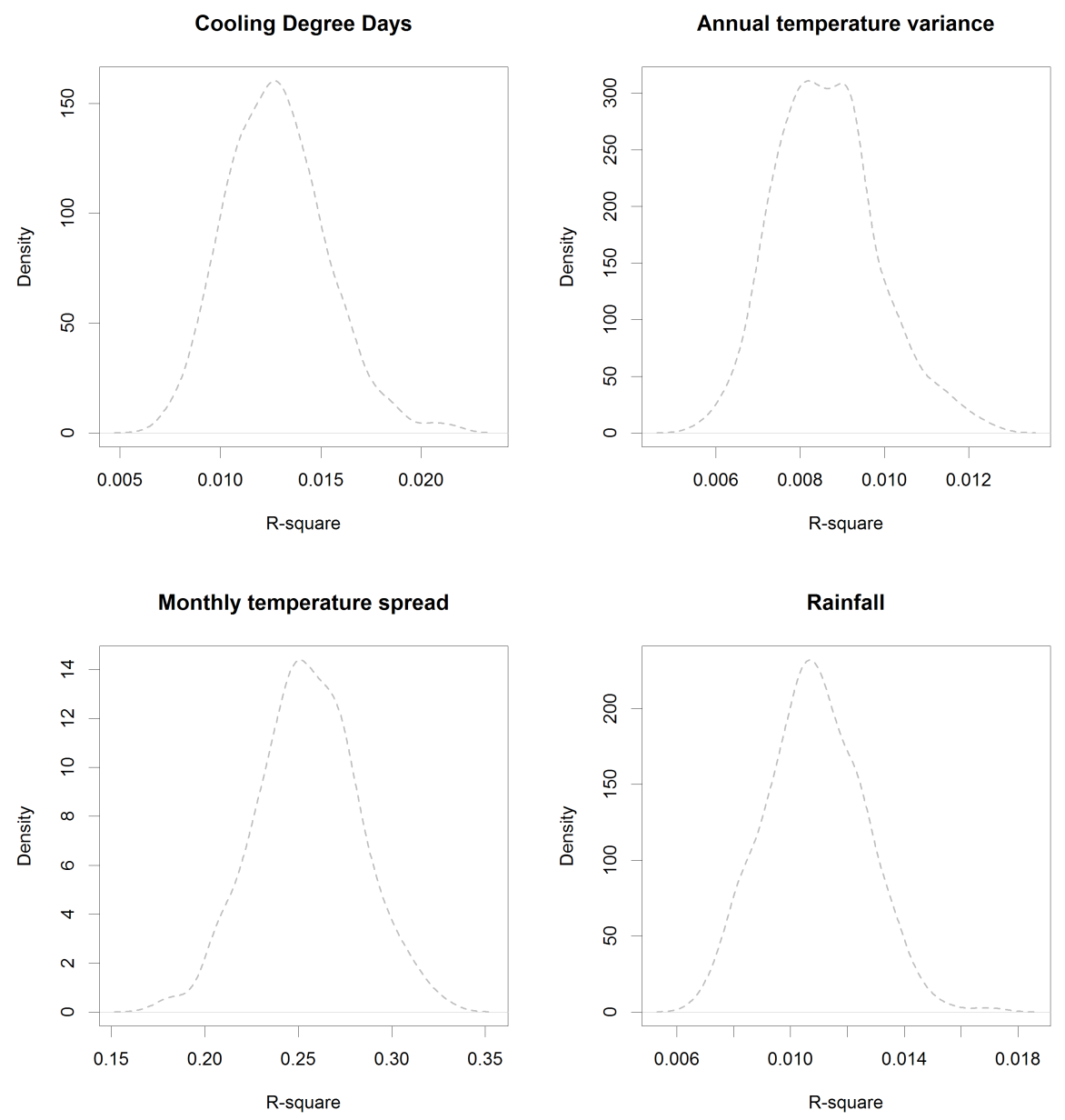

${ }^{2}$ Marginal and conditional $R^{2}$ values are reported in separate graphs for micro-climate effect because of the large difference in explanatory power in models with and without random intercepts. This is not unexpected, given that weather pattern differences among cities is certainly far greater than differences in different locations of the same city. 
Figure SA17: Bootstrap densities of conditional R-square values, micro-climate effect models
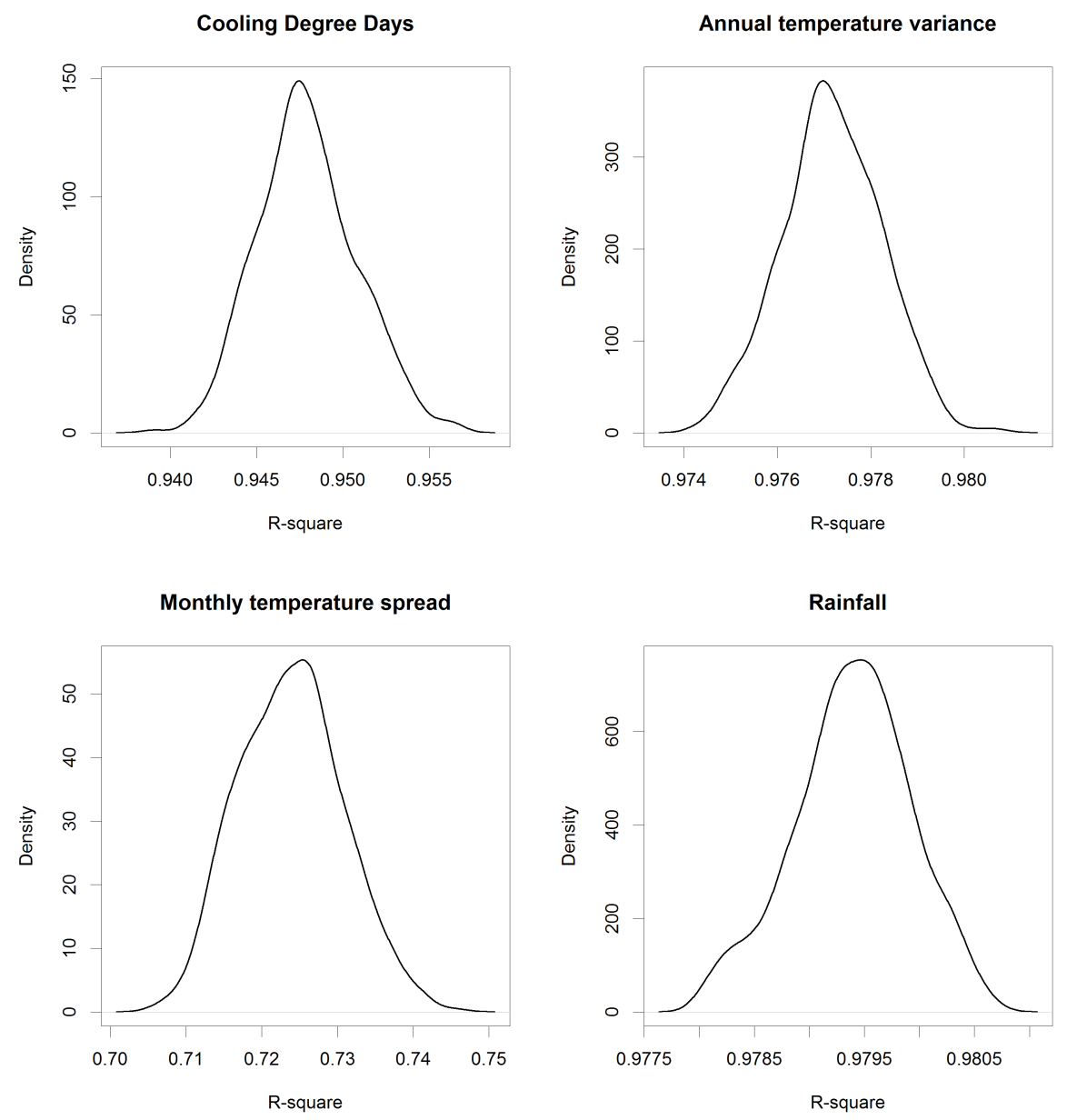
Figure SA18: Bootstrap densities of of coefficients on elv, micro-climate effect models
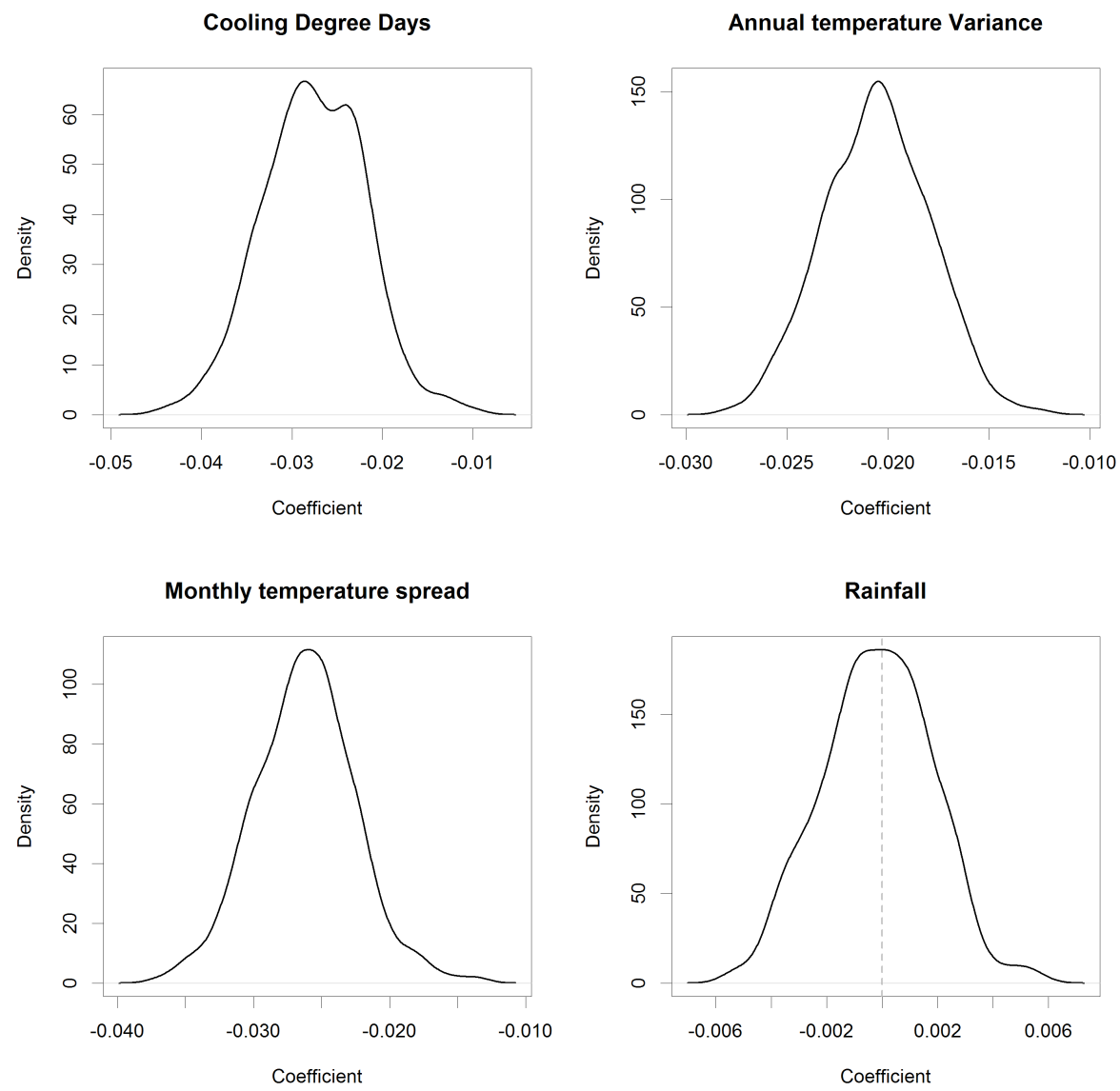
Figure SA19: Bootstrap densities of of coefficients on ral, micro-climate effect models
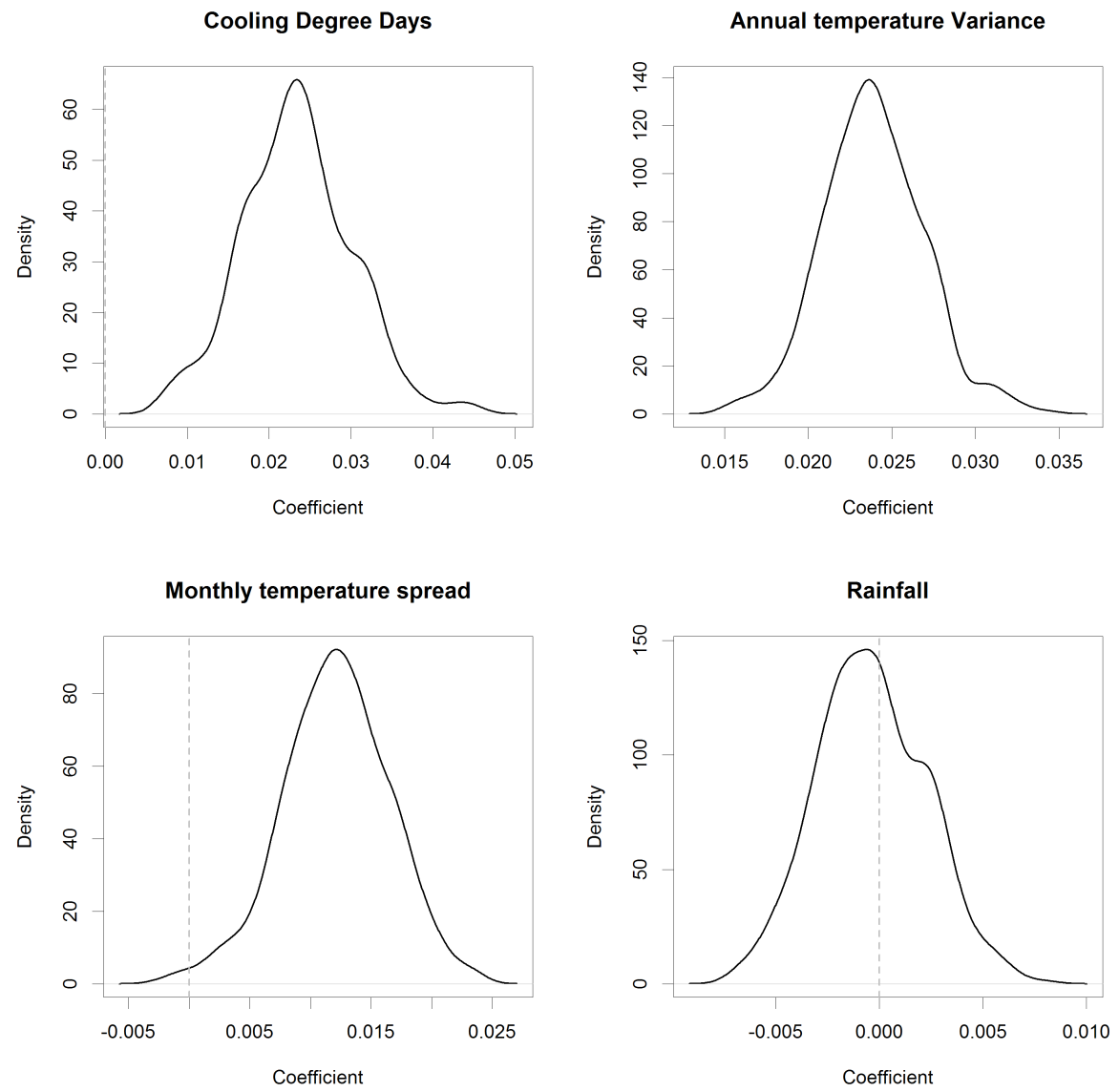
Figure SA20: Bootstrap densities of of coefficients on $\mathrm{elv} \cdot \mathrm{ral}$, micro-climate effect models
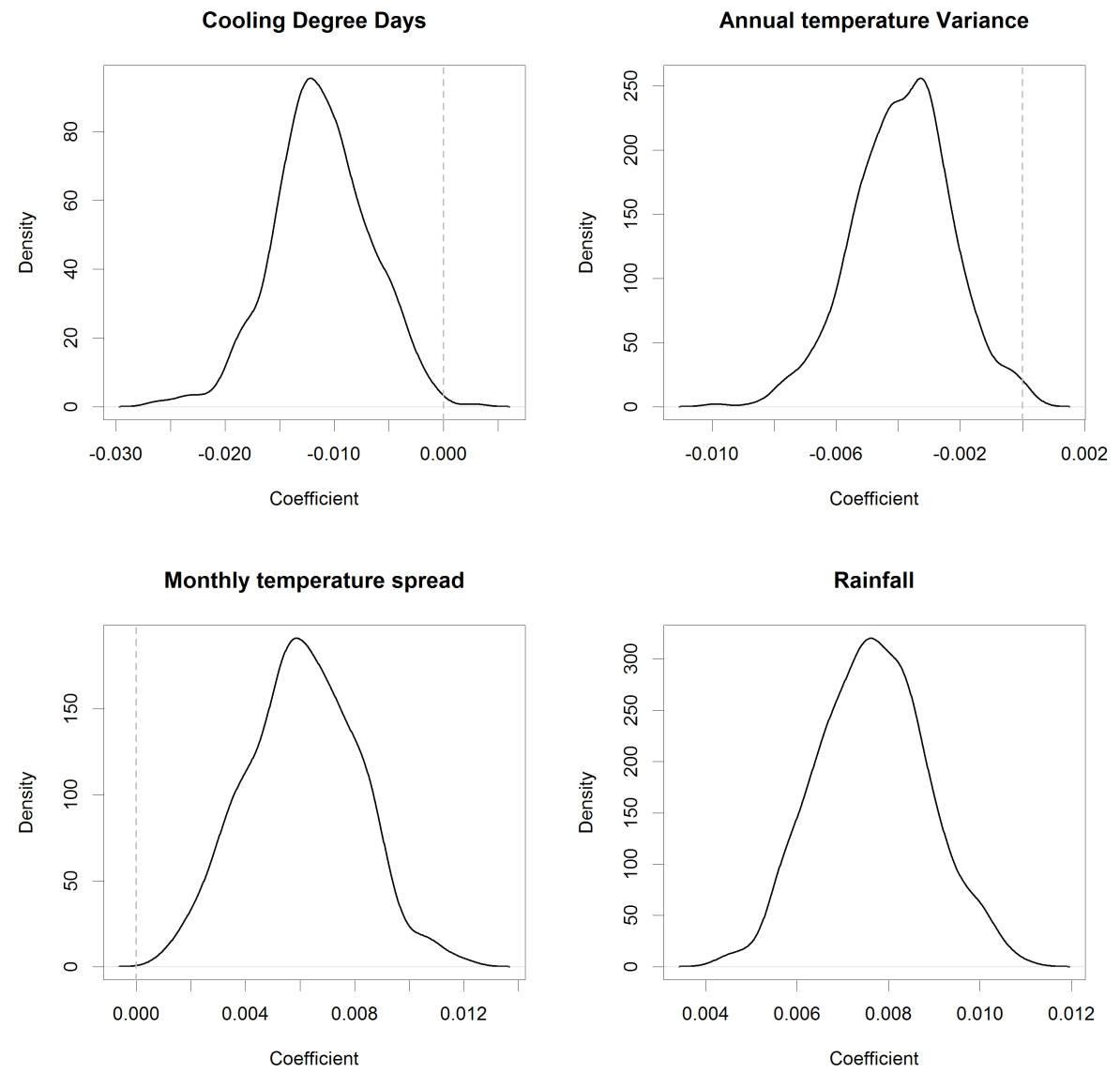
Table SA12: Regression output summary, public transit, commuting by walking, and congestion effect models

\begin{tabular}{|c|c|c|c|c|c|c|}
\hline & \multicolumn{2}{|c|}{ Congestion score ${ }^{3}$} & \multicolumn{2}{|c|}{ Public transit } & \multicolumn{2}{|c|}{ Walking } \\
\hline & Coef & BS p-val & Coef & BS p-val & Coef & BS p-val \\
\hline (Intercept) & 23.75134 & 0.01 & 3.17019 & $<0.01$ & -0.38621 & 0.382 \\
\hline lnelevvar & 0.065405 & 0.348 & -0.03729 & 0.028 & -0.05582 & $<0.01$ \\
\hline elevrelative & -0.81978 & $<0.01$ & 0.069593 & $<0.01$ & -0.01137 & 0.338 \\
\hline elevmeanINTelevvar & 0.104312 & 0.134 & -0.0169 & 0.048 & 0.014553 & 0.112 \\
\hline $\ln (\mathrm{DTd}$ drivetimeNT $)$ & -19.4906 & $<0.01$ & 0.203426 & 0.084 & 0.12132 & 0.258 \\
\hline $\ln ($ DTdrivedist $)$ & -4.57309 & $<0.01$ & -0.02599 & 0.286 & -0.10416 & 0.044 \\
\hline $\ln ($ DTdrivetime7am) & 13.48516 & $<0.01$ & -0.07058 & 0.224 & -0.09536 & 0.208 \\
\hline $\ln (\mathrm{DT}$ drivetime7pm) & 11.62255 & $<0.01$ & -0.11407 & 0.224 & -0.09094 & 0.266 \\
\hline lnawater & -0.15541 & $<0.01$ & $-6.8 \mathrm{E}-05$ & 0.484 & 0.006645 & $<0.01$ \\
\hline elev_relative:Inawater & -0.01041 & 0.294 & $5.13 \mathrm{E}-06$ & 0.484 & -0.00115 & 0.28 \\
\hline spacorcongest & 0.001747 & $<0.01$ & - & - & - & - \\
\hline $\ln \left(\right.$ spacor$\left.^{*}\right)$ & - & - & 0.37246 & $<0.01$ & 0.290772 & $<0.01$ \\
\hline lnhumdensity & 0.793475 & 0.104 & $-5.78 \mathrm{E}-02$ & 0.162 & 0.122879 & 0.056 \\
\hline $\ln ($ totalhouse $)$ & -1.56613 & 0.084 & $1.83 \mathrm{E}-01$ & 0.034 & 0.223272 & 0.03 \\
\hline $\ln ($ aland $)$ & -0.27196 & 0.316 & $-2.33 \mathrm{E}-02$ & 0.346 & 0.206778 & $<0.01$ \\
\hline $\ln ($ coastkm $)$ & -1.14609 & $<0.01$ & $-3.01 \mathrm{E}-02$ & $<0.01$ & -0.01243 & 0.15 \\
\hline $\ln ($ totaloccuphouse $)$ & 1.211583 & 0.138 & $-1.19 \mathrm{E}-01$ & 0.142 & -0.37314 & $<0.01$ \\
\hline $\ln$ (housepoverty) & 0.150207 & 0.154 & $8.66 \mathrm{E}-03$ & 0.264 & 0.018531 & 0.152 \\
\hline $\ln ($ unemployment $)$ & -0.00499 & 0.486 & $2.06 \mathrm{E}-02$ & 0.056 & -0.01605 & 0.146 \\
\hline OOHrate & -0.03653 & $<0.01$ & $-3.35 \mathrm{E}-03$ & $<0.01$ & -0.00503 & $<0.01$ \\
\hline $\ln (\mathrm{GINI})$ & 1.325789 & 0.042 & $-1.45 \mathrm{E}-02$ & 0.4 & 0.074893 & 0.16 \\
\hline $\ln ($ medianhouseincome $)$ & 0.145696 & 0.378 & $-1.25 \mathrm{E}-02$ & 0.364 & -0.03223 & 0.23 \\
\hline $\ln ($ meanincomeQT1) & 0.038376 & 0.422 & $6.27 \mathrm{E}-03$ & 0.362 & -0.01794 & 0.194 \\
\hline $\ln ($ meanincomeQT2) & -0.06987 & 0.44 & $-5.93 \mathrm{E}-03$ & 0.434 & -0.03596 & 0.174 \\
\hline $\ln ($ meanincomeQT3) & 0.309994 & 0.276 & $-2.32 \mathrm{E}-02$ & 0.288 & -0.04809 & 0.182 \\
\hline $\ln ($ meanincomeQT4) & 0.476957 & 0.182 & $-7.37 \mathrm{E}-02$ & 0.064 & -0.00949 & 0.434 \\
\hline $\ln ($ meanincomeQT5) & 0.64928 & 0.054 & $-4.68 \mathrm{E}-02$ & 0.118 & 0.059083 & 0.088 \\
\hline $\ln ($ meanincome5percent $)$ & 0.318624 & 0.11 & $-1.74 \mathrm{E}-02$ & 0.242 & 0.032821 & 0.13 \\
\hline $\ln ($ Blackpercent $)$ & 0.068679 & 0.25 & $4.48 \mathrm{E}-02$ & $<0.01$ & -0.06521 & $<0.01$ \\
\hline $\ln ($ Asianpercent $)$ & 0.414846 & $<0.01$ & $1.48 \mathrm{E}-02$ & 0.094 & 0.031752 & 0.012 \\
\hline $\ln ($ Elderly $)$ & 0.159953 & 0.198 & $-1.42 \mathrm{E}-03$ & 0.48 & -0.01937 & 0.176 \\
\hline hhsize & -0.79937 & $<0.01$ & $4.35 \mathrm{E}-02$ & 0.052 & -0.02943 & 0.18 \\
\hline hhsizemarried & -0.01019 & 0.488 & $7.95 \mathrm{E}-03$ & 0.336 & -0.03503 & 0.05 \\
\hline $\ln ($ marriedpct $)$ & -0.25745 & 0.2 & $-4.12 \mathrm{E}-02$ & 0.092 & -0.13405 & $<0.01$ \\
\hline $\ln ($ bachelorpct $)$ & 0.166604 & 0.172 & $-4.12 \mathrm{E}-02$ & 0.02 & -0.00721 & 0.358 \\
\hline $\ln ($ gradpct $)$ & 0.425728 & $<0.01$ & $-1.20 \mathrm{E}-02$ & 0.188 & 0.039154 & $<0.01$ \\
\hline
\end{tabular}
${ }^{3}$ Percentage of workers commuting by public transit and percentage of workers commuting by
walking are log-transformed. Congestion scores are not log-transformed. 
Figure SA21: Bootstrap densities of marginal and conditional R-square values, transit and congestion effect models
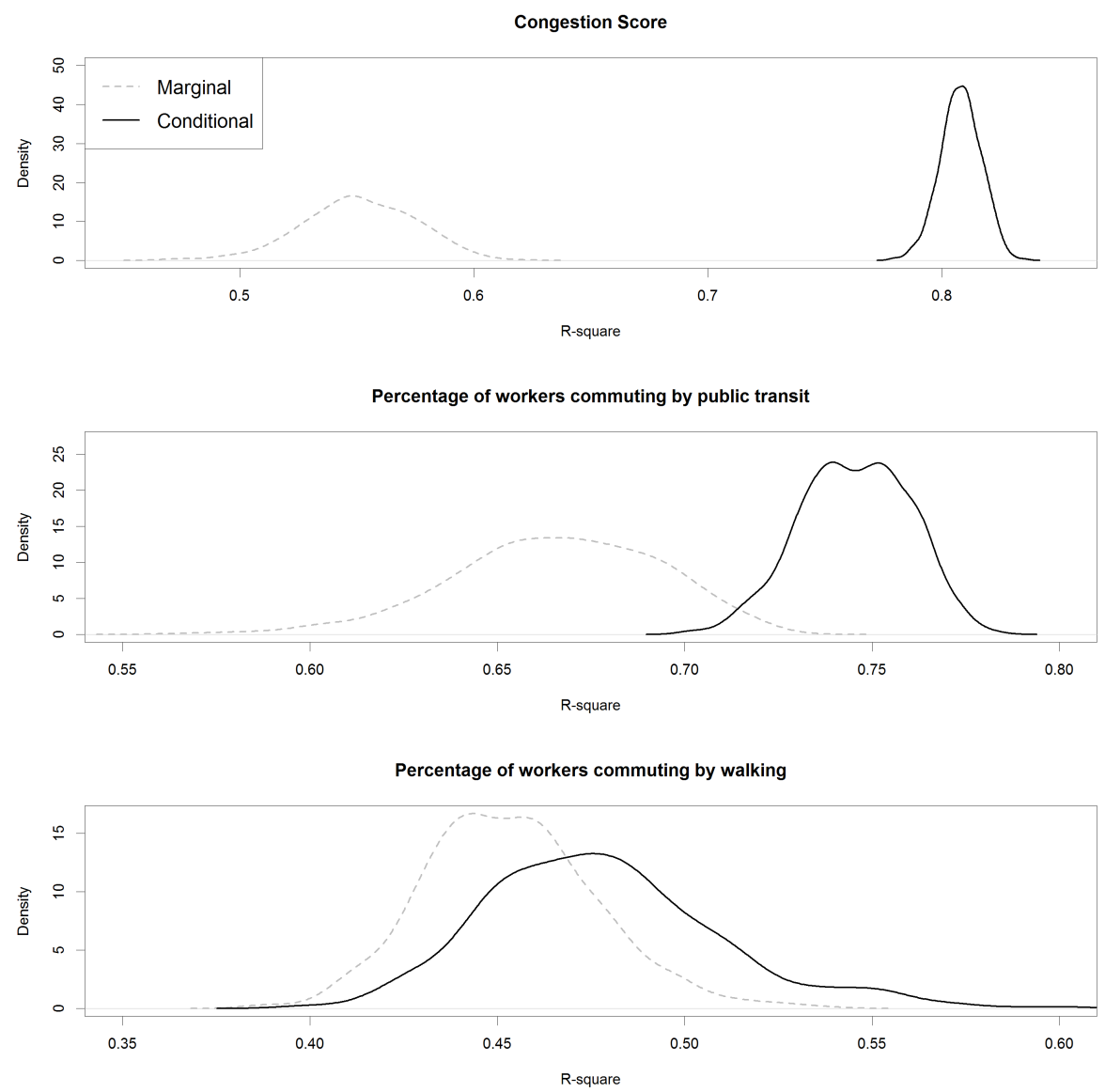
Figure SA22: Bootstrap densities of of coefficients on elv, transit and congestion effect models
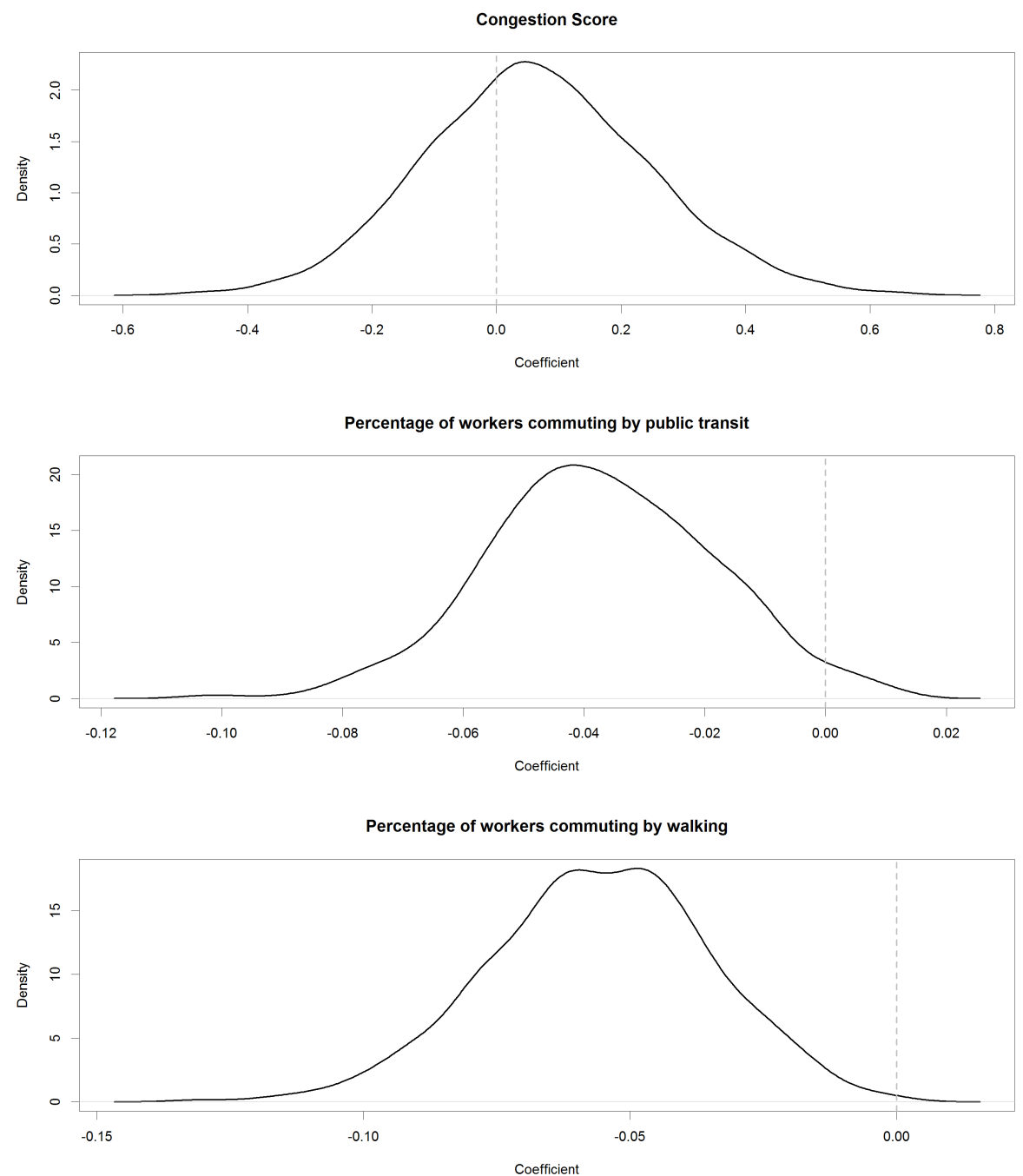
Figure SA23: Bootstrap densities of of coefficients on $\mathrm{ral}$, transit and congestion effect models
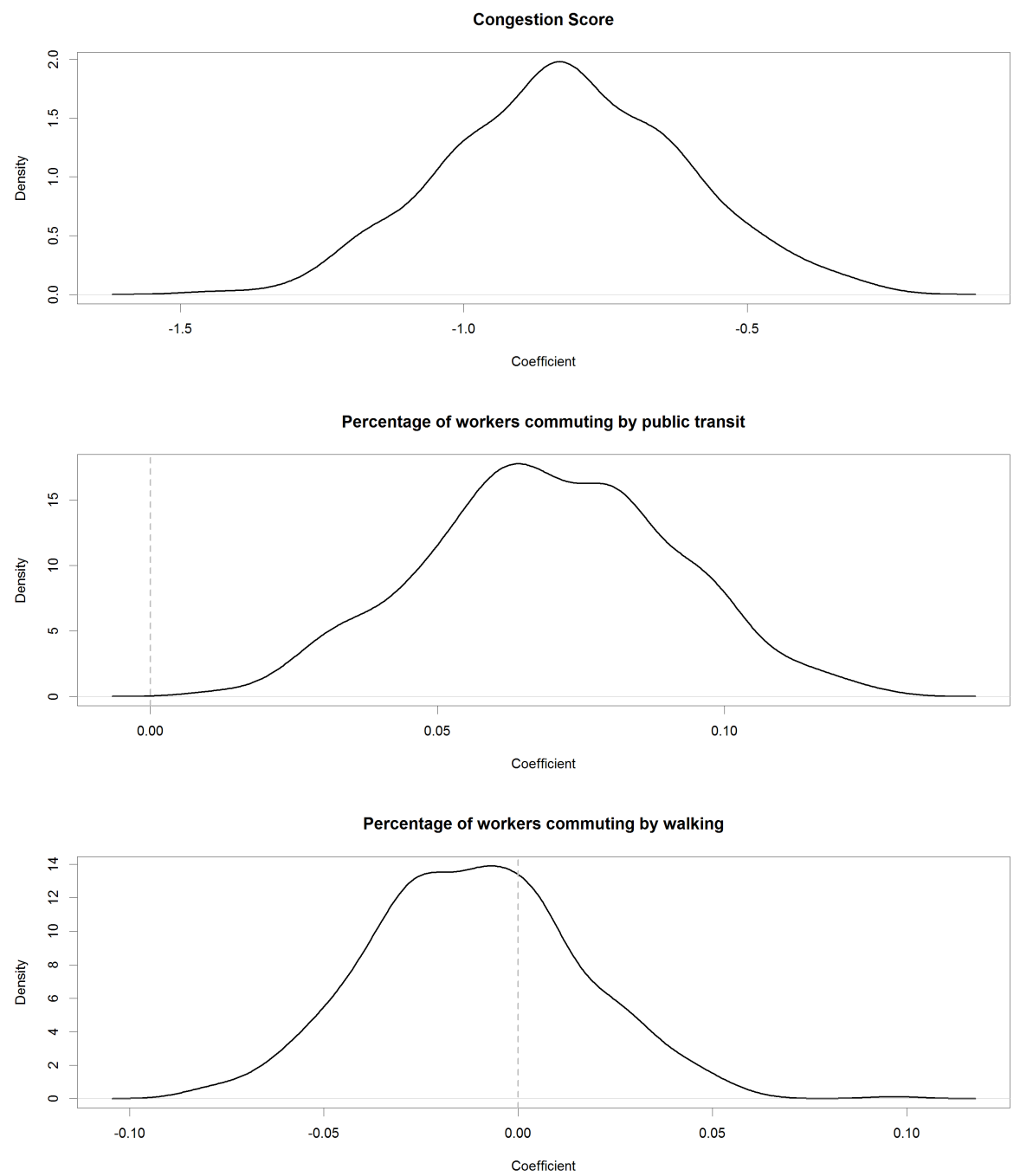
Figure SA24: Bootstrap densities of of coefficients on $\mathrm{elv} \cdot \mathrm{ral}$, transit and congestion effect models
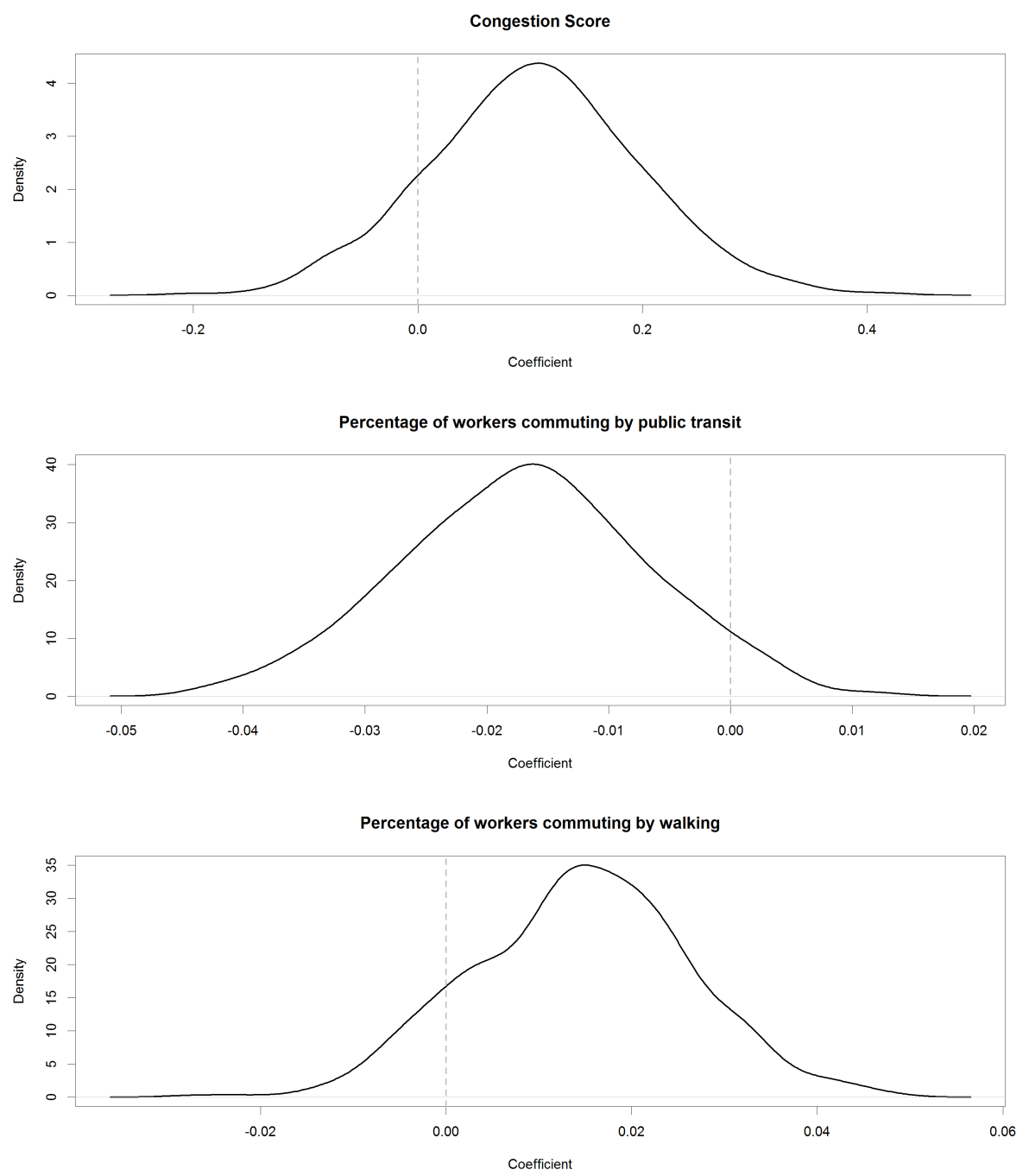
Table SA13: Regression output summary, crime effect models

\begin{tabular}{|c|c|c|c|c|c|c|}
\hline & \multicolumn{2}{|c|}{ Murder ${ }^{4}$} & \multicolumn{2}{|c|}{ Rape } & \multicolumn{2}{|c|}{ Robbery } \\
\hline & Coef & BS p-val & Coef & BS p-val & Coef & BS p-val \\
\hline (Intercept) & 0.964582 & 0.018 & 1.828506 & 0.012 & 3.00378 & 0.034 \\
\hline lnelevvar & -0.00951 & 0.036 & -0.02157 & 0.02 & -0.17994 & $<0.01$ \\
\hline elevrelative & -0.01653 & 0.022 & -0.00417 & 0.408 & 0.003729 & 0.462 \\
\hline elevmeanINTelevvar & 0.001323 & 0.318 & 0.005232 & 0.196 & -0.01212 & 0.162 \\
\hline $\ln (\mathrm{DTd}$ rivetimeNT) & -0.0545 & 0.118 & -0.42 & $<0.01$ & -0.34486 & 0.026 \\
\hline $\ln (\mathrm{DTdrivedist})$ & 0.002055 & 0.472 & 0.006089 & 0.37 & -0.03216 & 0.296 \\
\hline $\ln ($ DTdrivetime7am) & 0.066415 & 0.056 & 0.224029 & $<0.01$ & 0.100964 & 0.26 \\
\hline $\ln (\mathrm{DT}$ drivetime7pm) & -0.01133 & 0.42 & 0.148533 & 0.044 & 0.162002 & 0.174 \\
\hline lnawater & -0.00149 & 0.032 & 0.0038 & $<0.01$ & -0.00185 & 0.26 \\
\hline elev_relative:Inawater & 0.000502 & 0.264 & -0.00151 & 0.104 & 0.002427 & 0.178 \\
\hline $\ln ($ spacor* $)$ & 0.048238 & $<0.01$ & 0.067119 & $<0.01$ & 0.330353 & $<0.01$ \\
\hline lnhumdensity & -0.06047 & 0.01 & -0.09488 & 0.02 & -0.27392 & $<0.01$ \\
\hline $\ln ($ totalhouse $)$ & 0.137296 & $<0.01$ & 0.276984 & $<0.01$ & 0.422828 & $<0.01$ \\
\hline $\ln ($ aland $)$ & -0.00282 & 0.468 & -0.01952 & 0.342 & 0.050857 & 0.292 \\
\hline $\ln ($ coastkm $)$ & -0.00513 & 0.032 & 0.010166 & 0.034 & 0.01335 & 0.164 \\
\hline $\ln$ (totaloccuphouse) & -0.12449 & 0.01 & -0.28063 & $<0.01$ & -0.35749 & 0.012 \\
\hline $\ln$ (housepoverty) & 0.002238 & 0.336 & 0.014789 & 0.086 & 0.033705 & 0.07 \\
\hline $\ln ($ unemployment) & 0.005056 & 0.162 & 0.009102 & 0.164 & 0.015467 & 0.206 \\
\hline OOHrate & 0.000135 & 0.354 & -0.00114 & 0.012 & -0.00215 & 0.016 \\
\hline $\ln (\mathrm{GINI})$ & 0.015003 & 0.298 & 0.020812 & 0.344 & 0.053314 & 0.308 \\
\hline $\ln ($ medianhouseincome $)$ & -0.00296 & 0.476 & 0.008025 & 0.374 & -0.00179 & 0.464 \\
\hline $\ln ($ meanincomeQT1) & -0.0044 & 0.27 & -0.01316 & 0.148 & -0.02543 & 0.154 \\
\hline $\ln ($ meanincomeQT2) & -0.02029 & 0.124 & -0.02018 & 0.214 & -0.03485 & 0.252 \\
\hline $\ln ($ meanincomeQT3) & -0.00465 & 0.408 & 0.008678 & 0.39 & 0.008828 & 0.414 \\
\hline $\ln ($ meanincomeQT4) & 0.005533 & 0.414 & -0.00902 & 0.382 & -0.01349 & 0.418 \\
\hline $\ln ($ meanincomeQT5) & -0.00193 & 0.468 & -0.00507 & 0.416 & -0.0214 & 0.348 \\
\hline $\ln ($ meanincome5percent) & -0.00225 & 0.414 & -0.00336 & 0.466 & -0.00904 & 0.418 \\
\hline $\ln ($ Blackpercent $)$ & 0.020247 & $<0.01$ & 0.025265 & $<0.01$ & 0.094014 & $<0.01$ \\
\hline $\ln ($ Asianpercent $)$ & -0.00119 & 0.422 & 0.017628 & 0.014 & 0.032186 & $<0.01$ \\
\hline $\ln$ (Elderly) & -0.00069 & 0.47 & -0.01858 & 0.06 & -0.02744 & 0.13 \\
\hline hhsize & 0.001745 & 0.444 & -0.00127 & 0.47 & -0.03836 & 0.182 \\
\hline hhsizemarried & -0.00108 & 0.47 & -0.00293 & 0.428 & 0.000643 & 0.478 \\
\hline $\ln ($ marriedpct $)$ & -0.02712 & 0.03 & -0.03184 & 0.068 & -0.04571 & 0.12 \\
\hline $\ln$ (bachelorpct) & -0.01113 & 0.112 & -0.0049 & 0.316 & -0.01223 & 0.288 \\
\hline $\ln (\operatorname{gradpct})$ & -0.00946 & 0.052 & -0.0079 & 0.17 & -0.03388 & 0.028 \\
\hline PercentPub & 0.000419 & 0.176 & -0.00104 & 0.052 & $-3.5 \mathrm{E}-05$ & 0.492 \\
\hline PercentWalk & $-7.9 \mathrm{E}-05$ & 0.44 & 0.001172 & 0.18 & 0.005308 & 0.012 \\
\hline
\end{tabular}

$\overline{{ }^{4} \text { All crime rate variables are log-transformed }}$ 
Table SA14: Regression output summary, crime effect models (continued)

\begin{tabular}{|c|c|c|c|c|}
\hline & \multicolumn{2}{|c|}{ Aggravated assault } & \multicolumn{2}{|c|}{ Burglary } \\
\hline & Coef & BS p-val & Coef & BS p-val \\
\hline (Intercept) & 4.572455 & $<0.01$ & 3.39491 & $<0.01$ \\
\hline lnelevvar & -0.12713 & $<0.01$ & -0.12622 & $<0.01$ \\
\hline elevrelative & 0.103886 & $<0.01$ & 0.041844 & 0.072 \\
\hline elevmeanINTelevvar & -0.04632 & $<0.01$ & -0.02742 & 0.016 \\
\hline $\ln (\mathrm{DT}$ drivetimeNT $)$ & -0.2764 & 0.06 & -0.50287 & $<0.01$ \\
\hline $\ln (\mathrm{DT}$ drivedist $)$ & -0.00831 & 0.436 & 0.077117 & 0.046 \\
\hline $\ln (\mathrm{DT}$ drivetime7am) & 0.192639 & 0.082 & 0.132342 & 0.132 \\
\hline $\ln ($ DTdrivetime7pm) & -0.06352 & 0.366 & 0.168533 & 0.112 \\
\hline lnawater & -0.00101 & 0.354 & -0.00261 & 0.15 \\
\hline elev_relative:Inawater & 0.000138 & 0.466 & 0.00052 & 0.422 \\
\hline $\ln ($ spacor* $)$ & 0.353799 & $<0.01$ & 0.333668 & $<0.01$ \\
\hline lnhumdensity & -0.24954 & $<0.01$ & -0.34535 & $<0.01$ \\
\hline $\ln ($ totalhouse $)$ & 0.388289 & $<0.01$ & 0.456055 & $<0.01$ \\
\hline $\ln ($ aland $)$ & 0.121016 & 0.104 & 0.026087 & 0.384 \\
\hline $\ln ($ coastkm $)$ & -0.01872 & 0.17 & 0.005551 & 0.34 \\
\hline $\ln ($ totaloccuphouse $)$ & -0.39793 & $<0.01$ & -0.34865 & $<0.01$ \\
\hline $\ln ($ housepoverty) & 0.04413 & 0.02 & 0.035134 & 0.03 \\
\hline $\ln$ (unemployment) & 0.032548 & 0.034 & 0.001229 & 0.46 \\
\hline OOHrate & -0.00154 & 0.056 & $-2 \mathrm{E}-05$ & 0.458 \\
\hline $\ln (\mathrm{GINI})$ & 0.007203 & 0.458 & 0.036148 & 0.348 \\
\hline $\ln ($ medianhouseincome $)$ & -0.00847 & 0.436 & 0.009447 & 0.412 \\
\hline $\ln ($ meanincomeQT1 $)$ & -0.02141 & 0.202 & -0.02102 & 0.152 \\
\hline $\ln ($ meanincomeQT2) & -0.06553 & 0.076 & -0.01559 & 0.348 \\
\hline $\ln ($ meanincomeQT3) & -0.0056 & 0.438 & 0.027189 & 0.292 \\
\hline $\ln ($ meanincomeQT4) & -0.04897 & 0.218 & 0.024678 & 0.334 \\
\hline $\ln ($ meanincomeQT5) & -0.07707 & 0.082 & -0.00251 & 0.486 \\
\hline $\ln ($ meanincome5percent) & -0.03732 & 0.14 & -0.01122 & 0.356 \\
\hline $\ln$ (Blackpercent) & 0.118586 & $<0.01$ & 0.066162 & $<0.01$ \\
\hline $\ln ($ Asianpercent $)$ & 0.015484 & 0.134 & 0.01187 & 0.182 \\
\hline $\ln ($ Elderly $)$ & -0.04154 & 0.03 & -0.04559 & 0.012 \\
\hline hhsize & -0.0071 & 0.402 & -0.05781 & 0.026 \\
\hline hhsizemarried & 0.003023 & 0.446 & -0.0202 & 0.158 \\
\hline $\ln ($ marriedpct $)$ & -0.05361 & 0.076 & -0.08326 & $<0.01$ \\
\hline $\ln$ (bachelorpct) & -0.03918 & 0.032 & -0.01684 & 0.168 \\
\hline $\ln ($ gradpct $)$ & -0.0612 & $<0.01$ & -0.01925 & 0.074 \\
\hline PercentPub & -0.00041 & 0.4 & -0.00353 & $<0.01$ \\
\hline PercentWalk & 0.002635 & 0.12 & 0.003191 & 0.026 \\
\hline
\end{tabular}


Table SA15: Regression output summary, crime effect models (continued)

\begin{tabular}{|c|c|c|c|c|}
\hline & \multicolumn{2}{|c|}{ Larceny } & \multicolumn{2}{|c|}{ Motor Vehicle Theft } \\
\hline & Coef & BS p-val & Coef & BS p-val \\
\hline (Intercept) & 4.527005 & $<0.01$ & 4.1287 & $<0.01$ \\
\hline lnelevvar & -0.20726 & $<0.01$ & -0.13558 & $<0.01$ \\
\hline elevrelative & 0.02047 & 0.288 & 0.050772 & 0.064 \\
\hline elevmeanINTelevvar & -0.01691 & 0.118 & -0.03894 & $<0.01$ \\
\hline $\ln (\mathrm{DTdrivetimeNT})$ & -0.85644 & $<0.01$ & -0.87003 & $<0.01$ \\
\hline $\ln$ (DTdrivedist) & 0.06202 & 0.15 & 0.1404 & $<0.01$ \\
\hline $\ln (\mathrm{DT}$ drivetime7am) & 0.144818 & 0.154 & 0.141144 & 0.156 \\
\hline $\ln ($ DTdrivetime7pm) & 0.42747 & $<0.01$ & 0.484465 & $<0.01$ \\
\hline lnawater & 0.002101 & 0.272 & 0.001287 & 0.364 \\
\hline elev_relative:Inawater & 0.0025 & 0.24 & -0.0009 & 0.374 \\
\hline $\ln ($ spacor* $)$ & 0.246772 & $<0.01$ & 0.386857 & $<0.01$ \\
\hline lnhumdensity & -0.37613 & $<0.01$ & -0.33447 & $<0.01$ \\
\hline $\ln ($ totalhouse $)$ & 0.343834 & 0.014 & 0.360701 & 0.016 \\
\hline $\ln ($ aland $)$ & 0.034434 & 0.38 & 0.033505 & 0.376 \\
\hline $\ln ($ coastkm $)$ & 0.046866 & $<0.01$ & 0.023572 & 0.148 \\
\hline $\ln$ (totaloccuphouse) & -0.21601 & 0.068 & -0.24632 & 0.054 \\
\hline $\ln ($ housepoverty) & 0.033147 & 0.09 & 0.064489 & $<0.01$ \\
\hline $\ln ($ unemployment) & -0.00373 & 0.422 & 0.017398 & 0.174 \\
\hline OOHrate & -0.00403 & $<0.01$ & -0.00265 & $<0.01$ \\
\hline $\ln (\mathrm{GINI})$ & 0.021299 & 0.402 & -0.01927 & 0.446 \\
\hline $\ln ($ medianhouseincome) & 0.016348 & 0.388 & 0.00538 & 0.464 \\
\hline $\ln ($ meanincomeQT1) & -0.01861 & 0.246 & -0.01733 & 0.218 \\
\hline $\ln ($ meanincomeQT2) & -0.01354 & 0.392 & -0.02854 & 0.282 \\
\hline $\ln ($ meanincomeQT3) & 0.040014 & 0.304 & 0.02256 & 0.334 \\
\hline $\ln ($ meanincomeQT4) & 0.037685 & 0.288 & -0.01473 & 0.394 \\
\hline $\ln ($ meanincomeQT5) & -0.01175 & 0.404 & -0.05301 & 0.164 \\
\hline $\ln ($ meanincome5percent) & -0.00629 & 0.432 & -0.03175 & 0.2 \\
\hline $\ln ($ Blackpercent $)$ & 0.028745 & 0.026 & 0.059835 & $<0.01$ \\
\hline $\ln ($ Asianpercent $)$ & 0.041867 & $<0.01$ & 0.029877 & 0.03 \\
\hline $\ln$ (Elderly) & -0.0179 & 0.234 & -0.04262 & 0.032 \\
\hline hhsize & -0.11815 & $<0.01$ & -0.06519 & 0.034 \\
\hline hhsizemarried & -0.02197 & 0.182 & -0.00984 & 0.334 \\
\hline $\ln ($ marriedpct $)$ & -0.08646 & 0.018 & -0.05846 & 0.056 \\
\hline $\ln$ (bachelorpct) & 0.021064 & 0.182 & -0.00952 & 0.35 \\
\hline $\ln (\operatorname{gradpct})$ & -0.00936 & 0.306 & -0.02892 & 0.036 \\
\hline PercentPub & -0.00327 & 0.022 & -0.00528 & $<0.01$ \\
\hline PercentWalk & 0.007606 & $<0.01$ & -0.00224 & 0.13 \\
\hline
\end{tabular}


Figure SA25: Bootstrap densities of marginal and conditional R-square values, crime effect models
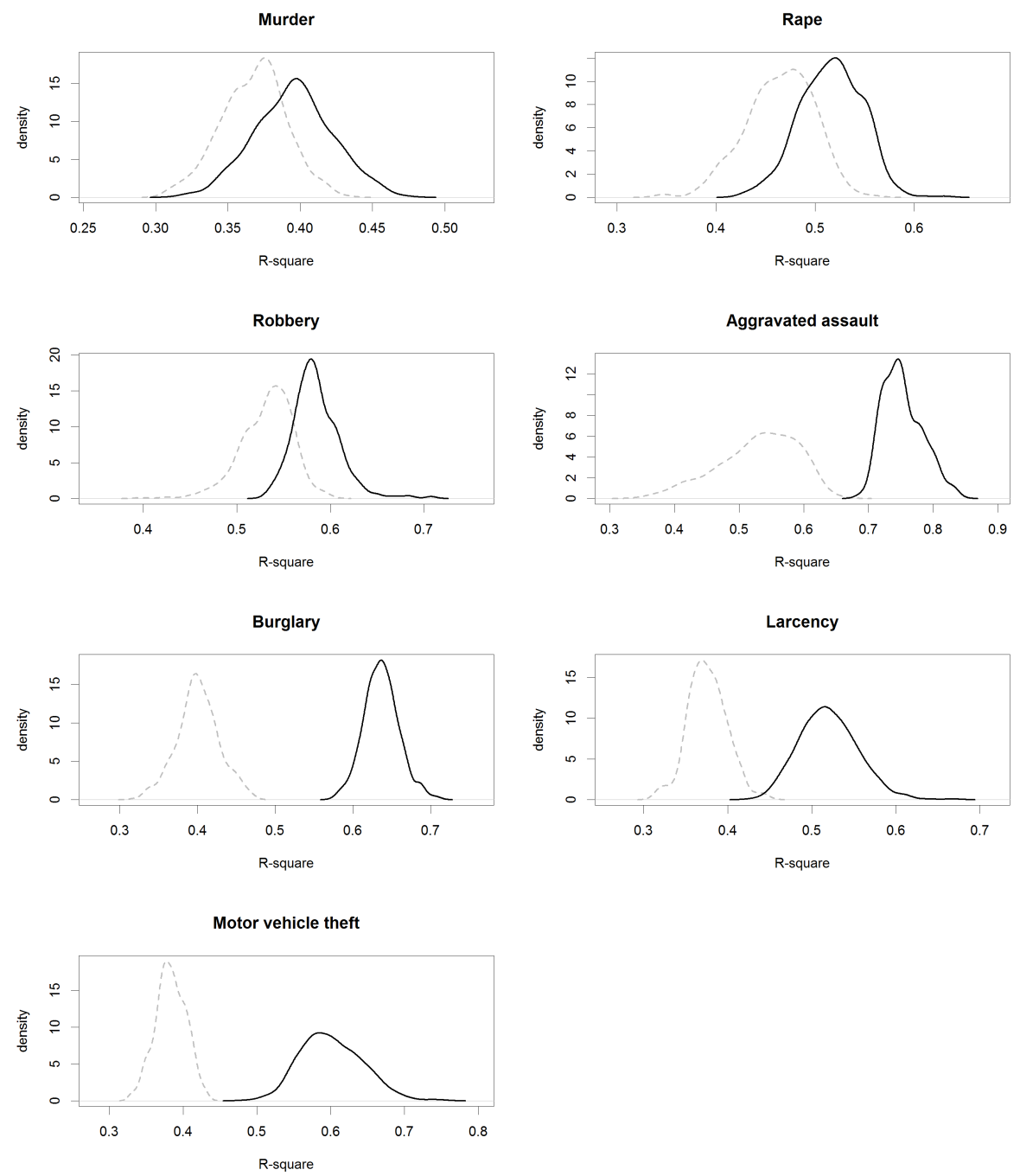
Figure SA26: Bootstrap densities of of coefficients on elv, crime effect models
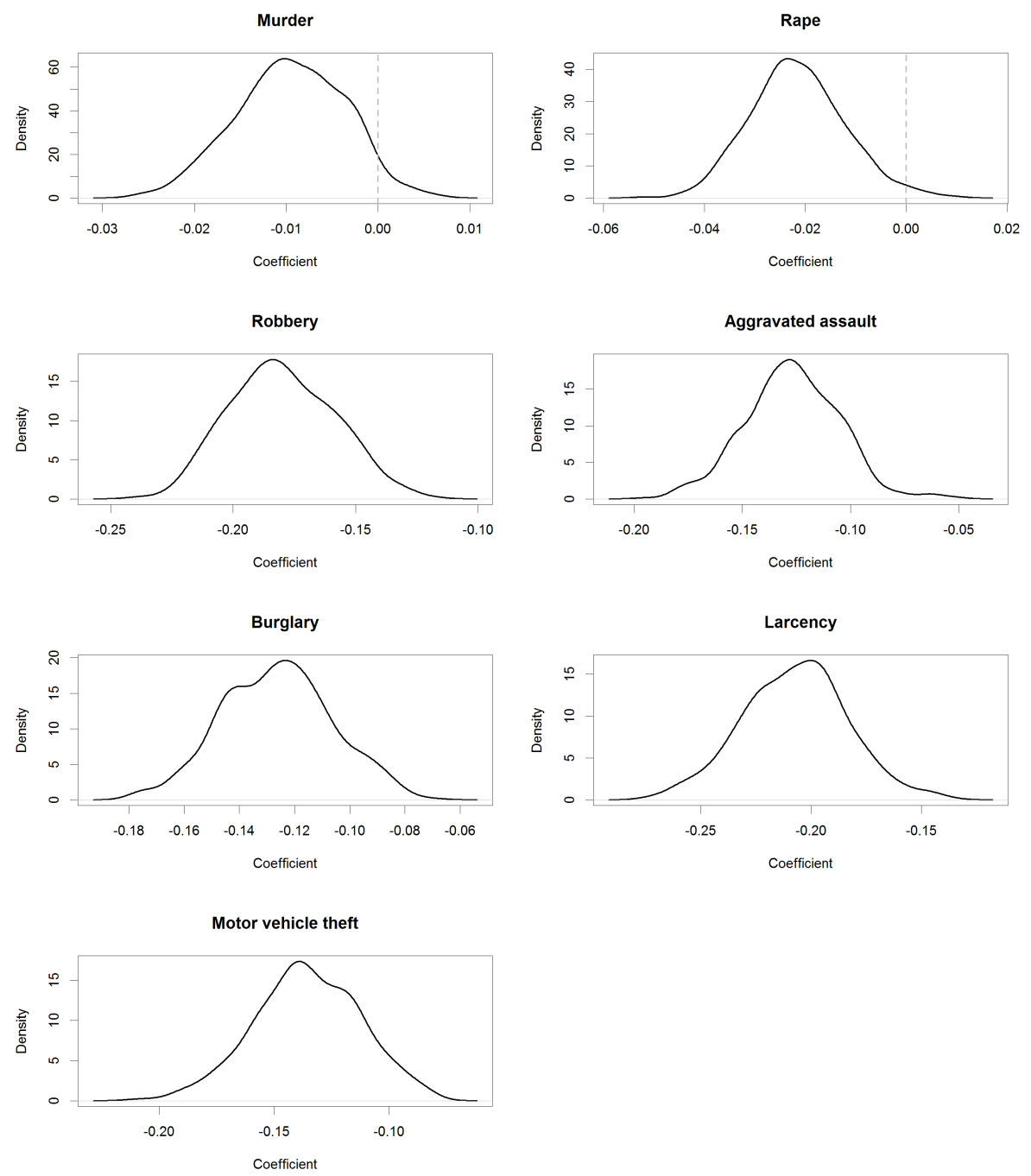
Figure SA27: Bootstrap densities of of coefficients on ral, crime effect models
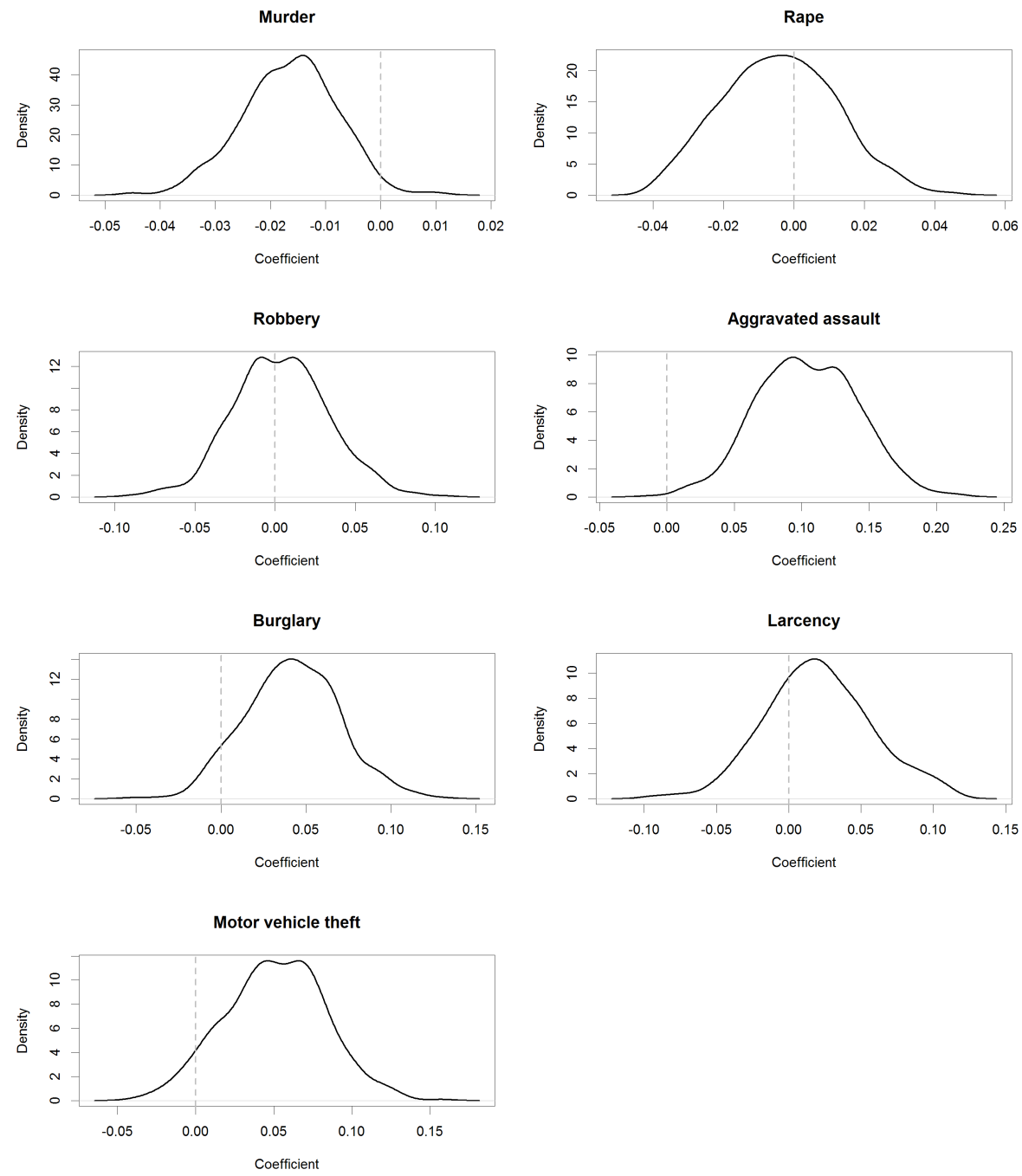
Figure SA28: Bootstrap densities of of coefficients on $\mathrm{elv} \cdot \mathrm{ral}$, crime effect models
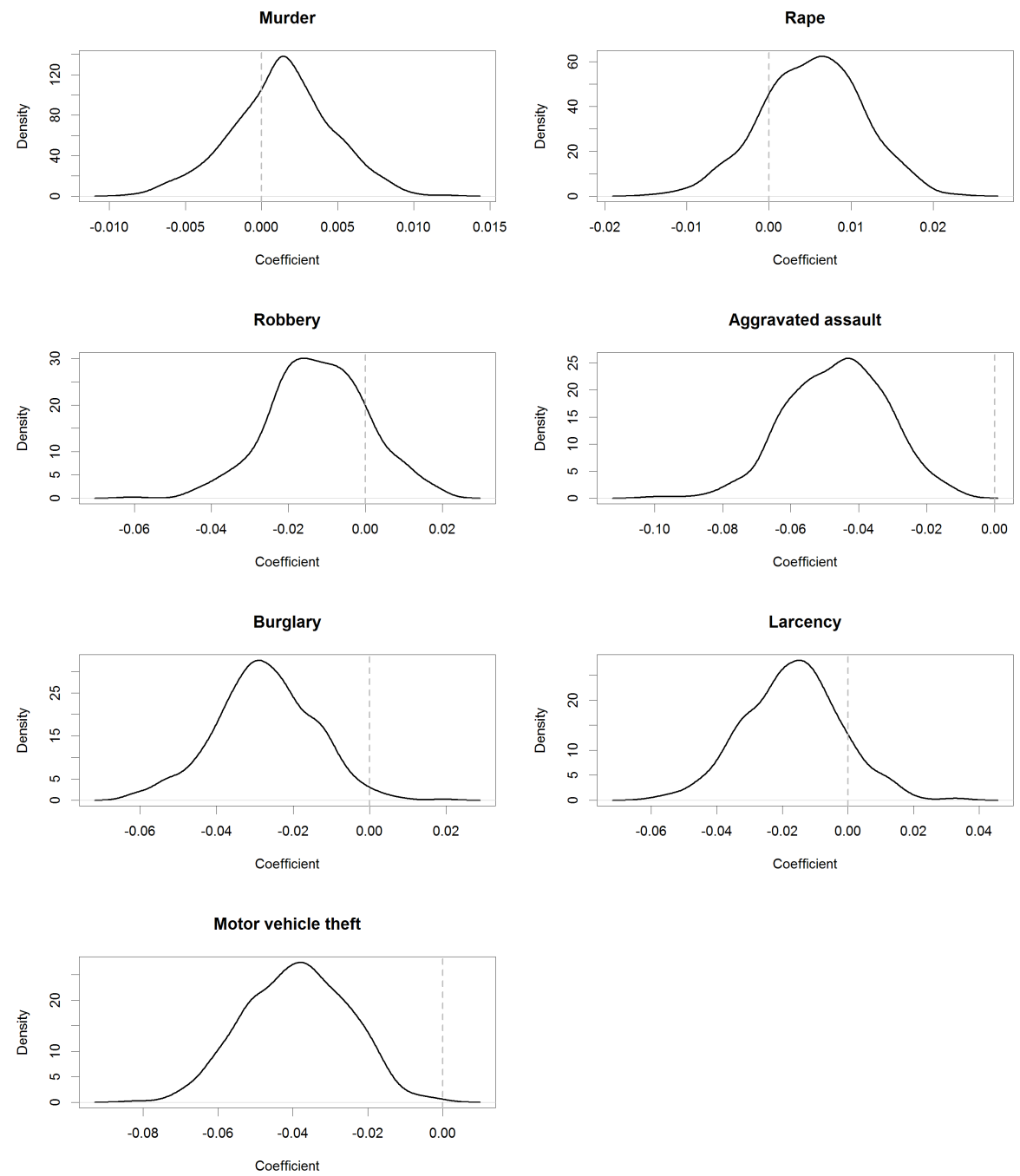